\title{
Regulation of thrombin generation at the surfaces of adherent platelets
}

Citation for published version (APA):

Briedé, J. J. (2001). Regulation of thrombin generation at the surfaces of adherent platelets. [Doctoral Thesis, Maastricht University]. Datawyse / Universitaire Pers Maastricht. https://doi.org/10.26481/dis.20011116jb

Document status and date:

Published: 01/01/2001

DOI:

10.26481/dis.20011116jb

Document Version:

Publisher's PDF, also known as Version of record

\section{Please check the document version of this publication:}

- A submitted manuscript is the version of the article upon submission and before peer-review. There can be important differences between the submitted version and the official published version of record.

People interested in the research are advised to contact the author for the final version of the publication, or visit the DOI to the publisher's website.

- The final author version and the galley proof are versions of the publication after peer review.

- The final published version features the final layout of the paper including the volume, issue and page numbers.

Link to publication

\footnotetext{
General rights rights.

- You may freely distribute the URL identifying the publication in the public portal. please follow below link for the End User Agreement:

www.umlib.nl/taverne-license

Take down policy

If you believe that this document breaches copyright please contact us at:

repository@maastrichtuniversity.nl

providing details and we will investigate your claim.
}

Copyright and moral rights for the publications made accessible in the public portal are retained by the authors and/or other copyright owners and it is a condition of accessing publications that users recognise and abide by the legal requirements associated with these

- Users may download and print one copy of any publication from the public portal for the purpose of private study or research.

- You may not further distribute the material or use it for any profit-making activity or commercial gain

If the publication is distributed under the terms of Article $25 \mathrm{fa}$ of the Dutch Copyright Act, indicated by the "Taverne" license above, 
Regulation of Thrombin Generation at the Surfaces of Adherent Platelets 
Cover: René Briedé

Printed by: Datawyse I Universitaire Pers Maastricht

ISBN 90-9015230-X

(C) Jacob Jan Briedé, Maastricht 2001 


\section{Regulation of Thrombin Generation at the}

\section{Surfaces of Adherent Platelets}

\section{PROEFSCHRIFT}

ter verkrijging van de graad van doctor aan

de Universiteit Maastricht,

op gezag van de Rector Magnificus, Prof. dr. A.C. Nieuwenhuijzen Kruseman

volgens het besluit van het College van Decanen,

in het openbaar te verdedigen op vrijdag 16 november 2001 om 14.00 uur

door

Jacob Jan Briedé 


\section{Promotor:}

Prof.dr. H.C. Hemker

\section{Co-promotor:}

Dr. T. Lindhout

\section{Beoordelingscommissie:}

Prof.dr. F.C.S. Ramaekers (voorzitter)

Dr. D. Baruch (INSERM, France)

Prof.dr. P.J.E.H.M. Kitslaar

Prof.dr.ir. L. Koole

Prof.dr. D.W. Slaaf

The work presented in this thesis is financed by program grant 902-26-192 from the Dutch Organization for Scientific Research (NWO).

Financial support by the Netherlands Heart Foundation and by the Dutch Organization for Scientific Research (NWO) for the publication of this thesis is gratefully acknowledged. 
"Het hoofd van de mens is rond, opdat de gedachten steeds weer van richting kunnen veranderen"

Francis Picabia 


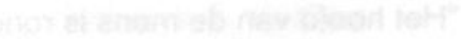

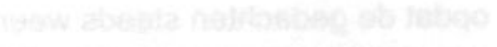




\section{Contents}

\section{Chapter 1}

General Introduction

\section{Chapter 2}

Heterogeneity in Microparticle Formation and Exposure of Anionic

Phospholipids at the Plasma Membrane of Single Adherent Platelets

\section{Chapter 3}

Contribution of Platelet-derived Factor Va to Thrombin Generation on Immobilized Collagen- and Fibrinogen-adherent Platelets

\section{Chapter 4}

Regulation of Platelet Factor Va-dependent Thrombin Generation by

Activated Protein $\mathrm{C}$ at the Surface of Collagen-adherent Platelets

\section{Chapter 5}

Von Willebrand Factor Stimulates Thrombin-induced Exposure of

Procoagulant Phospholipid on the Surface of Fibrin-adherent Platelets

\section{Chapter 6}

General Discussion and Concluding Remarks

\section{Chapter 7}

Nederlandse Samenvatting

List of Publications

Dankwoord

Curriculum Vitae 
271791700

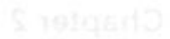


Chapter 1

General Introduction 


\section{Blood}

Vertebrates have evolved a circulatory system for supplying their cells with continuous and adequate amounts of nutrients and for the removal of their waste products. In humans this system is developed into a closed vascular system in which blood is flowing to fulfill these functions. Blood can be divided into two fractions: a corpuscular fraction in which cells or parts of cells can be found and a plasma fraction containing the soluble plasma proteins. The corpuscular fraction consists of three different cell types. The red blood cells (erythrocytes) take care of the oxygen and carbon dioxide transport in blood; the white cells (leukocytes) are involved in the immune response and blood platelets (thrombocytes) play a pivotal role in blood haemostase.

Loss of a significant amount of blood after a vascular injury is incompatible with life and therefore the blood circulation is provided with a haemostatic system that prevents blood loss up on vessel wall damage. This haemostatic system is charged with the difficult task to react rapidly on blood loss by clotting at the site of injury only. It requires the local initiation of the blood coagulation pathway resulting in the recruitment and activation of the appropriate cells and (plasma) enzymes counterbalanced by an anticoagulant pathway to prevent propagation through the vascular system. At the site of injury these reactions involve a concerted action between the recruited cells and enzymes.

\section{Platelet production and removal from blood}

Platelets are generated by fragmentation of the bone marrow precursor cells, the megakaryocytes, and circulate in human blood at a concentration of about $1.5-4.4 \mathrm{x}$ $10^{11}$ cells/l (1) with a life span of $8-10$ days (2). The cells are anucleate and in a resting state shaped as small discs with dimensions of approximately $3.0 \times 0.5 \mu \mathrm{m}$ (3). Unperturbed endothelial cells lining intact blood vessels continuously release substances like NO and prostacyclin (4) to keep the platelets in an inactivated, nonadhesive form (5-7). Most platelets are irreversible sequestered from the circulation by the spleen ( 8 ), liver and bone marrow (9) after senescence, however removal also takes place by involvement in the maintenance of the vascular integrity.

\section{Haemostase}

Blood loss as a result of an injury is prevented by the haemostatic system. Haemostase is the consequence of a close cooperation between the damaged vessel wall, activated platelets and plasma enzymes. The process of haemostase can be distinguished in three different constituents. After injury of the smallest vessels such as the capillaries, arterioles and venules bleeding is initially stopped by local 
vasoconstriction. Further blood loss and blood loss in larger vessels is anticipated by the formation of a primary haemostatic plug consisting of a platelet aggregate formed at the site of the damaged vessel wall. Subsequently this platelet plug is stabilized by the formation of a dense network of insoluble polymerized protein strands. The formation of this fibrin network is the result of a series of biochemical reactions taking place at the site of injured vessel wall. A detailed description of the mechanisms resulting in the formation of the platelet plug and the role of platelets in fibrin formation is further elaborated in the following sections.

\section{Primary platelet plug formation}

The subendothelium is synthesized by the endothelial cells overlying the subendothelium and by the smooth muscle cells and fibroblasts underneath and in between the subendothelium (10). It consists of connective tissue composed of fibrillar components such as different types of collagens (11), fibronectin $(12,13)$ elastic tissue microfibrils including elastin, thrombospondin and fibrillin (14) and other non-fibrillar proteins as proteoglycans (15), laminin (16), and vWf (17-19). The consequence of vessel wall damage caused by injury, surgery, atherosclerotic plaque rupture or by interventions like balloon angioplasty or stenting is a break in the continuity of the endothelial cell layer and exposure of the subendothelium to the bloodstream. Platelets rapidly adhere to the exposed subendothelial layer at the site of the damaged vessel wall. Platelets bind to the individual components present in the subendothelial matrix via a repertoire of receptors exposed on their plasma membrane.

\section{Platelet adhesion to the subendothelial matrix proteins}

In this section the different platelet adhesive subendothelial matrix proteins are described including the platelet receptors involved.

Von Willebrand Factor. Platelet adhesion in blood flow to the subendothelial has an absolute requirement for vWf (20). This vWf is present in the vessel wall itself, deposited by endothelial cells or can be absorbed from plasma or secreted by activated platelets. The interaction between platelet receptor GP Ib and $\mathrm{VWf}$ is essential for initial platelet adhesion, particularly under conditions of high shear stress $(21,22)$. The GP Ib is a subunit of the GP Ib-V-IX complex (Fig. 1) expressed on the platelet membrane $(23,24)$. Absence or decreased expression of the GP Ib-V-IX complex or expression of a dysfunctional complex is associated with the BernardSoulier syndrome $(25,26)$. It is characterized clinically by a prolonged skin bleeding time, morphological enlarged platelets and thrombocytopenia and clinical manifestations include prolonged bleeding from trauma, surgery or dental extractions (27). However, the interaction between the GP Ib-V-IX complex alone and VWf under 
high shear conditions can only slow down the platelets resulting in platelet translocation (28). To obtain a stable arrest of platelets that involves $\mathrm{VWf}$ binding, the interaction of the platelet receptor GP Ilbllla (integrin $\alpha_{110} \beta_{3}$ ) with vWf or other adhesive proteins is necessary (29).

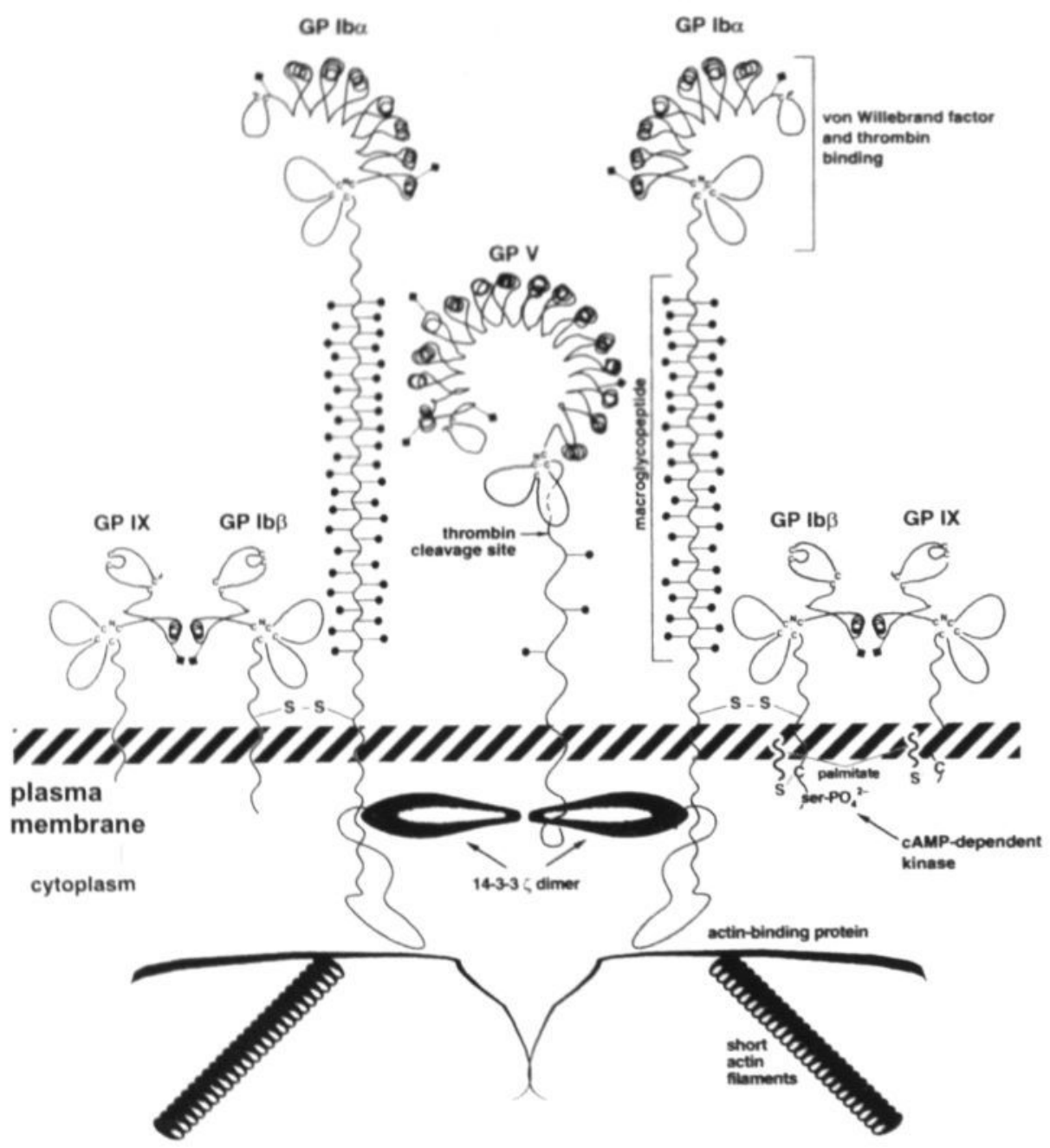

Figure 1 Schematic representation of the platelet GP Ib-V-IX complex. Key structural features of the complex are shown. Diamonds on stalks represent $\mathrm{N}$-linked carbohydrates and circles on stalks represent O-linked carbohydrates. (Adapted from (30)). 
GP Ill on the plasma membrane of resting platelets (31). This receptor consists of a twochain $\alpha$ subunit bound noncovalently to a single chain $\beta$ subunit and recognizes the sequence RGD (Fig 2) in its adhesive ligands like fibrinogen and vWf. The receptor is defective or deficient in Glanzmann thrombasthenia (32) which is clinically associated with hemorrhagic manifestations including purpura, gastrointestinal bleeding. hematuria, menorrhagia and bleeding following trauma or surgery (33). GPIlbllla is expressed in a low affinity/avidity state on resting platelets and conversion to a high affinity and avidity state requires platelet activation by soluble agonists (e.g. thrombin, $A D P$, epinephrine thromboxane $A_{2}$ ) (34) or by adhesive proteins like collagen. In case of platelet adhesion to $\mathrm{VWf}$ it is thought that the primary interaction with GP Ib-V-IX complex results in GP IIbllla activation (35).

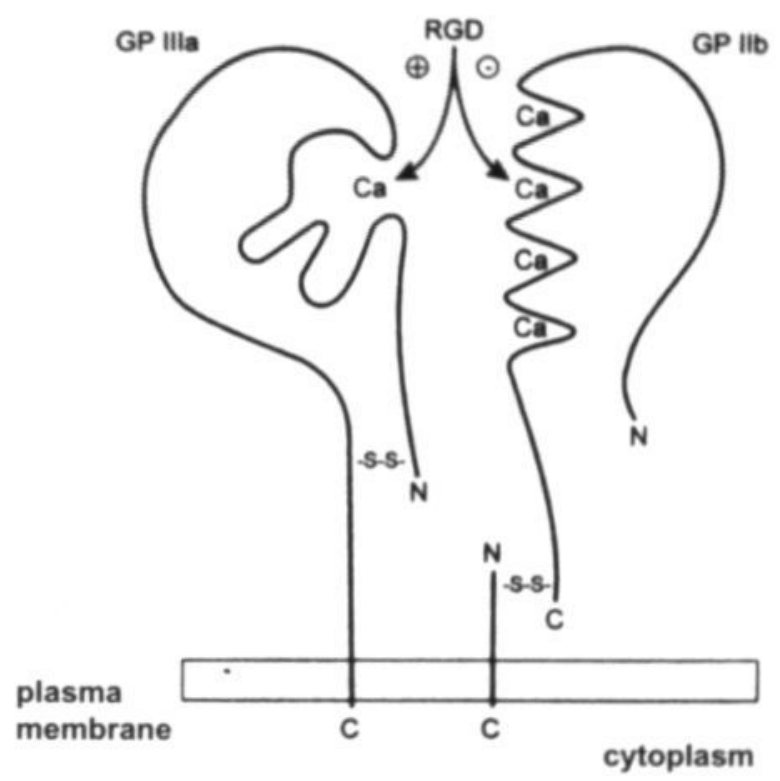

Figure 2 Schematic representation of the platelet GP Ilbilla receptor. RGD binding sites are shown as normally occupied by calcium (Adapted from (36)).

Collagens. The collagens type I, III, IV, V, VI VIII and XIII can be encountered in the blood vessel wall (37). Although GP IV $(38,39)$ and the 65 and $68 / 72 \mathrm{kDa}$ collagen receptors have been reported to play a role, GP lalla (integrin $\alpha_{2} \beta_{1}$ ) (40) and GP VI (41) are probably the physiological important receptors involved in the direct plateletcollagen interactions. Patients lacking these receptors suffer from bleeding problems $(41,42)$. But also binding of vWf to the subendothelial collagens type I (43), III (44) and VI (45) has been demonstrated. Collagen-bound VWf can mediate platelet binding via the interaction between platelet GP lb and these types of collagen under flow conditions (46-49). 
Fibronectin. Fibronectin present in the vessel wall is associated with collagen or vWf and platelet adhesion under shear conditions is dependent on GP Ib interactions with this vWf (50). In direct platelet interactions with fibronectin the receptors GP IIbllla (51) and GP Iclla (integrin $\alpha_{5} \beta_{1}$ ) (52) are involved in a platelet activation-dependent and independent manner, respectively.

Laminin. As fibronectin, also laminin cannot support platelet adhesion under high shear rates (53). There is no evidence that other matrix proteins could support platelet adhesion to laminin. Platelet interactions under static conditions occurs via a specific laminin platelet receptor, the integrin $\alpha_{6} \beta_{1}(54)$, which does not require platelet activation for this interaction. But also a $67 \mathrm{kDa}$ receptor has reported to play partly a role in static platelet-laminin adhesion (55).

Thrombospondin. Binding of the platelet receptors GP lalla and GP IIbllla (56) to thrombospondin has been shown; from which the GPlalla was the preferable receptor (57). Under shear conditions, thrombospondin also supported platelet adhesion, in which the platelet receptors GP lalla, GP IIbIlla, GP IV and the vitronectin receptor were all involved (58). However, in an extracellular matrix of human vascular endothelial cells no role for thrombospondin in platelet adhesion under shear conditions was found (59).

Vitronectin. Vitronectin (complement S-protein) present in the vessel wall originates from blood and is deposited in the extracellular matrix after binding to divers cellular receptors and subsequent extravasation $(60,61)$. Like fibronectin and $v W f$ it contains the RGD sequence. Other structural motifs of the molecule play a role in the regulation of the complement system and fibrinolysis (62). The contribution of vitronectin to platelet adhesion on the damaged vessel wall is unclear. Although platelets express 50 to 100 copies of the vitronectin receptor $\alpha_{v} \beta_{3}(63)$, thrombin activated platelets bind to vitronectin in-vitro predominantly via the GP Ilbllla receptor $(63,64)$.

\section{Platelet aggregate formation}

The formation of the primary haemostatic plug is further completed by adhesion of platelets to the platelets initially adhered to the damaged vessel wall, followed by more platelet-platelet interactions that finally results in a platelet aggregate. Different plasma proteins are responsible for linking platelets together. From these agglutinative proteins fibrinogen is the most important one. Fibrinogen is present in blood plasma at a concentration of 2-6 g/L and in the $\alpha$-granula of platelets (65), which content is released after platelet activation. Soluble fibrinogen does not bind to unstimulated platelets, but forms a bridge between adjacent activated platelet by binding to their GP IIbllla receptors (66-68).

Except for the collagens, the other proteins responsible for platelet adhesion to the subendothelial matrix are also found in blood where they participate in platelet aggregation. The plasma vWf concentration is about $8 \mu \mathrm{g} / \mathrm{ml}(69)$ and also found in 
the platelet granula (65). Fibrinogen alone can only mediate platelet interactions under low shear conditions (70). As in platelet adhesion, vWf becomes absolutely required when platelets aggregate under high shear conditions and whenever vWf mediates platelet aggregation it must engage both of its platelets platelet receptors GP Ib and GP Ilb IIla (70-72).

Fibronectin is present in the platelet $\alpha$-granula (73) and in plasma (concentration approximately $300 \mathrm{mg} / \mathrm{L}(74)$, but its role in platelet aggregation is inhibitory because it competes with fibrinogen for binding to the activated GP IIbllla receptor (75-77). Thrombospondin is only a trace protein in plasma (78), but is present in the $\alpha$-granula of platelets and is released in high concentrations during haemostasis (79). Binding of released thrombospondin participates in the platelet signaling process excited during platelet aggregation (80) and a promoting effect (81) as well as an inhibiting effect on thrombin-induced platelet aggregation was found (82). Vitronectin is present in plasma at a concentration of about $240 \mathrm{mg} / \mathrm{L}(83,84)$ and as fibronectin it modulates platelet aggregation by interfering the interaction of fibrinogen with activated GP IIbllla (85).

\section{Platelet activation}

Platelets that adhere and aggregate at the site of the damaged vessel wall become activated. Firstly, de-endothelialization or injury of the endothelium results in a locally diminished release of agents that prevent platelets from being activated. Secondly. the binding of platelets to the proteins of the subendothelial matrix or the interaction of platelets with plasma proteins during aggregation will provoke an intracellular signaling finally resulting in platelet shape changes, secretion of platelet agonists and the transformation into coagulation-promoting surfaces.

In general, intracellular signaling in platelets goes via the phospholipase C (PLC) pathway. Activation of PLC results in the formation of two second messengers via cleavage of phosphaditylinositol 4,5-biphosphate into respectively inositol 1,4,5triphosphate $\left(\mathrm{IP}_{3}\right)$ and diacylglycerol (DAG). The former releases calcium from intracellular calcium stores (86). Furthermore, the resulting increase of the cytosolic calcium concentration $\left[\mathrm{Ca}^{2+}\right]$, is reinforced by subsequent calcium influx from the extracellular medium $(87,88)$. An elevation in intracellular calcium synergistically with the activation of protein kinase C (PKC) via DAG causes secretion (89). The release of platelet dense granula liberates ADP and serotonin, each capable of activating platelets via their specific receptors on the plasma membrane. This release of platelet activating factors is further accompanied by the release of a set of platelet activating substances, such as thromboxane $A_{2}\left(T \times A_{2}\right)$. Tx $A_{2}$ is produced from arachidonic acid released via the phospholipase $A_{2}$ pathway that is also activated in platelet stimulation.

For activation by soluble agonists platelets display specific receptors, most of which are seven transmembrane, G-coupled proteins $(90,91)$. An important soluble 
platelet activator is the coagulation protease thrombin, formed in the coagulation cascade described further on. Human platelets express multiple thrombin receptors on their plasma membrane. Thrombin signaling is, at least in part, mediated by the $G$ protein-coupled protease-activated receptors (PARs) PAR1 and PAR4 (92), but also evidence have been collected that binding of thrombin to GP Ib is involved in platelet activation $(93,94)$.

From the subendothelial matrix proteins, the binding of vWf to platelet GP Ib results in platelet signaling resulting in activation of PKC, an increase in $\left[\mathrm{Ca}^{2+}\right]$, and synthesis of $\operatorname{TXA}_{2}(35,95)$. The interaction of platelets with collagen results in much stronger activation. The major signaling goes via GP VI. Dimerization of this receptor by collagen stimulates tyrosine phosphorylation in the $\gamma$-chain of the immunoglobulin receptor (FcR $)(96,97)$, that is associated with GP VI in the platelet plasma membrane. It shares with collagen-induced signaling via GP lalla that both pathways result in increased $\left[\mathrm{Ca}^{2+}\right]$, and activation of PKC (98).

\section{The pro- and anti-coagulant pathways}

The plug of aggregated platelets is stabilized by the formation of a network of insoluble polymerized fibrin strands. The formation of fibrin is the result of a waterfallresembling set of biochemical reactions taking place on the plasma membrane of activated platelets and other activated or disrupted cells present at the site of injury. Furthermore, fibrin formation is localized at the site of damage by the exposure of the trigger of the coagulation pathway to blood at the site of damage only. A rapid response of the coagulation pathway is ensured by the presence of the other proteins in an inactive form in blood. These zymogens are activated by another already activated coagulation enzyme (denoted by an "a" added to their roman numbers) via limited proteolysis. The activated enzymes only exert their full activity in case a complex is formed with a so-called cofactor, and when these complexes are assembled on anionic membrane phospholipids containing surfaces in the presence of calcium ions. Three key regulating membrane-bound enzyme complexes are involved in the procoagulant pathway, and two complexes are involved in the anticoagulant pathway.

Procoagulant pathways. The procoagulant pathway (Fig. 3) is triggered by the tissue factor factor:Vlla complex. After vascular injury tissue factor (TF), a transmembrane protein found on cells present in the vessel wall, becomes exposed to blood. TF is constitutively expressed by fibroblasts in the adventitia and TF expression can be rapidly induced in smooth muscle cells in the media of the vessel wall. Furthermore, endothelial cells and circulating monocytes can be stimulated to transiently express TF. In blood plasma circulating factor VIla or VII binds to TF and factor VII is consequently activated. The resulting membrane-bound TF:factor VIla complex converts the factors IX and X into their active forms. Factor IXa associates with the activated cofactor factor VIIla to form the membrane-associated tenase complex that 


\section{Procoagulant pathways}

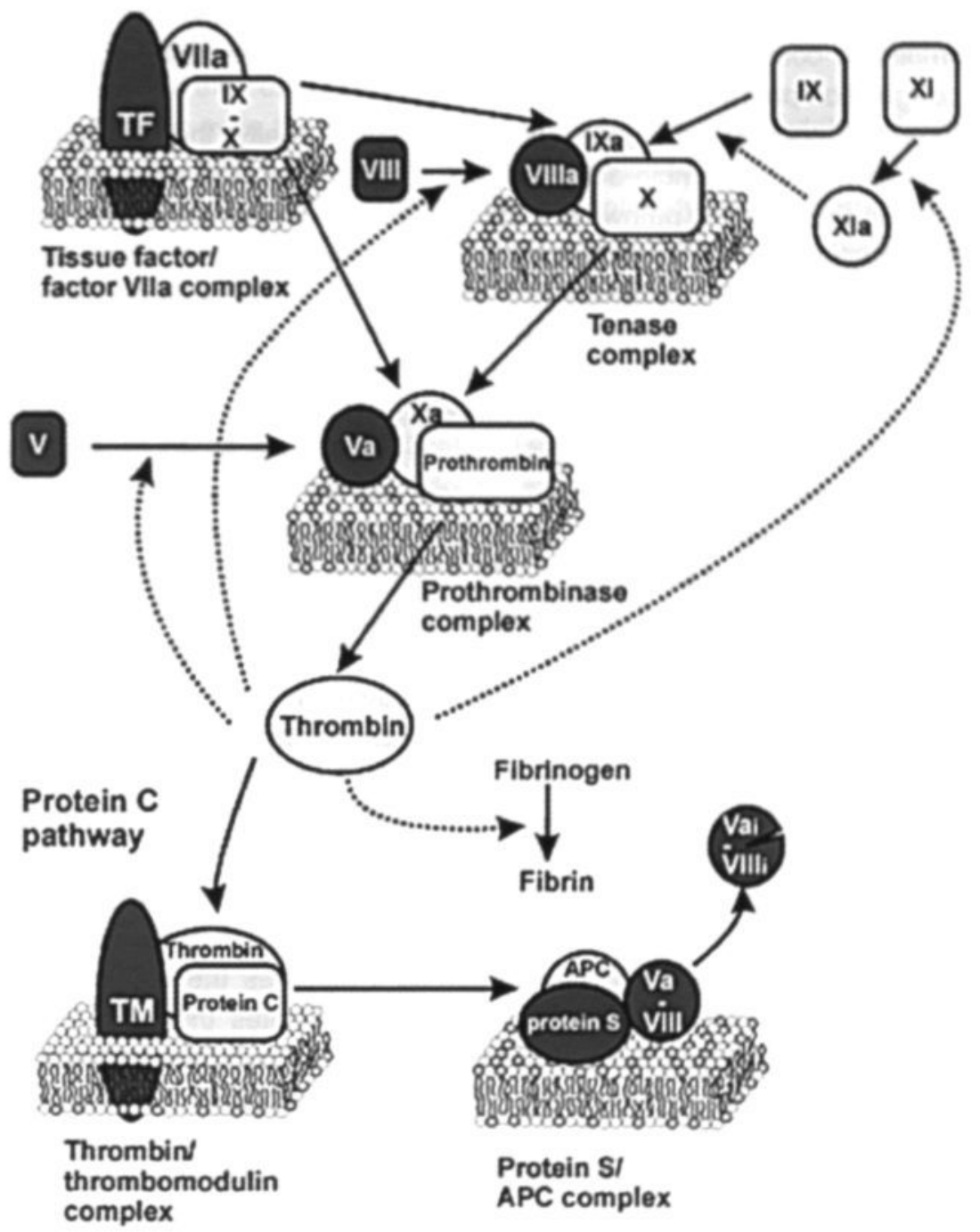

Figure 3 Membrane associated enzym complexes in the procoagulant and the protein $\mathbf{C}$ pathway. The upper half of the figure shows the procoagulant pathways resulting in thrombin formation. The lower part of the figure shows the protein $\mathrm{C}$ pathway. Not shown is the inactivation by activated protein C of factor Va or VIIla assembled in the prothrombinase and tenase complex respectively. The suffix ' $a$ ' indicates the activated form of a coagulation factor, while $\mathrm{T}$ indicates the inactivated form. Aminophospholipids are represented by dark polar headgroups. cholinephospholipids by white polar headgroups. 
also activates factor X. Factor $\mathrm{Xa}$ forms, in a comparable manner as factor IX, a membrane-associated complex with the activated cofactor factor $\mathrm{Va}$. The so-formed prothrombinase complex rapidly converts prothrombin in the key-regulating enzyme of the coagulation pathway, thrombin.

Thrombin converts fibrinogen into fibrin and finally the cross-linked fibrin network is formed by thrombin-activated factor XIII. If adequate amounts of thrombin are formed in the extrinsic pathway, it will activate the factors factors V and VIII, and moreover, factor XI will be activated, resulting in a second burst of thrombin generation via the intrinsic pathway $(99,100)$. Thrombin limits its own formation via activation of the protein C pathway, one of the pathways included in the anticoagulant pathways.

Anticoagulant pathways. The activity and quantity of thrombin formed is regulated by different anticoagulants that can be divided, on basis of their mechanism of action, into the direct factor $\mathrm{Xa}$ and thrombin inhibitors and the protein $\mathrm{C}$ pathway. Inhibitors circulate in blood and directly neutralize the activity of proteases involved in the coagulant pathways. The activity of the TF:factor VIla complex is effectively inhibited by the Kunitz type inhibitor tissue factor pathway inhibitor (TFPI) in complex with factor Xa (101). About $2 \%$ of the total vascular amount of TFPI is found in the platelets (102) and released after platelet activation. Serine protease inhibitors (serpins), like antithrombin III (AT-III) and $\alpha 2$-macroglobulin $(\alpha 2 \mathrm{M})$ block the active site of the serine proteases e.g. thrombin, factor Xa, factor Xla, factor IXa etc.

Protein $\mathrm{C}$ is a zymogen circulating in plasma and is in the presence of thrombomodulin activated by thrombin into activated protein C (APC). Thrombomodulin (TM) is a transmembrane protein constitutively expressed on the plasma membrane of endothelial cells. Upon binding to TM, thrombin loses the ability to activate platelets or to clot fibrinogen, while it acquires the capacity to activate protein C (103). The serine protease APC down regulates thrombin formation via limited proteolysis of factor VIIla and factor Va (104) the cofactors of the tenase and prothrombinase complex, respectively. Activity of protein $C$ is enhanced by the presence of the cofactor protein $\mathrm{S}$ and anionic phospholipid containing membranes (105). A hereditary disorder related to the protein C pathway is caused by a single point mutation in the factor $\mathrm{V}$ gene producing a factor $\mathrm{V}(\mathrm{a})$ (factor $\mathrm{V}_{\text {Leiden }}$ ) that has a decreased sensitivity to inactivation by APC. Carriership of the factor $V_{\text {Leiden }}$ mutation is associated with an increased risk of venous thrombosis (106).

\section{Acceleration of the pro- and anti-coagulant pathways by platelet activation}

The formation of a fibrin network via the coagulation pathway is strongly accelerated by activated platelets. The plasma membrane of activated platelets serve as a platform for the assembly of the coagulation enzyme complexes. Binding of the coagulation factors proficiently increases their local concentrations by confining them in a two-dimensional space and may result in conformational changes that favor their 
interactions. The presence of the anionic phospholipid phosphatidylserine (PS) in the outer leaflet of the platelet plasma membrane strongly enhance the activity of coagulation complexes, but also promote the anticoagulant reactions that provide feedback inhibition of the coagulation reactions.

In all eukaryotic cells the phospholipids are asymmetrical distributed over both membrane leaflets (107). The outer leaflet is enriched in cholinephospholipids, whereas the aminophospholipids, particularly phosphatidylserine, occupy the inner leaflet. This asymmetry is generated and preserved by a phospholipid-specific translocase that rapidly transports the aminophospholipids from the outer to the inner leaflet of the plasma membrane (108). In cooperation with this translocase a less specific floppase slowly transports the amino- and cholinephospholipids from the inner to the outer plasma membrane leaflet (109).

Activation of blood cells, specifically platelets, results in an inhibition of the translocase and floppase activities, while an increased $\left[\mathrm{Ca}^{2+}\right]$ activates another lipid transporter, the calcium-dependent scramblase. This results in a fast bi-directional movement of all phospholipids leading to rapid loss of phospholipid asymmetry and the appearance of the aminophospholipids including PS at the surface of the platelets (110, 111). Kinetically, the presence of PS containing phospholipid membranes strongly decreases the $K_{m}$ for factor $X$ and prothrombin activation from far above to far below their plasma concentration $(112,113)$. Activated platelets offer binding sites for the enzyme-substrate complexes for the prothrombinase and tenase complex resulting in an acceleration of factor $X$ and prothrombin activation $(114,115)$. Next to this activation of the procoagulant pathway, activated platelets also stimulate the anticoagulant protein C pathway (116).

Besides PS, additional membrane components are proposed to contribute to the acceleration of procoagulant pathways. Specific receptors on the plasma membrane of platelets for prothrombin, factor Va, VIIla and Xa have been suggested to play a role in the procoagulant activity of platelets (117-121).

\section{Detection of PS-exposure by binding of annexin V}

Annexin $\mathrm{V}$ is a glycoprotein belonging to a family of structurally related proteins referred to as the "annexins". Annexin V was first discovered and isolated from the placenta. Currently, annexin $V$ is found in many human tissues e.g. lung, liver, kidney, skin, heart, uterus, spleen and skeletal muscle (122) and in trace amounts in blood (123). Annexin V binds with a high affinity and calcium-dependent to phospholipid membranes containing the anionic phospholipid PS, but not to membranes in which anionic phospholipids are absent $(124,125)$. In platelets activated with different agonists the number of annexin $\mathrm{V}$ binding sites exposed is in good agreement with the degree of PS exposure and the thrombin generating capacity under conditions where phospholipid is the limiting factor $(126,127)$. Therefore, this high affinity and preferential binding of fluorescent labeled annexin $V$ to membranes containing PS, 
makes annexin V a suitable tool for the detection of PS exposed at the plasma membrane surface of activated platelets.

\section{Objective of this thesis}

Most studies concerning the thrombin generating capacity of platelets are performed in suspensions. The limitation of this experimental approach is that processes as platelet adhesion to immobilized adhesive proteins, being the first step in aggregate formation, and single cell phenomena, i.e. ligand-induced changes in $\left[\mathrm{Ca}^{2+}\right]_{i}$ and heterogeneity in PS exposure at the platelet plasma membrane, can not be studied. In an attempt to investigate these processes under well-defined flow regimes and their consequences for the regulation of thrombin formation on the platelet membrane surface, we studied platelets that adhered to immobilized proteins in the absence of other blood cells and plasma proteins. This approach enabled us to investigate the influence of purified matrix and plasma proteins on platelet adhesion, PS exposure and the regulation of thrombin generation on the surface of adherent platelets under flow conditions.

In an initial study we observed that platelets that adhered from a plasma milieu to immobilized fibrinogen exposed PS and supported thrombin generation (128). Because in this study plasma was removed only after platelet adhesion and with a $\mathrm{Ca}^{2+}$-containing buffer, platelet activation by thrombin could not be excluded. To investigate the effects of immobilized fibrinogen on platelet activation in the absence of thrombin we analyzed platelet adhesion to immobilized fibrinogen in a buffer system by utilizing washed platelets. Single cell shape changes in adherent platelets, its relation to $\mathrm{Ca}^{2+}$-induced platelet activation and PS exposure are described in chapter 2. We found a marked heterogeneity in $\mathrm{Ca}^{2+}$-induced PS exposure within a population of adherent platelets as well as at the level of single PS-exposing cells. The consequences of this heterogeneity for the kinetics of thrombin generation under flow are further explored and described in chapter 3. Thrombin generation was studied on the surfaces of fibrinogen- and collagen-adherent. In the latter case virtually all platelets exposed PS. The combined results indicated that platelets provide a highly efficient catalytic surface for thrombin generation when both PS and platelet-bound factor $\mathrm{Va}$ are present. No other platelet receptor was found to be required for thrombin generation. However, the release and activation of platelet factor $\mathrm{V}$ appeared to be a rate-limiting step in thrombin generation. Inactivation of factor Va by activated protein C (APC) could therefore be an important reaction in the down-regulation of thrombin formation at the platelet surface (chapter 4). It was however reported that this inactivation of factor Va is APC resistant. Our study on collagen-adherent platelets showed that the prothrombinase activity (factor Va) was effectively neutralized by APC. Chapter $\mathbf{5}$ describes a study on the function of thrombin- and von Willebrand factor-mediated platelet-fibrin interaction in the 
formation of thrombogenic platelets. This reaction is thought to be critical for the development of a growing thrombus.

\section{References}

1. C.B. Thompson, J.A. Jakubowski. The pathophysiology and clinical relevance of platelet heterogeneity. Blood 72 (1988) 1-8.

2. R.I. Handin, Hemorrthagic Disorders II. Platelets and Purpura. In: S. Beck ed., Hematology Cambridge, MIT press (1987) 433-456.

3. J.H. Hartwig. K. Barkalow, A. Azim, J. Italiano. The elegant platelet: signals controlling actin assembly. Thromb. Haemos. 82 (1999) 392-398.

4. T.F. Luscher, G. Noll. Endothelium dysfunction in the coronary circulation. J. Cardiovasc. Pharmacol. 24 (1994) S16-26.

5. R. Busse, A. Luckhoff, E. Bassenge. Endothelium-derived relaxant factor inhibits platelet activation, Naunyn. Schmiedebergs Arch. Pharmacol. 336 (1987) 566-571.

6. M.W. Radomski, R.M. Palmer, S. Moncada. The anti-aggregating properties of vascular endothelium: interactions between prostacyclin and nitric oxide. Br. J. Pharmacol. 92 (1987) 639-646.

7. M.W. Radomski, R.M. Palmer, S. Moncada. Endogenous nitric oxide inhibits human platelet adhesion to vascular endothelium. Lancet 2 (1987) 1057-1058.

8. H. Wadenvik, J. Kutti. The spleen and pooling of blood cells. Eur. J. Haematol. 41 (1988) 1-5.

9. A.D. Heyns, M.G. Lotter, P.N. Badenhorst, O.R. van Reenen, H. Pieters, P.C. Minnaar, F.P. Retief. Kinetics, distribution and sites of destruction of "'indium-labelled human platelets. Br. J. Haematol. 44 (1980) 269-280.

10. P.F. Nievelstein, P.G. de Groot. Interaction of blood platelets with the vessel wall, Haemostasis 18 (1988) 342-359.

11. B. Kehrel. Platelet-collagen interactions. Semin. Thromb. Hemost. 21 (1995) 123-129.

12. P.G. Natali, D. Galloway, M.R. Nicotra, C. De Martino. Topographic association of fibronectin with elastic fibers in the arterial wall. An immunohistochemical study. Connect. Tissue Res. 8 (1981) 199-204.

13. W.P. Houdijk, J.J. Sixma. Fibronectin in artery subendothelium is important for platelet adhesion. Blood 65 (1985) 598-604.

14. X.X. Wu, R.E. Gordon, R.W. Glanville, H.J. Kuo, R.R. Uson, J.H. Rand. Morphological relationships of von Willebrand factor, type VI collagen, and fibrillin in human vascular subendothelium. Am. J. Pathol. 149 (1996) 283-291.

15. D.J. Bidanset, C. Guidry, L.C. Rosenberg. H.U. Choi, R. Timpl, M. Hook. Binding of the proteoglycan decorin to collagen type VI. J. Biol. Chem. 267 (1992) 5250-5256.

16. F.J. Leu, E. Engvall, I. Damjanov. Heterogeneity of basement membranes of the human genitourinary tract revealed by sequential immunofluorescence staining with monocional antibodies to laminin. J. Histochem. Cytochem. 34 (1986) 483-489.

17. D. Meyer, G. Pietu, E. Fressinaud, J.P. Girma. Von Willebrand factor. structure and function. Mayo Clin. Proc. 66 (1991) 516-523. 
18. J.J. Sixma, P.G. de Groot. Von Willebrand factor and the blood vessel wall. Mayo Clin. Proc. 66 (1991) 628-633.

19. Z.M. Ruggeri, J. Ware. Von Willebrand factor. Faseb. J. 7 (1993) 308-316.

20. T.B. Tschopp, H.J. Weiss, H.R. Baumgartner. Decreased adhesion of platelets to subendothelium in von Willebrand's disease. J. Lab. Clin. Med. 83 (1974) 296-300.

21. K.S. Sakariassen, P.F. Nievelstein, B.S. Coller, J.J. Sixma. The role of platelet membrane glycoproteins $\mathrm{lb}$ and IIb-IIla in platelet adherence to human artery subendothelium. $\mathrm{Br} . \mathrm{J}$. Haematol. 63 (1986) 681-691.

22. H.J. Weiss. Flow-related platelet deposition on subendothelium. Thromb. Haemost. 74 (1995): $117-122$

23. J.A. Lopez, J.F. Dong. Structure and function of the glycoprotein Ib-IX-V complex. Curr. Opin. Hematol. 4 (1997) 323-329.

24. J. Ware. Molecular analyses of the platelet glycoprotein Ib-IX-V receptor. Thromb. Haemost. 79 (1998) 466-478.

25. M.C. Berndt, C. Gregory, B.H. Chong. H. Zola, P.A. Castaldi. Additional glycoprotein defects in Bernard-Soulier's syndrome: confirmation of genetic basis by parental analysis. Blood 62 (1983) 800-807.

26. K.J. Clemetson, J.L. McGregor, E. James, M. Dechavanne, E.F. Luscher. Characterization of the platelet membrane glycoprotein abnormalities in Bernard-Soulier syndrome and comparison with normal by surface-labeling techniques and high-resolution two-dimensional gel electrophoresis. J. Clin. Invest. 70 (1982) 304-311.

27. M.C. Berndt, D.J. Fournier, P.A. Castaldi. Bernard-Soulier syndrome. Baillieres Clin. Haematol. 2 (1989) 585-607.

28. B. Savage, E. Saldivar, Z.M. Ruggeri. Initiation of platelet adhesion by arrest onto fibrinogen or translocation on von Willebrand factor. Cell 84 (1996) 289-297.

29. B. Savage, S.J. Shattil, Z.M. Ruggeri. Modulation of platelet function through adhesion receptors. A dual role for glycoprotein IIb-IIla (integrin $\alpha_{110} \beta_{3}$ ) mediated by fibrinogen and glycoprotein Ib-von Willebrand factor. J. Biol. Chem. 267 (1992) 11300-11306.

30. J.A. Lopez, R.K. Andrews, V. Afshar Kharghan, M.C. Berndt. Bernard-Soulier syndrome. Blood 91 (1998) 4397-4418.

31. C.L. Wagner, M.A. Mascelli, D.S. Neblock, H.F. Weisman, B.S. Coller, R.E. Jordan. Analysis of GPIIb/llla receptor number by quantification of 7 E3 binding to human platelets. Blood 88 (1996) 907-914.

32. B.S. Coller, U. Seligsohn, H. Peretz, P.J. Newman. Glanzmann thrombasthenia: new insights from an historical perspective. Semin. Hematol. 31 (1994) 301-311.

33. J.S. Bennett, M.A. Kolodziej. Disorders of platelet function. Dis. Mon. 38 (1992) 577-631.

34. P.J. Sims, M.H. Ginsberg. E.F. Plow, S.J. Shattil. Effect of platelet activation on the conformation of the plasma membrane glycoprotein IIb-Illa complex. J. Biol. Chem. 266 (1991) 7345-7352.

35. Y. Ozaki, K. Satoh, Y. Yatomi, S. Miura, Y. Fujimura, S. Kume. Protein tyrosine phosphorylation in human platelets induced by interaction between glycoprotein Ib and von Willebrand factor. Biochim. Biophys. Acta 1243 (1995) 482-488. 
36. M. Madan, S.D. Berkowitz, J.E. Tcheng. Glycoprotein Ilb/llla integrin blockade. Circulation 98 (1998) 2629-2635.

37. J.J. Sixma, G. Hindriks, H. Van Breugel, R. Hantgan, P.G. de Groot. Vessel wall proteins adhesive for platelets. J. Biomater. Sci. Polym. Ed. 3 (1991) 17-26.

38. M. Diaz Ricart, N.N. Tandon, M. Carretero, A. Ordinas, E. Bastida, G.A. Jamieson. Platelets lacking functional CD36 (glycoprotein IV) show reduced adhesion to collagen in flowing whole blood. Blood 82 (1993) 491-496.

39. K. Matsuno, M. Diaz Ricart, R.R. Montgomery, R.H. Aster, G.A. Jamieson, N.N. Tandon. Inhibition of platelet adhesion to collagen by monocional anti-CD36 antibodies. Br. J. Haematol. 92 (1996) 960-967.

40. E.U. Saelman, H.K. Nieuwenhuis, K.M. Hese, P.G. de Groot, H.F. Heijnen, E.H. Sage, S. Williams, L. McKeown, H.R. Grainick, J.J. Sixma. Platelet adhesion to collagen types I through VIII under conditions of stasis and flow is mediated by GPla/lla ( $\alpha_{2} \beta_{1}$ integrin). Blood 83 (1994) 1244-1250.

41. K. Shinmyozu, M. Kuriyama, T. Okadome, Y. Maruyama, I. Maruyama, M. Osame. Collagen adhesion-aggregation abnormality: congenital platelet membrane glycoprotein VI deficiency. Rinsho Ketsueki 31 (1990) 660-664.

42. H.K. Nieuwenhuis, K.S. Sakariassen, W.P. Houdijk, P.F. Nievelstein, J.J. Sixma. Deficiency of platelet membrane glycoprotein la associated with a decreased platelet adhesion to subendothelium: a defect in platelet spreading. Blood 68 (1986) 692-695.

43. F.I. Pareti, Y. Fujimura, J.A. Dent, L.Z. Holland, T.S. Zimmerman, Z.M. Ruggeri. Isolation and characterization of a collagen binding domain in human von Willebrand factor. J. Biol. Chem. 261 (1986) 15310-15315.

44. G.J. Roth, K. Titani, L.W. Hoyer, M.J. Hickey. Localization of binding sites within human von Willebrand factor for monomeric type III collagen. Biochemistry 25 (1986) 8357-8361.

45. J.H. Rand, N.D. Patel, E. Schwartz, S.L. Zhou, B.J. Potter, 150-kD von Willebrand factor binding protein extracted from human vascular subendothelium is type VI collagen. J. Clin. Invest. 88 (1991) 253-259.

46. J.M. Ross, L.V. McIntire, J.L. Moake, J.H. Rand. Platelet adhesion and aggregation on human type VI collagen surfaces under physiological flow conditions. Blood 85 (1995) 1826-1835.

47. H. Lankhof, Y.P. Wu, T. Vink, M.E. Schiphorst, H.G. Zerwes, P.G. de Groot, J.J. Sixma. Role of the glycoprotein Ib-binding A1 repeat and the RGD sequence in platelet adhesion to human recombinant von Willebrand factor. Blood 86 (1995) 1035-1042.

48. B.R. Alevriadou, J.L. Moake, N.A. Turner, Z.M. Ruggeri, B.J. Folie, M.D. Phillips, A.B. Schreiber, M.E. Hrinda, L.V. McIntire. Real-time analysis of shear-dependent thrombus formation and its blockade by inhibitors of von Willebrand factor binding to platelets. Blood 81 (1993) 1263-1276

49. E. Fressinaud, D. Baruch, J.P. Girma, K.S. Sakariassen, H.R. Baumgartner, D. Meyer. Von Willebrand factor-mediated platelet adhesion to collagen involves platelet membrane glycoprotein IIb-IIla as well as glycoprotein Ib. J. Lab. Clin. Med. 112 (1988) 58-67

50. S. Beumer, H.F. Heijnen, I.J. M.J. E. Orlando, P.G. de Groot, J.J. Sixma. Platelet adhesion to fibronectin in flow: the importance of von Willebrand factor and glycoprotein $\mathrm{lb}$. Blood 86 (1995): $3452-3460$. 
51. J.M. Gardner, R.O. Hynes. Interaction of fibronectin with its receptor on platelets. Cell 42 (1985) 439-448.

52. R.S. Piotrowicz, R.P. Orchekowski, D.J. Nugent, K.Y. Yamada, T.J. Kunicki. Glycoprotein Ic-lla functions as an activation-independent fibronectin receptor on human platelets. J. Cell. Biol. 106 (1988) 1359-1364.

53. G. Hindriks, M.J. ljsseldijk, A. Sonnenberg. J.J. Sixma, P.G. de Groot. Platelet adhesion to laminin: role of $\mathrm{Ca}^{2 *}$ and $\mathrm{Mg}^{2 *}$ ions, shear rate, and platelet membrane glycoproteins. Blood 79 (1992) 928-935.

54. A. Sonnenberg. P.W. Modderman, F. Hogervorst. Laminin receptor on platelets is the integrin VLA-6. Nature 336 (1988) 487-489.

55. N.N. Tandon, E.A. Holland, U. Kralisz, H.K. Kleinman, F.A. Robey, G.A. Jamieson. Interaction of human platelets with laminin and identification of the $67 \mathrm{kDa}$ laminin receptor on platelets. Biochem. J. 274 (1991) 535-542.

56. G.P. Tuszynski, M.A. Kowalska. Thrombospondin-induced adhesion of human platelets. J. Clin. Invest. 87 (1991) 1387-1394.

57. M.A. Kowalska, G.P. Tuszynski. Interaction of thrombospondin with platelet glycoproteins GPla-Ila and GPIIb-IIla. Biochem. J. 295 (1993) 725-730,

58. F.R. Agbanyo, J.J. Sixma, P.G. de Groot, L.R. Languino, E.F. Plow. Thrombospondin-platelet interactions. Role of divalent cations, wall shear rate, and platelet membrane glycoproteins. J. Clin. Invest. 92 (1993) 288-296.

59. W.P. Houdijk, P.G. de Groot, P.F. Nievelstein, K.S. Sakariassen, J.J. Sixma. Subendothelial proteins and platelet adhesion. von Willebrand factor and fibronectin, not thrombospondin, are involved in platelet adhesion to extracellular matrix of human vascular endothelial cells. Arteriosclerosis 6 (1986) 24-33.

60. H.C. de Boer, K.T. Preissner, B.N. Bouma, P.G. de Groot. Internalization of vitronectinthrombin-antithrombin complex by endothelial cells leads to deposition of the complex into the subendothelial matrix. J. Biol. Chem. 270 (1995) 30733-30740.

61. K.T. Preissner, B. Potzsch. Vessel wall-dependent metabolic pathways of the adhesive proteins, von-Willebrand-factor and vitronectin. Histol. Histopathol. 10 (1995) 239-251.

62. K.T. Preissner. The role of vitronectin as multifunctional regulator in the hemostatic and immune systems. Blut 59 (1989) 419-431.

63. B.S. Coller, D.A. Cheresh, E. Asch, U. Seligsohn. Platelet vitronectin receptor expression differentiates Iraqi-Jewish from Arab patients with Glanzmann thrombasthenia in Israel. Blood 77 (1991) 75-83.

64. P. Thiagarajan, K. Kelly. Interaction of thrombin-stimulated platelets with vitronectin (S-protein of complement) substrate: inhibition by a monoclonal antibody to glycoprotein IIb-IIla complex. Thromb. Haemost. 60 (1988) 514-517.

65. E.M. Cramer, W. Vainchenker, G. Vinci, J. Guichard, J. Breton Gorius. Gray platelet syndrome: immunoelectron microscopic localization of fibrinogen and von Willebrand factor in platelets and megakaryocytes. Blood 66 (1985) 1309-1316.

66. R.P. McEver, E.M. Bennett, M.N. Martin. Identification of two structurally and functionally distinct sites on human platelet membrane glycoprotein IIb-IIla using monoclonal antibodies. J. Biol. Chem. 258 (1983) 5269-5275. 
67. J.C. Loftus, R.M. Albrecht. Use of colloidal gold to examine fibrinogen binding to human platelets. Scan. Electron. Microsc. Pt 4 (1983) 1995-1999.

68. J.C. Loftus, R.M. Albrecht. Redistribution of the fibrinogen receptor of human platelets after surface activation. J. Cell. Biol. 99 (1984) 822-829.

69. J. Amiral, B. Adalbert, M. Adam. Application of enzyme immunoassays to coagulation testing. Clin. Chem. 30 (1984) 1512-1516.

70. Y. Ikeda, M. Handa, K. Kawano, T. Kamata, M. Murata, Y. Araki, H. Anbo, Y. Kawai, K. Watanabe, I. Itagaki, et al. The role of von Willebrand factor and fibrinogen in platelet aggregation under varying shear stress. J. Clin. Invest. 87 (1991) 1234-1240.

71. D.M. Peterson, N.A. Stathopoulos, T.D. Giorgio, J.D. Hellums, J.L. Moake. Shear-induced platelet aggregation requires von Willebrand factor and platelet membrane glycoproteins $\mathrm{Ib}$ and IIb-Illa. Blood 69 (1987) 625-628.

72. Y. Miyazaki, S. Nomura, T. Miyake, H. Kagawa, C. Kitada, H. Taniguchi, Y. Komiyama, Y. Fujimura, Y. Ikeda, S. Fukuhara. High shear stress can initiate both platelet aggregation and shedding of procoagulant containing microparticles. Blood 88 (1996) 3456-3464.

73. M.B. Zucker, M.W. Mosesson, M.J. Broekman, K.L. Kaplan. Release of platelet fibronectin (cold-insoluble globulin) from alpha granules induced by thrombin or collagen; lack of requirement for plasma fibronectin in ADP-induced platelet aggregation. Blood 54 (1979) 8-12.

74. D.F. Mosher. Physiology of fibronectin. Annu. Rev. Med. 35 (1984) 561-575.

75. J. Tanabe, H. Fujita, A. Iwamatsu, H. Mohri, T. Ohkubo. Fibronectin inhibits platelet aggregation independently of RGD sequence. J. Biol. Chem. 268 (1993) 27143-27147.

76. P.J. Thurlow, D.A. Kenneally, J.M. Connellan. The role of fibronectin in platelet aggregation. Br. J. Haematol. 75 (1990) 549-556.

77. S.A. Santoro. Inhibition of platelet aggregation by fibronectin. Biochem. Biophys. Res. Commun. 116 (1983) 135-140.

78. K.J. Kao, P.A. Klein. A monoclonal antibody-based enzyme-linked immunosorbent assay for quantitation of plasma thrombospondin. Am. J. Clin. Pathol. 86 (1986) 317-323.

79. J. Dawes, K.J. Clemetson, G.O. Gogstad, J. McGregor, P. Clezardin, C.V. Prowse, D.S. Pepper. A radioimmunoassay for thrombospondin, used in a comparative study of thrombospondin, $\beta$-thromboglobulin and platelet factor 4 in healthy volunteers. Thromb. Res.; 29 (1983) 569-581.

80. S. Rabhi Sabile, V. Thibert, C. Legrand. Thrombospondin peptides inhibit the secretiondependent phase of platelet aggregation. Blood Coagul. Fibrinolysis 7 (1996) 37-240.

81. G.P. Tuszynski, V.L. Rothman, A. Murphy, K. Siegler, K.A. Knudsen. Thrombospondin promotes the aggregation of platelets. Prog. Clin. Biol. Res. 283 (1988) 211-217.

82. K.J. Kao, D.M. Shaut, P.A. Klein. Functional involvement of thrombospondin in platelet aggregation induced by low versus high concentrations of thrombin. Thromb. Haemost. 55 (1986) 136-142.

83. R. Shunto, A. Shirakami, A. Ohara, N. Toibana, S. Saito. Activation of blood coagulation and fibrinolysis in vibration syndrome. Int Arch Occup Environ Health 1991; 63: 293-296.

84. J. Kobayashi, S. Yamada, H. Kawasaki. Distribution of vitronectin in plasma and liver tissue: relationship to chronic liver disease. Hepatology 20 (1994) 1412-1417. 
85. H. Mohri, T. Ohkubo. How vitronectin binds to activated glycoprotein IIb-llla complex and its function in platelet aggregation. Am. J. Clin. Pathol. 96 (1991) 605-609.

86. M.J. Berridge. Inositol trisphosphate and calcium signalling. Nature 1993; 361: 315-325.

87. M.T. Alonso, J. Alvarez, M. Montero, A. Sanchez, J. Garcia Sancho. Agonist-induced $\mathrm{Ca}^{2 *}$ influx into human platelets is secondary to the emptying of intracellular $\mathrm{Ca}^{2 *}$ stores. Biochem. J. 280 (1991) 783-789.

88. J.W.M. Heemskerk, S.O Sage. Calcium signalling in platelets and other cells. Platelets 5 (1994) 295-316.

89. T.R. Walker, S.P. Watson. Synergy between $\mathrm{Ca}^{2+}$ and protein kinase $\mathrm{C}$ is the major factor in determining the level of secretion from human platelets. Biochem. J. 289 (1993) 277-282.

90. D. Blockmans, H. Deckmyn, J. Vermylen. Platelet activation. Blood Rev. 9 (1995) 143-156.

91. L.F. Brass, D.R. Manning, K. Cichowski, C.S. Abrams. Signaling through G proteins in platelets: to the integrins and beyond. Thromb. Haemost. 78 (1997) 581-589.

92. M.L. Kahn, M. Nakanishi Matsui, M.J. Shapiro, H. Ishihara, S.R. Coughlin. Protease-activated receptors 1 and 4 mediate activation of human platelets by thrombin. J. Clin. Invest. 103 (1999) 879-887.

93. L. De Marco, M. Mazzucato, A. Masotti, Z.M. Ruggeri. Localization and characterization of an $\alpha$-thrombin-binding site on platelet glycoprotein Iba. J. Biol. Chem. 269 (1994) 6478-6484.

94. N.J. Greco, N.N. Tandon, G.D. Jones, R. Kornhauser, B. Jackson, N. Yamamoto, K. Tanoue, G.A. Jamieson. Contributions of glycoprotein $\mathrm{lb}$ and the seven transmembrane domain receptor to increases in platelet cytoplasmic $\left[\mathrm{Ca}^{2+}\right]$ induced by $\alpha$-thrombin. Biochemistry 35 (1996) $906-$ 914.

95. M.H. Kroll, T.S. Harris, J.L. Moake, R.I. Handin, A.I. Schafer. Von Willebrand factor binding to platelet GPIb initiates signals for platelet activation. J. Clin. Invest. 88 (1991) 1568-1573.

96. J.M. Gibbins, M. Okuma, R. Farndale, M. Barnes, S.P. Watson. Glycoprotein VI is the collagen receptor in platelets which underlies tyrosine phosphorylation of the Fc receptor $\gamma$-chain. FEBS Lett. 413 (1997) 255-259.

97. M. Tsuji, Y. Ezumi, M. Arai, H. Takayama. A novel association of Fc receptor gamma-chain with glycoprotein $\mathrm{VI}$ and their co-expression as a collagen receptor in human platelets. J. Biol. Chem. 272 (1997) 23528-23531.

98. K. Inoue, Y. Ozaki, K. Satoh, Y. Wu, Y. Yatomi, Y. Shin, T. Morita. Signal transduction pathways mediated by glycoprotein la/lla in human platelets: comparison with those of glycoprotein VI. Biochem. Biophys. Res. Commun. 256 (1999) 114-120.

99. D. Gailani, G.J. Broze Jr. Factor XI activation in a revised model of blood coagulation. Science 253 (1991) 909-912.

100. P.A. von dem Borne, J.C. Meijers, B.N. Bouma. Feedback activation of factor XI by thrombin in plasma results in additional formation of thrombin that protects fibrin clots from fibrinolysis. Blood 86 (1995) 3035-3042.

101. T. Lindhout, J. Franssen, G.M. Willems. Kinetics of the inhibition of tissue factor-factor Vlla by tissue factor pathway inhibitor. Thromb. Haemost. 74 (1995) 910-915.

102. A.K. Lindahl, P.M. Sandset, U. Abildgaard. The present status of tissue factor pathway inhibitor. Blood Coagul. Fibrinolysis. 3 (1992) 439-449. 
103. C.T. Esmon. Thrombomodulin as a model of molecular mechanisms that modulate protease specificity and function at the vessel surface. Faseb J. 9 (1995) 946-955.

104. C.A. Fulcher, J.E. Gardiner, J.H. Griffin, T.S. Zimmerman. Proteolytic inactivation of human factor VIII procoagulant protein by activated human protein $\mathrm{C}$ and its analogy with factor $\mathrm{V}$. Blood 63 (1984) 486-489.

105. H.M. Bakker, G. Tans, T. Janssen Claessen, M.C.L.G.D. Thomassen, H.C. Hemker, J.H. Griffin, J. Rosing. The effect of phospholipids, calcium ions and protein S on rate constants of human factor Va inactivation by activated human protein C. Eur. J. Biochem. 208 (1992) 171 178.

106. B. Zoller, B. Dahlback. Linkage between inherited resistance to activated protein $\mathrm{C}$ and factor V gene mutation in venous thrombosis. Lancet 343 (1994) 1536-1538.

107. J.A. Op den Kamp. Lipid asymmetry in membranes. Annu. Rev. Biochem. 48 (1979) $47-71$.

108. C. Diaz, A.J. Schroit. Role of translocases in the generation of phosphatidylserine asymmetry. J. Membr. Biol. 151 (1996) 1-9.

109. R.F.A. Zwaal, A.J. Schroit. Pathophysiologic implications of membrane phospholipid asymmetry in blood cells. Blood 89 (1997) 1121-1132.

110. E.M. Bevers, P. Comfurius, J.L. van Rijn, H.C. Hemker, R.F.A. Zwaal. Generation of prothrombin-converting activity and the exposure of phosphatidylserine at the outer surface of platelets. Eur. J. Biochem. 122 (1982) 429-436.

111. E.M. Bevers, P. Comfurius, R.F.A. Zwaal. Changes in membrane phospholipid distribution during platelet activation. Biochim. Biophys. Acta. 736 (1983) 57-66.

112. J. Rosing. G. Tans, J.W. Govers Riemslag. R.F.A. Zwaal, H.C. Hemker. The role of phospholipids and factor $\mathrm{Va}$ in the prothrombinase complex. J. Biol. Chem. 255 (1980) 274283.

113. G. van Dieijen, G. Tans, J. Rosing, H.C. Hemker. The role of phospholipid and factor VIIla in the activation of bovine factor X. J. Biol. Chem. 256 (1981) 3433-3442.

114. E.M. Bevers, J. Rosing, R.F.A. Zwaal. Development of procoagulant binding sites on the platelet surface. Adv. Exp. Med. Biol. 192 (1985) 359-371.

115. J. Rosing, J.L. van Rijn, E.M. Bevers, G. van Dieijen, P. Comfurius, R.F.A. Zwaal. The role of activated human platelets in prothrombin and factor X activation. Blood 65 (1985) 319-332.

116. G. Tans, J. Rosing, M.C.L.G.D Thomassen, M.J. Heeb, R.F.A. Zwaal, J.H. Griffin. Comparison of anticoagulant and procoagulant activities of stimulated platelets and platelet-derived microparticles. Blood 77 (1991) 2641-2648.

117. M.E. Nesheim, E. Furmaniak Kazmierczak, C. Henin, G. Cote. On the existence of platelet receptors for factor V(a) and factor VIII(a). Thromb. Haemost. 70 (1993) 80-86.

118. M. Kalafatis, N.A. Swords, M.D. Rand, K.G. Mann. Membrane-dependent reactions in blood coagulation: role of the vitamin K-dependent enzyme complexes. Biochim. Biophys. Acta 1227 (1994) 113-129.

119. J.M. Scandura, S.S. Ahmad, P.N. Walsh. A binding site expressed on the surface of activated human platelets is shared by factor $X$ and prothrombin. Biochemistry 35 (1996) 8890-8902.

120. T.V. Byzova, E.F. Plow. Networking in the hemostatic system. Integrin $\alpha_{m i} \beta_{3}$ binds prothrombin and influences its activation. J. Biol. Chem. 272 (1997) 27183-27188. 
121. B.A. Bouchard, C.S. Catcher, B.R. Thrash, C. Adida, P.B. Tracy. Effector cell protease receptor-1, a platelet activation-dependent membrane protein, regulates prothrombinasecatalyzed thrombin generation. J. Biol. Chem. 272 (1997) 9244-9251

122. C.P.M. Reutelingsperger, W. van Heerde, R. Hauptmann, C. Maassen, R.G. van Gool, P. de Leeuw, A. Tiebosch. Differential tissue expression of Annexin VIII in human. FEBS Lett. 349 (1994) 120-124.

123. J. Romisch, E. Schuler, B. Bastian, T. Burger, F.G. Dunkel, A. Schwinn, A.A. Hartmann, E.P. Paques. Annexins I to $\mathrm{VI}$ : quantitative determination in different human cell types and in plasma after myocardial infarction. Blood Coagul. Fibrinolysis 3 (1992) 11-17.

124. J.F. Tait, D. Gibson, K. Fujikawa. Phospholipid binding properties of human placental anticoagulant protein-I, a member of the lipocortin family. J. Biol. Chem. 264 (1989) 7944-7949.

125. H.A.M. Andree, C.P.M. Reutelingsperger, R. Hauptmann, H.C. Hemker, W.T. Hermens, G.M. Willems. Binding of vascular anticoagulant alpha (VAC alpha) to planar phospholipid bilayers. J. Biol. Chem. 265 (1990) 4923-4928.

126. P. Thiagarajan, J.F. Tait. Binding of annexin V/placental anticoagulant protein I to platelets. Evidence for phosphatidylserine exposure in the procoagulant response of activated platelets. Biol. Chem. 265 (1990) 17420-17423.

127. J. Dachary-Prigent, J.M. Freyssinet, J.M. Pasquet, J.C. Carron, A.T. Nurden. Annexin V as a probe of aminophospholipid exposure and platelet membrane vesiculation: a flow cytometry study showing a role for free sulfhydryl groups. Blood 81 (1993) 2554-2565.

128. D. Billy, J. Briedé, J.W.M. Heemskerk, H.C. Hemker, T. Lindhout. Prothrombin conversion under flow conditions by prothrombinase assembled on adherent platelets. Blood Coagul. Fibrinolysis 8 (1997) 168-174. 


\section{Chapter 2}

Heterogeneity in Microparticle Formation and Exposure of Anionic Phospholipids at the Plasma Membrane of Single Adherent Platelets

Jacob J. Briedé, Johan W. M. Heemskerk, H. Coenraad Hemker and Theo Lindhout Biochimica et Biophysica Acta 1451 (1999), 163-172 


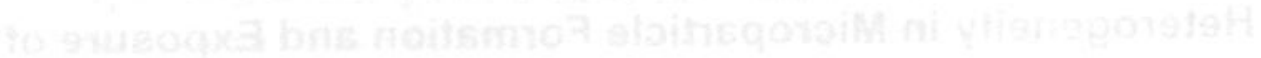

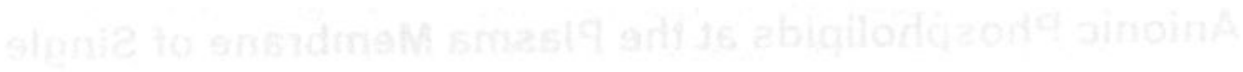

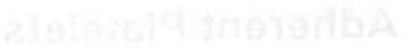




\section{Summary}

Adherent platelets were examined for their ability to form microvesicles and procoagulant sites for thrombin formation. Epifluorescence and phase-contrast microscopy were employed to visualize shape changes, changes in intracellular $\mathrm{Ca}^{2+}$ levels $\left(\left[\mathrm{Ca}^{2+}\right]\right)$, vesiculation of the plasma membrane and appearance of anionic phospholipids in the outer leaflet of the plasma membrane, as probed by annexin $\mathrm{V}$ binding. In the absence of extracellular $\mathrm{Ca}^{2+}$ two stable populations of adherent platelets were observed. The majority of the adherent platelets were fully spread and about $10 \%$ remained in a non-spread dendritic state. In the presence of extracellular $\mathrm{Ca}^{2+}$ vesiculation at the surface of spread platelets occurred at a rather slow rate (10\% of the platelets after $20 \mathrm{~min})$ concomitantly with an increase in $\left[\mathrm{Ca}^{2+}\right]$, and binding of annexin V. However, a small fraction of the adherent platelets ( 1\%) responded much faster. Ionomycin-enhanced influx of $\mathrm{Ca}^{2+}$ in dendritic platelets resulted in a rapid transformation of these platelets into inflated, balloon-shaped, platelets having a diameter of $2.0 \pm 0.7 \mu \mathrm{m}$ without notable microvesicle formation. In contrast, fully spread platelets retained their shape but obtained frayed edges as a result of microvesicle formation. Confocal scanning fluorescence microscopy indicated that annexin $\mathrm{V}$ bound to very distinct sites at the outer plasma membrane of spread as well as balloon-shaped platelets. Inhibition of platelet calpain activity suppressed ionomycin-enhanced microvesicle formation and ballooning of platelets, but not annexin $\mathrm{V}$ binding. These findings indicate that vesiculation and ballooning. but not the exposure of phosphatidylserine at the outer leaflet of the adherent platelet membrane, are associated with cytoskeleton destruction. Altogether, the data suggest a similar relationship between $\left[\mathrm{Ca}^{2+}\right]$; and the formation of platelet procoagulant sites as reported for platelets in suspension. However, the present investigations on single adherent platelets reveal for the first time that adhesion and spreading of platelets is not necessarily associated with the appearance of procoagulant sites. Secondly, an unexpected diversity was observed among adherent platelets with respect to sensitivity to $\mathrm{Ca}^{2+}$-induced generation of procoagulant sites and $\mathrm{Ca}^{2+}$-induced vesiculation of plasma membrane. It is tempting to speculate that this diversity is of importance for the procoagulant response of platelets to a haemostatic challenge elicited by an injured vessel wall. 


\section{Introduction}

The interaction of platelets with fibrinogen and extracellular matrix proteins, like collagen and fibronectin, is followed by a sequence of responses: 1) platelet shape change, 2) secretion of components from intracellular granula, 3) loss of phospholipid asymmetry in the plasma membrane and 4) membrane vesiculation (reviewed in (16)). These responses serve different biological functions: haemostatic plug formation and recruiting other blood cells to sites of injury. Loss of phospholipid asymmetry and vesiculation of the plasma membrane has been studied extensively because of the crucial importance of these processes in maintaining normal haemostasis (7-10).

There is good evidence that agonist-induced elevation of platelet $\left[\mathrm{Ca}^{2+}\right]$ inhibits an ATP-dependent phospholipid pump (translocase) that specifically shuttles aminophospholipids from the outer to the inner leaflet of the cellular plasma membrane. In addition, high $\left[\mathrm{Ca}^{2+}\right]$ activates a non-ATP-dependent phospholipid transporter (scramblase) that rapidly shuttles phospholipids from the inner to the outer leaflet. The net effect of increased $\left[\mathrm{Ca}^{2+}\right]_{\text {i }}$ is surface exposure of anionic phospholipids like phosphatidylserine (see (11) for a review). Increased $\left[\mathrm{Ca}^{2+}\right]_{\text {i }}$ also stimulates cytoplasmic calpain activity, which degrades the cytoskeleton (12). Cytoskeleton degradation is thought to be responsible for microvesicle formation at the plasma membrane and shedding of microparticles that have anionic phospholipids at their surface $(13,14)$.

Most of our understanding of the agonist-mediated generation of procoaguant platelets arises from studies with platelet suspensions. However, it remains to be seen whether platelets form a homogeneous population with respect to sensitivity to agonist-mediated activation. This question can only be answered when single platelets are studied. Studies on adherent single platelets are of special interest because they allow gathering of information about the contribution of outside-in signaling on platelet shape change, release reaction and even the development of procoagulant activity (reviewed in (15)). In this signaling process, the cytosolic $\mathrm{Ca}^{2+}$ concentration, $\left[\mathrm{Ca}^{2+}\right]$; plays an essential role as a second messenger $(16,17)$.

In this chapter we report on the interaction between single platelets and immobilized fibrinogen, one of the most potent platelet adhesive substrates, and the consequences for platelet morphology, $\left[\mathrm{Ca}^{2+}\right]$ and exposure of anionic phospholipids at the outer leaflet of the plasma membrane, utilizing combined video-enhanced epifluorescence and phase-contrast microscopy. Digital image-processing techniques were employed to analyze and quantify the temporal relationship between the different platelet responses upon the addition of agents that control $\left[\mathrm{Ca}^{2+}\right]$, and calpain activity of fibrinogen-adherent platelets. 


\section{Materials and Methods}

Materials. Fura-2 acetoxymethyl ester was purchased from Molecular Probes (Leiden, The Netherlands). Bovine serum albumin (BSA), bovine fibrinogen (fraction I, type IV), econazole nitrate (1-[2-([4-chlorophenyl] $]$ methoxy)-2-(2,4dichlorophenyl)ethyl]-1H-imidazole nitrate), 1,4-diazobicyclo[2.2.2]octane (DABCO), apyrase and ionomycin were from Sigma (St. Louis, USA). Calpain inhibitor (MDL28170) carbamic acid, [1-(((1-formyl-2-phenylmethyl)amino)carboxyl)-2methylpropyl]-phenylmethyl ester was from Meryll Dow (Cincinnati, USA). Oregon Green 488-labeled annexin V (OG-annexin V) was a product of NeXins Research (Hoeven, The Netherlands).

Loading of platelets with fura-2 and MDL-28170. Suspensions of washed platelets were prepared as previously described (18). Briefly, blood was drawn from healthy donors, who had not taken any anti-platelet medication in the preceding two weeks. Platelet-rich plasma, prepared by centrifugation, was incubated with $3 \mu \mathrm{mol} / \mathrm{I}$ fura-2 acetoxymethyl ester or $200 \mu \mathrm{mol} / \mathrm{MDL}-28170$ at $37{ }^{\circ} \mathrm{C}$ for 1 hour in the presence of apyrase $(0.1 \mathrm{U} / \mathrm{ml})$. The platelets were then sedimented by centrifugation, washed twice with HEPES buffer composed of $10 \mathrm{mmol} / \mathrm{HEPES}, 136 \mathrm{mmol} / \mathrm{NaCl}, 5$ $\mathrm{mmol} / \mathrm{l}$ glucose, $2.7 \mathrm{mmol} / \mathrm{l} \mathrm{KCl}, 2 \mathrm{mmol} / \mathrm{l} \mathrm{MgCl}_{2}, \mathrm{BSA}(0.5 \mathrm{mg} / \mathrm{ml})$ and apyrase $(0.1$ $\mathrm{U} / \mathrm{ml}$ ), pH 6.6. Finally, the platelets were resuspended in HEPES buffer of the same composition, but adjusted to $\mathrm{pH} 7.45$. Platelets were counted on a Coulter counter (Coulter, Miami, USA) and the suspensions were adjusted to $5 \times 10^{7}$ platelets $/ \mathrm{ml}$.

Preparation of fibrinogen-coated coverslips. Fibrinogen-coated glass coverslips were prepared as previously described (19). Briefly, cleaned glass coverslips (diameter $22 \mathrm{~mm}$ ) were exposed for 1 hour at room temperature to a solution of 10 $\mathrm{mg} / \mathrm{ml}$ fibrinogen in $40 \mathrm{mmol} / \mathrm{l}$ phosphate buffer, $150 \mathrm{mmol} / \mathrm{l} \mathrm{NaCl}, \mathrm{pH}$ 7.4. The coverslips were rinsed with HEPES buffer $\mathrm{pH} 7.45$ and mounted in an incubation chamber made from Teflon (height $7.5 \mathrm{~mm}$, inner diameter $19.5 \mathrm{~mm}$ ).

Platelet adhesion to immobilized fibrinogen. The incubation chamber was filled with a suspension of washed platelets $\left(300 \mu l, 1.5 \times 10^{7}\right.$ platelets $)$ and incubated at room temperature for 40 minutes. After incubation, non-attached platelets were removed by rinsing the chamber 5 times with $250 \mu$ l HEPES buffer pH 7.45.

Phase-contrast imaging. Positive phase-contrast images were obtained with an inverted microscope (Nikon Diaphot 200; Nikon, Tokyo, Japan) using a Nikon 100x quartz oil-immersion objective containing a phase plate. The phase-contrast transmission images were recorded with an infrared camera (VPM 6132 monochrome high-resolution charge-coupled device camera, Vista Co, Norbain, UK). Quanticell 500 software (Applied Imaging, Newcastle, UK) was used for analyzing the phasecontrast images. 
Fluorescence imaging. For fluorescence imaging, light from a Xenon lamp passed a computer-controlled excitation and neutral density filter wheel, and reached the objective of the inverted microscope through an UV-transparent liquid light guide and a dichroic long-pass filter. The emission light passed a computer-controled emission filter wheel, and finally reached a low-light level intensified, charge-coupled device camera working at standard video rate (Photonic Sciences, Robertsbridge, UK). Fura-2 signals were detected with alternating $340 \mathrm{~nm}$ and $380 \mathrm{~nm}$ excitation filters (bandpasses of $15 \mathrm{~nm}$ ), a $400 \mathrm{~nm}$ dichroic mirror, and $510 \mathrm{~nm}$ emission filter (bandpass of $40 \mathrm{~nm}$ ). Oregon Green 488 fluorescence was observed with a $485 \mathrm{~nm}$ excitation filter (bandpass of $40 \mathrm{~nm}$ ), a $505 \mathrm{~nm}$ dichroic long-pass filter, and a $530 \mathrm{~nm}$ emission filter (bandpass of $30 \mathrm{~nm}$ ). Oregon Green and fura-2 fluorescence images were digitized and averaged; background images were subtracted and stored. There was no interference between the fura-2 and the Oregon Green 488 fluorescence signals. The fluorescence images were off-line analyzed using Quanticell 700 software. The calibration of fluorescence ratio to molar concentrations of intracellular $\mathrm{Ca}^{2+}$ was according to Grynkiewicz et al (20).

Confocal scanning laser microscopy of adherent platelets. Washed platelets were allowed to adhere at room temperature to fibrinogen, immobilized to a glass coverslip, during 40 minutes. Non-adhered platelets were removed by rinsing with HEPES buffer $\mathrm{pH}$ 7.45. Then adherent platelets were incubated with $5 \mu \mathrm{mol} / \mathrm{l}$ ionomycin, directly followed by $3 \mathrm{mmol} / / \mathrm{CaCl}_{2}$ and $1 \mu \mathrm{g} / \mathrm{ml} \mathrm{OG}$-annexin $\mathrm{V}$. After 10 minutes HEPES buffer $\mathrm{pH} 7.45$ was replaced by HEPES buffer $\mathrm{pH} 8.0$ containing 3 $\mathrm{mmol} / / \mathrm{CaCl}_{2}$ and $2 \%(\mathrm{w} / \mathrm{v})$ DABCO. The fibrinogen-coated glass coverslip with adhered platelets was covered with a concave glass coverslip and sealed. Oregon Green 488 fluorescent platelets were visualized using a MRC 600 confocal scanning laser device (Bio-Rad, Hemel Hempstead, UK) mounted onto an Axiophot microscope (Zeiss, Oberkochen, Germany) with a Nikon $63 x$ quartz oil-immersion objective. Z-scans with steps of $0.5 \mu \mathrm{m}$ were made. Every scan was 6 times averaged using Kalman filtering (21).

\section{Results}

Platelet responses following adhesion to immobilized fibrinogen in the absence of extracellular $\mathrm{Ca}^{2+}$. Platelets that adhere to immobilized fibrinogen in the absence of extracellular $\mathrm{Ca}^{2+}$ first developed pseudopodia and within $40 \mathrm{~min} 90 \%$ of the platelets were fully spread (platelets 1,2 and 3 in Fig 1A). The other $10 \%$ of the platelets remained in a non-spread dendritic state (platelet 4 in Fig. 1A). Prolongation of the incubation time did not alter the ratio of fully spread over dendritic platelets. The findings as shown in Fig. 1A are representative for all experiments performed under 

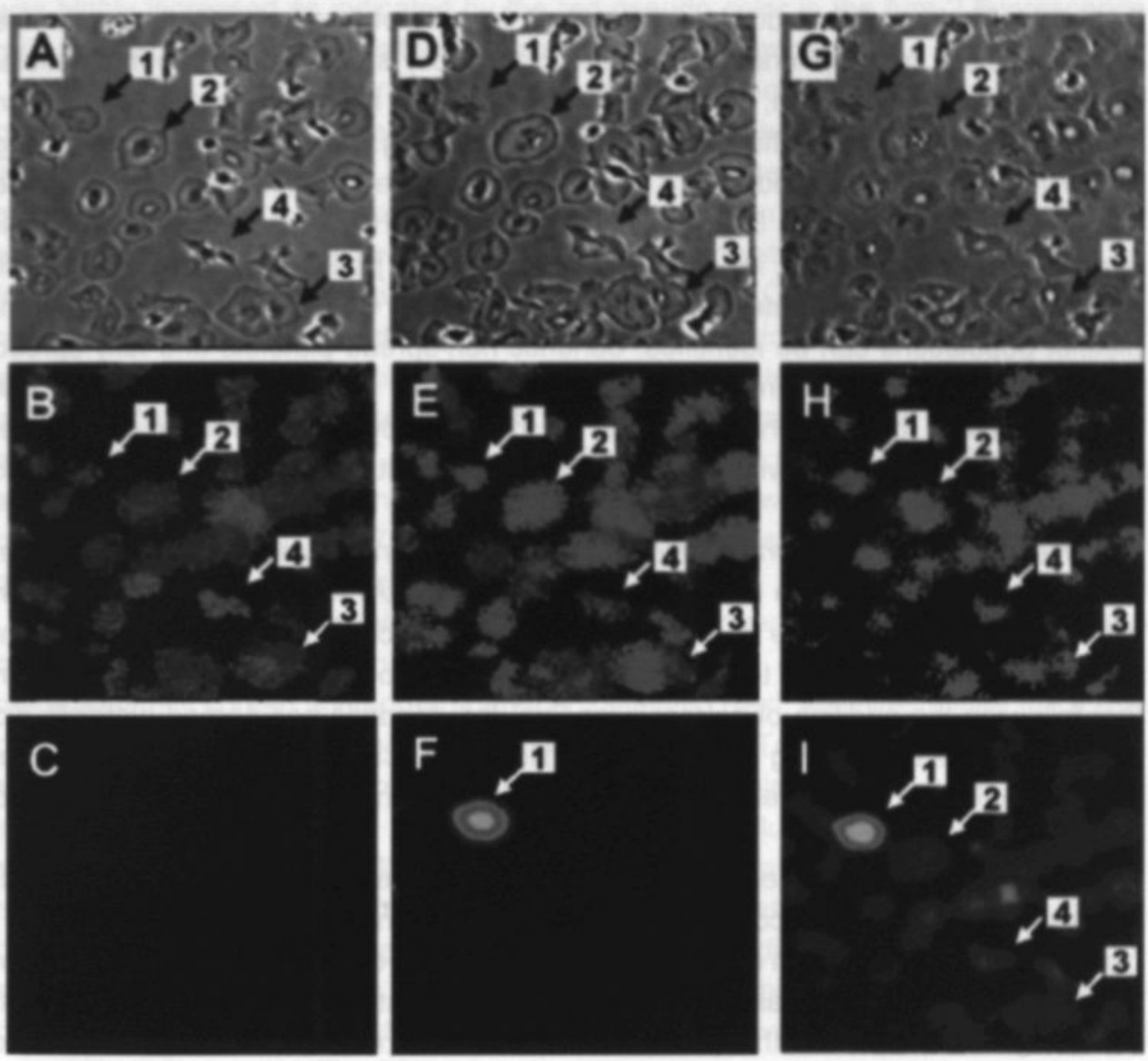

Figure 1 Effect of extracellular $\mathrm{Ca}^{2+}$ on morphology, $\left[\mathrm{Ca}^{2+}\right]$, and annexin $\mathrm{V}$ binding of adherent platelets. Platelets loaded with fura- 2 were exposed to immobilized fibrinogen for 40 minutes. The first row of images show phase-contrast images of the adherent platelets in absence of extracellular $\mathrm{Ca}^{2+}$ (A), followed by a $10 \mathrm{~min}$ incubation with $3 \mathrm{mmol} / \mathrm{CaCl}$ and $1 \mu \mathrm{g} / \mathrm{ml}$ Oregon Green 488-labeled annexin V (D) and a 5 min incubation with $5 \mu \mathrm{mol} / \mathrm{h}$ ionomycin $(G)$. The second row are the fura-2 fluorescence ratio images and the third row represents the OG-annexin $V$ fluorescence images of the corresponding microscopic fields shown in A, D and G, respectively. Further experimental details are given under Materials and Methods. 
these conditions and thus donor-independent. In spite of the dramatic shape change of the platelets, from spherical non-adhering to a fully spread state, the intracellular free calcium concentration, $\left[\mathrm{Ca}^{2+}\right]$, remained low as indicated by the blue/green pseudo color of the fura-2 fluorescence ratio image (Fig. 1B). Continuous monitoring of the fura-2 signal showed that a vast majority of the platelets had an invariable $\left[\mathrm{Ca}^{2+}\right]$ of about $50 \mathrm{nmol} / \mathrm{l}$. Some platelets (less than $10 \%$ and irrespective of their morphology) showed small, irregular oscillations in $\left[\mathrm{Ca}^{2+}\right]$, between 30 and $100 \mathrm{nmol} / \mathrm{l}$. Together, these data indicate that when no extracellular $\mathrm{Ca}^{2+}$ is present two adherent platelet populations can be identified: dendritic non-spread platelets and fully spread platelets. In spite of a different morphology both stable populations have similar low $\left[\mathrm{Ca}^{2+}\right]$. Thus, if platelet shape change is triggered by the interaction of platelet receptors (integrin $\alpha_{416} \beta_{3}$ ) with immobilized fibrinogen, it seems not to be related to calcium signaling.

Responses of adherent platelets to increased extracellular $\mathrm{Ca}^{2+}$ concentration. Adherent platelets from the previous experiment (Fig. 1A) were incubated for $10 \mathrm{~min}$ with $3 \mathrm{mmol} / / \mathrm{CaCl}_{2}$. The averaged intracellular calcium levels of the adherent platelets increased from 50 to $70 \mathrm{nmol} / \mathrm{l}$ over a time period of $10 \mathrm{~min}$. It is clearly seen that following the addition of extracellular $\mathrm{Ca}^{2+}$ the dendritic non-spread platelets did spread to some extent. (Fig 1D, platelet 4). However, $\left[\mathrm{Ca}^{2+}\right]_{i}$ of these platelets did not change, indicating that spreading of these platelets is not signaled by an increased $\left[\mathrm{Ca}^{2+}\right]$.

When besides extracellular calcium also OG-annexin $V(1 \mu \mathrm{g} / \mathrm{ml})$ was added, one platelet in the microscopic field under examination bound annexin $V(F i g .1 F$, platelet 1). Close inspection of the corresponding phase-contrast image of this platelet (Fig 1D, platelet 1) revealed that this particular platelet showed frayed edges, indicating vesiculation of the plasma membrane. Inspection of other microscopic fields for OG-annexin $V$ fluorescence revealed that about $1 \%$ of the adherent platelets bound annexin $\mathrm{V}$, showed frayed edges and had somewhat elevated $\left[\mathrm{Ca}^{2+}\right]_{i}$ of about $150 \mathrm{nmol} / \mathrm{l}$. On prolonged incubation with $3 \mathrm{mmol} / / \mathrm{CaCl}_{2}$ an increasing number of OG-annexin V-binding platelets were seen. After $30 \mathrm{~min}$ about $10 \%$ of all adherent platelets were stained with OG-annexin V. Annexin V binding was preceded by a rapid increase of $\left[\mathrm{Ca}^{2+}\right]_{i}$ from 70 to $150 \mathrm{nmol} / \mathrm{l}$. Non-annexin $\mathrm{V}$ binding platelets had $\left[\mathrm{Ca}^{2+}\right]_{\mathrm{i}}$ of about $70 \mathrm{nmol} / \mathrm{l}$. Thus, whereas spreading of platelets appeared not to be signaled by cytosolic calcium, vesiculation and loss of phospholipid asymmetry can be associated with elevated $\left[\mathrm{Ca}^{2+}\right]_{i}$ of adherent platelets. To see whether vesiculation of the membrane and/or exposure of PS could be induced in all adherent platelets the $\mathrm{Ca}^{2+}$ ionophore ionomycin $(5 \mu \mathrm{mol} / \mathrm{l})$ was used to increase the rate of inflow of extracellular $\mathrm{Ca}^{2+}$. Within $5 \mathrm{~min}$ after the addition of ionomycin all spread platelets showed frayed edges (Fig. 1G) and bound annexin V (Fig. 1I). The [Ca $\left.{ }^{2+}\right]$ of all cells 
was highly increased as indicated by the red pseudo color in the fura- 2 fluorescence ratio image (Fig. $1 \mathrm{H}$ ) and was found to vary around $700 \mathrm{nmol} / \mathrm{l}$.

The question can be raised whether the OG-annexin V-stained platelets, as platelet 1 in Fig. 1F, had already exposed anionic phospholipid before the addition of extracellular $\mathrm{Ca}^{2+}$. Because binding of annexin $\mathrm{V}$ requires $\mathrm{Ca}^{2+}$, we addressed this question by utilizing econazole, a drug that has been shown to block influx of extracellular $\mathrm{Ca}^{2+}(22)$. After an incubation of $20 \mathrm{~min}$ with $10 \mu \mathrm{mol} / \mathrm{l}$ econazole, we found that all adherent platelets showed constant low [Ca] of about $75 \mathrm{nmol} / /$ and none of the adherent platelets showed binding of annexin V, indicating that influx of extracellular $\mathrm{Ca}^{2+}$ is essential to make that some platelets (less than $1 \%$ of all adherent cells) rapidly loose their phospholipid asymmetry. That the econazoletreated platelets could react on an influx of extracellular $\mathrm{Ca}^{2+}$ was confirmed by the addition of the $\mathrm{Ca}^{2+}$ ionophore ionomycin $(5 \mu \mathrm{mol} / \mathrm{l})$ which resulted in high and constant elevated $\left[\mathrm{Ca}^{2+}\right]_{i}$ of $700 \mathrm{nmol} / \mathrm{l}$, fraying of the plasma membrane and binding of OG-annexin $\mathrm{V}$ to all platelets within $5 \mathrm{~min}$.

Vesiculation of the plasma membrane of adherent platelets. So far the observations on vesiculation of the plasma membrane of adherent platelets were made with fully spread and spread-dendritic platelets. Next, we investigated the ability of non-spread dendritic platelets to form microparticles. To this end $\mathrm{CaCl}_{2}(3 \mathrm{mmol} / \mathrm{l})$ and ionomycin $(5 \mu \mathrm{mol} / \mathrm{l})$ were added simultaneously to platelets that were adhered to immobilized fibrinogen in the absence of extracellular $\mathrm{Ca}^{2+}$. Phase-contrast microscopy showed that fully spread platelets (like platelets 1 and 2 in fig. 2A) retained this shape but with frayed edges (Fig. 2B: platelets 1 and 2). The non-spread dendritic platelets (like platelets 3 and 4 in fig. 2A) immediately changed into balloonshaped structures (Fig. 2B: platelets 3 and 4). The balloon-like shape of these platelets became evident when focussed 1-2 $\mu \mathrm{m}$ above the glass coverslip with immobilized fibrinogen (Fig. 2C).

To confirm the balloon-like shape and to find out how the anionic phospholipids are distributed in the outer leaflet of the plasma membrane, confocal scanning laser microscopy of adherent platelets, exposed to $3 \mathrm{mmol} / \mathrm{l} \mathrm{CaCl} 2$ and $5 \mu \mathrm{mol} / \mathrm{l}$ ionomycin, was performed in the presence of OG-annexin V (Fig. 3). Scans were started at the surface of the coverslip with steps of $0.5 \mu \mathrm{m}$. The first $1.5 \mu \mathrm{m}$ above the glass coverslip surface showed OG-annexin $V$ fluorescence associated with spread platelets forming microvesicles at their plasma membranes. The next $2 \mu \mathrm{m}$ showed circular patterns of fluorescence with some heavily stained spots. Fig. 3 indicates two interesting features. Firstly, dendritic, non-spread platelets were indeed transformed to inflated balloons with an estimated diameter of $2.0 \pm 0.7 \mu \mathrm{m}$. Secondly, the spotlike distribution of annexin $\mathrm{V}$ binding sites indicates a heterogeneous distribution of the anionic phospholipids in the plasma membrane. 

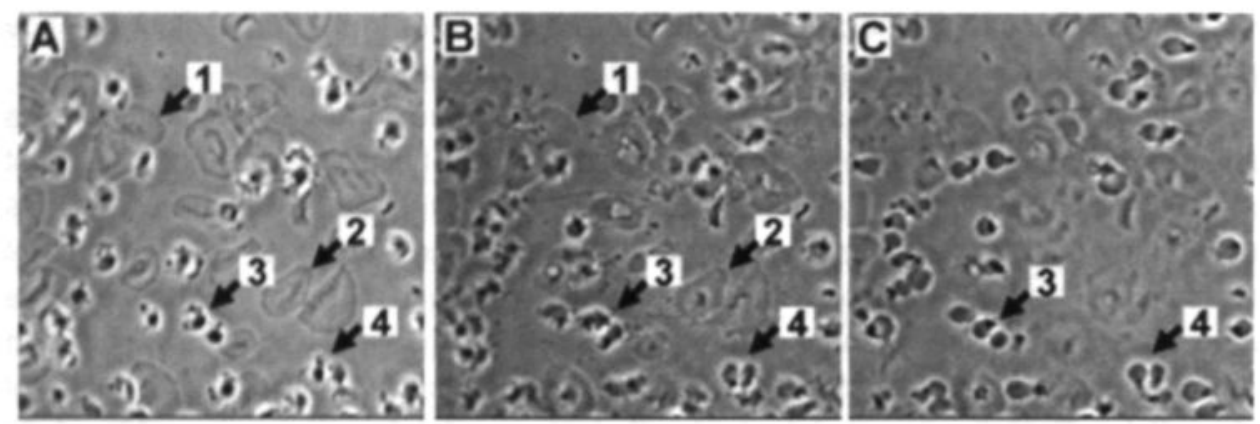

Figure 2 lonomycin-induced morphological changes in dendritic and fully spread platelets. Platelets adhered to immobilized fibrinogen were incubated with HEPES buffer $\mathrm{pH} 7.45$ containing $3 \mathrm{mmol} / / \mathrm{CaCl}_{2}$ and $5 \mu \mathrm{mol} / /$ ionomycin. Phasecontrast images show: one particular microscopic field prior to the addition of $\mathrm{CaCl}_{2}$ and ionomycin (A), 5 min after the addition of $\mathrm{CaCl}_{2}$ and ionomycin (B) and focussed 1-2 $\mu \mathrm{m}$ above surface of the coverslip (C).

Investigations with fura-2 loaded platelets showed that when balloon-platelets were treated with ionomycin the $\left[\mathrm{Ca}^{2+}\right]_{i}$ rapidly increased to values around $700 \mathrm{nmol} / \mathrm{l}$. Because intracellular calpain is activated by high $\left[\mathrm{Ca}^{2+}\right]_{\mathrm{i}}$ it is feasible that the transition of dendritic-shaped platelets into inflated balloon-like, without notable spreading, might be the result of a rapid destruction of the cytoskeleton. Strong support for this notion was obtained from experiments with a calpain inhibitor, MDL-28170, loaded platelets. In the presence of MDL-28170 a rapid influx of extracellular $\mathrm{Ca}^{2+}$ did not result in the appearance of balloon-shaped platelets, but the hyaloplasma did spread between pseudopodia of the dendritic platelets (Fig. 4). In addition, MDL-28170 also blocked vesiculation of the plasma membrane of the spread platelets. The same experiments with fura- 2 and MDL-28170 loaded platelets showed that MDL-28170 did not affect the increase in $\left[\mathrm{Ca}^{2+}\right]_{\text {i }}$ when these platelets were incubated with ionomycin. Also the annexin V binding of MDL-28170 loaded platelets after stimulation with ionomycin was not different from those not loaded with the calpain inhibitor (data not shown). Thus, as has been reported for platelets in suspension (8), loss in phospholipid asymmetry is not necessarily associated with vesiculation of the plasma membrane of adherent platelets. 


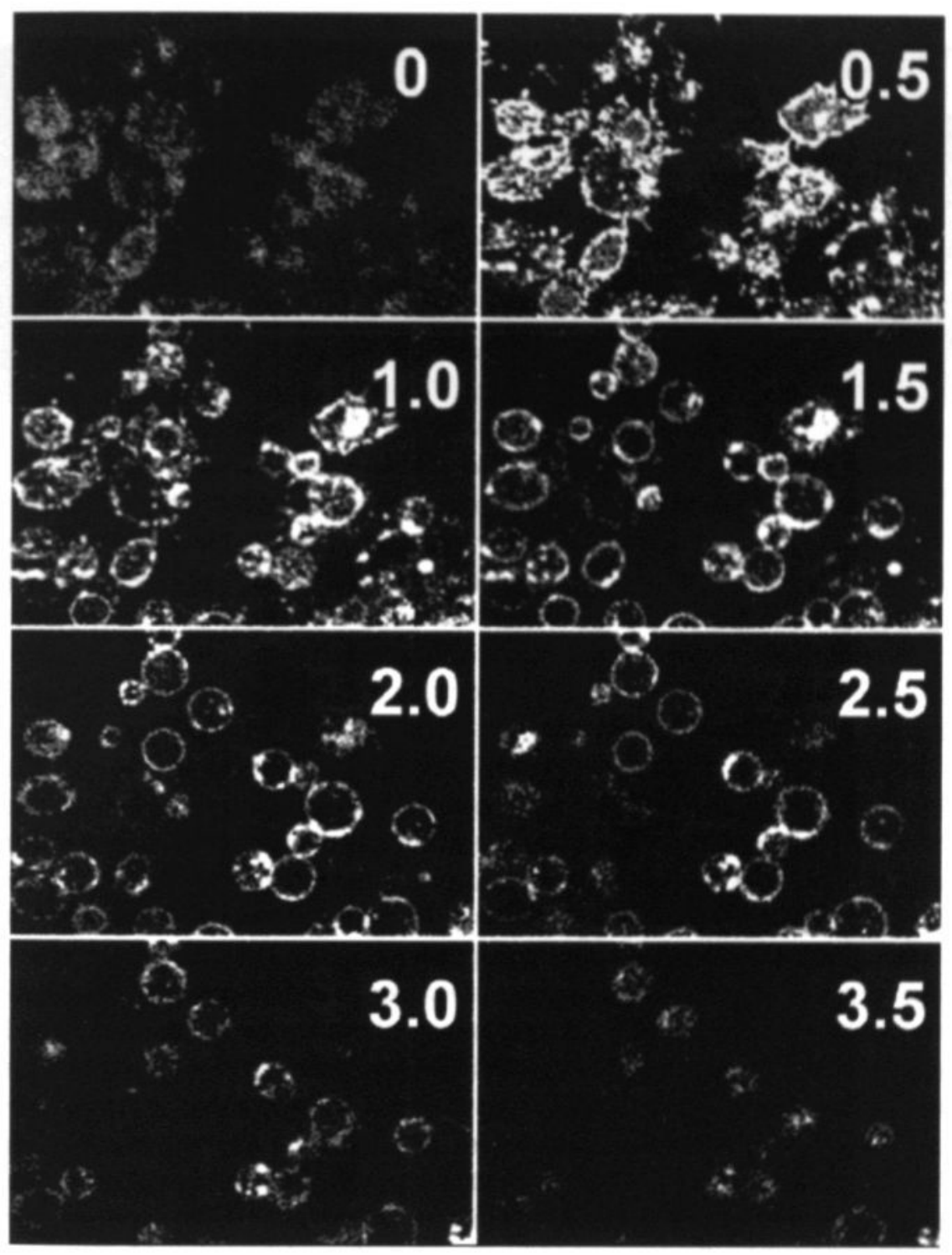

Figure 3 Confocal laser microscopy of ionomycin activated platelets. Platelets were exposed to immobilized fibrinogen for $40 \mathrm{~min}$ and incubated for $10 \mathrm{~min}$ with HEPES buffer pH 7.45 containing $3 \mathrm{mmol} / / \mathrm{CaCl}_{2} .5 \mu \mathrm{mol} / \mathrm{l}$ ionomycin and $1 \mu \mathrm{g} / \mathrm{ml}$ Oregon Green 488-labeled annexin V. Confocal scanning laser microscopy was performed with steps of $0.5 \mu \mathrm{m}$. The images show OG-annexin $V$ fluorescence at the indicated distance from the surface (in $\mu \mathrm{m}$ ) of the coverslip. 

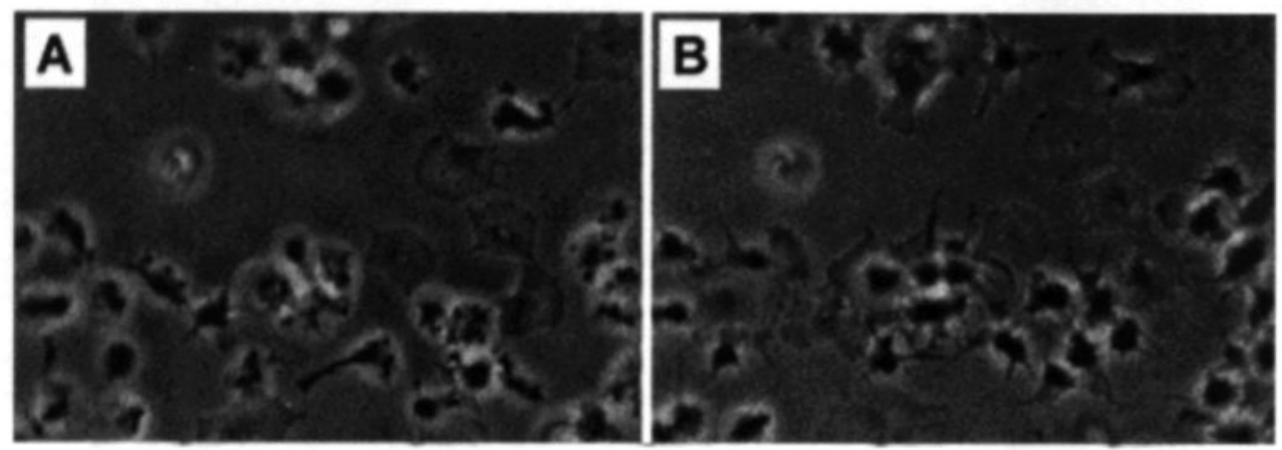

Figure 4 Effect of calpain inhibitor on microvesicle formation of adherent platelets. Adherent platelets loaded with the calpain inhibitor MDL-28170 were exposed to $3 \mathrm{mmol} / / \mathrm{CaCl}_{2}$ and $5 \mu \mathrm{mol} / /$ ionomycin. The phase-contrast images show: $\mathrm{A}$ ) adherent platelets prior the addition of $\mathrm{CaCl}_{2}$ and ionomycin; B) the same microscopic field 5 min after the addition of $\mathrm{CaCl}_{2}$ and ionomycin.

\section{Discussion}

In the absence of extracellular $\mathrm{Ca}^{2+}$ the majority of washed platelets readily spread on a surface coated with immobilized fibrinogen once they adhered to the surface and had formed pseudopodia. Some platelets, about $10 \%$ of those that adhered, however, did not spread but kept a dendritic shape. All adhesion experiments under these conditions showed this phenomenon, suggesting that the existence of two classes of adhering platelets is not donor dependent. According to the fura-2 measurements no striking differences were found in the intracellular calcium concentration $\left(\left[\mathrm{Ca}^{2+}\right]_{i}\right)$ between the two platelet populations. As a matter of fact, a low $\left[\mathrm{Ca}^{2+}\right]_{i}$ of about 50 $\mathrm{nmol} / \mathrm{l}$ was found in all adherent platelets. Surprisingly, addition of extracellular $\mathrm{Ca}^{2+}$ initiated the spreading of the dendritic platelets, but was not accompanied with a significant increase in $\left[\mathrm{Ca}^{2+}\right]_{\mathrm{i}}$. The finding that spreading of platelets does not require an elevated $\left[\mathrm{Ca}^{2+}\right]_{i}$ is in agreement with earlier reports $(18,23,24)$, but are in contrast with work reported by lkeda et al (25). These authors found that $\left[\mathrm{Ca}^{2+}\right]_{\mathrm{i}}$ increased when platelets adhered to immobilized fibrinogen and concluded that the increased $\left[\mathrm{Ca}^{2+}\right]$, plays a key role in achieving morphological changes of platelets that adhere to immobilized fibrinogen.

The dentritic and spread platelets were further analyzed for a (partially) loss of their asymmetric distribution of plasma membrane phospholipids by examining their annexin $\mathrm{V}$ binding properties after the adition of $3 \mathrm{mmol} / \mathrm{l} \mathrm{CaCl}$. This concentration was chosen because the binding of annexin $\mathrm{V}$ requires $2-3 \mathrm{mmol} / \mathrm{l} \mathrm{Ca}{ }^{2+}(26)$. None of the adherent platelets that were incubated with extracellular calcium and econazole, a 
calcium channel blocker (22), bound annexin V. This clearly indicates that the outer leaflet of the plasma membrane of adherent platelets, either non-spread dendritic or fully spread, does not contain the anionic phospholipid, phosphatidylserine. On prolonged incubation with extracellular $\mathrm{Ca}^{2+}$, in the absence of econazole, an increasing number of adherent platelets showed increased $\left[\mathrm{Ca}^{2+}\right]$, (about $\left.150 \mathrm{nmol} / \mathrm{l}\right)$, vesiculation of the plasma membrane and could be stained with annexin V. It is apparent that, as reported for platelets in suspension, that elevated $\left[\mathrm{Ca}^{2+}\right]_{\mathrm{i}}$ evokes dramatic shape changes of the plasma membrane and the loss of phospholipid asymmetry (14). It is of interest to note that we repeatedly observed that $1 \%$ of the adherent platelets responded within a few minutes to addition of extracellular calcium with vesiculation of the membrane and annexin $\mathrm{V}$ binding. These few platelets may be of importance for a rapid onset of thrombin generation because membranes with exposed anionic phospholipids may serve as sites for the assembly of the prothrombin and factor X converting enzyme complexes (see (27) for a review). Traces of thrombin thus formed are assumed to stimulate the generation of additional procoagulant sites, which in turn enables an explosive thrombin generation.

Because of the different susceptibilities platelets may have in responding to agonists, like extracellular $\mathrm{Ca}^{2+}$ and thrombin, we addressed the question whether the two platelet populations with different spreading abilities respond differently in surface exposure of procoagulant phospholipid. This work confirms that the formation of procoagulant sites at the platelet surface is signaled by $\left[\mathrm{Ca}^{2+}\right]_{i}$ (reviewed in (11)). Changes in $\left[\mathrm{Ca}^{2+}\right]_{i}$ in its turn is induced by a variety of physiological important agonists, e.g. thrombin. Thrombin induces a repetitive spiking of $\left[\mathrm{Ca}^{2+}\right]_{1}$ in individual fibrinogen-adherent platelets (18), so in this study we used the calcium ionophore, ionomycin, for a constant influx of extracellular $\mathrm{Ca}^{2+}$. As expected, the constant high $\left[\mathrm{Ca}^{2+}\right]$, was associated with the appearance of binding sites for annexin V. We further confirmed that vesiculation of the membrane of spread platelets, but not binding of annexin V, could be prevented when platelets were loaded with the membrane permeable calpain inhibitor MDL-28170. These observations are compatible with the notion that $\mathrm{Ca}^{2+}$-dependent activation of calpain results in destruction of cytoskeleton and hence microvesicle formation $(14,28)$. However, what remained unnoticed in other studies was the finding that a rapid increase of $\left[\mathrm{Ca}^{2+}\right]$, of dendritic platelets did not result in spreading of these platelets as was observed under conditions of a slowly increasing $\left[\mathrm{Ca}^{2+}\right]_{\mathrm{i}}$, nor in vesiculation of the membrane, but was associated with a rapid transformation into inflated balloon-like platelets with diameter of $2.0 \pm 0.7 \mu \mathrm{m}$. It is tempting to speculate that the lesser extent of integrin $\alpha_{\mathrm{nb}} \beta_{3}$-mediated interaction of the dendritic platelets with the fibrinogen-coated surface allows after destruction of the cytoskeleton the formation of a balloon-shaped platelet rather than the appearance of small microvesicles at the plasma membrane. Indeed, when adherent dendritic platelets loaded with the calpain inhibitor MDL-28170 were incubated with ionomycin 
and extracellular $\mathrm{Ca}^{2+}$ these platelets spread and were not transformed in a balloonlike shape.

Confocal microscopy demonstrated that the annexin $\mathrm{V}$ binding sites, and thus the procoagulant sites, were not uniformly distributed over the plasma membrane of adherent platelets. The confocal scans revealed a few intensively stained spots at the surface of the balloon-shaped platelets, whereas for spread platelets the fluorescence seemed to be associated with the many sites where microvesicles were formed.

In summary, this study utilizing washed platelets and immobilized fibrinogen demonstrated an unexpected diversity in the rate of appearance of procoagulant sites on adherent platelets, a difference in the ability of these platelets to form microparticles and a very heterogeneous distribution of procoagulant sites at the plasma membrane of single surface-bound platelets. The consequences of this diversity for the initiation and propagation of thrombin formation are the subject of further investigations.

\section{ACKNOWLEDGEMENTS}

We would like to thank Dr. E. M. Bevers for his valuable suggestions and Dr. J. Broers for his assistance in performing confocal laser scanning microscopy.

\section{References}

1. R.F.A. Zwaal, A.J. Schroit. Pathophysiologic implications of membrane phospholipid asymmetry in blood cells. Blood 89 (1997) 1121-1132.

2. J.J. Sixma, G.H. van Zanten, E.G. Huizinga, R.M. van der Plas, M. Verkley, Y.P. Wu, P. Gros, P.G. de Groot. Platelet adhesion to collagen: an update. Thromb. Haemost. 78 (1997) 434-438.

3. Z.M. Ruggeri. The role of von Willebrand factor and fibrinogen in the initiation of platelet adhesion to thrombogenic surfaces. Thromb. Haemost. 74 (1995) 460-463.

4. Z.M. Ruggeri, Mechanisms initiating platelet thrombus formation, Thromb. Haemost. 78 (1997) 611-616.

5. J. Hawiger. Mechanisms involved in platelet vessel wall interaction. Thromb. Haemost. 74 (1995) 369-372.

6. M.A. Packham. Role of platelets in thrombosis and hemostasis. Can. J. Physiol. Pharmacol. 72 (1994) 278-284.

7. E.M. Bevers, P. Comfurius, R.F.A. Zwaal. Platelet procoagulant activity: physiological significance and mechanisms of exposure. Blood Rev. 5 (1991) 146-154. 
8. J.M. Pasquet, J. Dachary-Prigent, A.T. Nurden. Comparison between the loss of platelet membrane asymmetry, microvesiculation and the tyrosine phosphorylation of proteins. Prostaglandins Leukot. Essent. Fatty Acids 57 (1997) 451-453.

9. N. Bettache, P. Gaffet, N. Allegre, L. Maurin, F. Toti, J.M. Freyssinet, A. Bienvenue. Impaired redistribution of aminophospholipids with distinctive cell shape change during $\mathrm{Ca}^{2 *}$-induced activation of platelets from a patient with Scott syndrome. Br. J. Haematol. 101 (1998) 50-58.

10. J. Dachary-Prigent, F. Toti, N. Satta, J.M. Pasquet, A. Uzan, J.M. Freyssinet. Physiopathological significance of catalytic phospholipids in the generation of thrombin. Semin. Thromb. Hemost. 22 (1996) 157-164.

11. R.F.A. Zwaal, P. Comfurius, E.M. Bevers. Mechanism and function of changes in membranephospholipid asymmetry in platelets and erythrocytes. Biochem. Soc. Trans. 21 (1993) 248 253.

12. F. Basse, P. Gaffet, A. Bienvenue. Correlation between inhibition of cytoskeleton proteolysis and anti-vesiculation effect of calpeptin during A23187-induced activation of human platelets: are vesicles shed by filopod fragmentation? Biochim. Biophys. Acta 1190 (1994) 217-224

13. J.E. Fox, C.D. Austin, C.C. Reynolds, P.K. Steffen. Evidence that agonist-induced activation of calpain causes the shedding of procoagulant-containing microvesicles from the membrane of aggregating platelets. J. Biol. Chem. 266 (1991) 13289-13295.

14. J. Dachary-Prigent, J.M. Pasquet, J.M. Freyssinet, A.T. Nurden. Calcium involvement in aminophospholipid exposure and microparticle formation during platelet activation: a study using $\mathrm{Ca}^{2 *}$-ATPase inhibitors. Biochemistry 34 (1995) 11625-11634.

15. S.J. Shattil, H. Kashiwagi, N. Pampori. Integrin signaling: the platelet paradigm. Blood 91 (1998) 2645-2657.

16. M.H. Kroll, A.I. Schafer. Biochemical mechanisms of platelet activation. Blood 74 (1989) 1181 1195.

17. W. Siess. Molecular mechanisms of platelet activation. Physiol. Rev. 69 (1989) 58-178.

18. J.W.M. Heemskerk, W.M.J. Vuist, M.A.H. Feijge, C.P.M. Reutelingsperger, T. Lindhout. Collagen but not fibrinogen surfaces induce bleb formation, exposure of phosphatidylserine, and procoagulant activity of adherent platelets: evidence for regulation by protein tyrosine kinase-dependent $\mathrm{Ca}^{2 *}$ responses. Blood 90 (1997) 2615-2625.

19. D. Billy, J. Briedé, J.W.M. Heemskerk, H.C. Hemker, T. Lindhout. Prothrombin conversion under flow conditions by prothrombinase assembled on adherent platelets. Blood Coagul. Fibrinolysis 8 (1997) 168-174.

20. G. Grynkiewicz, M. Poenie, R.Y. Tsien. A new generation of $\mathrm{Ca}^{2 *}$ indicators with greatly improved fluorescence properties. J. Biol. Chem. 260 (1985) 3440-3450.

21. M. van Engeland, H.J. Kuijpers, F.C. Ramaekers, C.P.M. Reutelingsperger, B. Schutte. Plasma membrane alterations and cytoskeletal changes in apoptosis. Exp. Cell Res. 235 (1997) 421 430.

22. J.G. Vostal, J.C. Fratantoni. Econazole inhibits thapsigargin-induced platelet calcium influx by mechanisms other than cytochrome P-450 inhibition. Biochem. J. 295 (1993) 525-529. 
23. B. Savage, S.J. Shattil, Z.M. Ruggeri. Modulation of platelet function through adhesion receptors. A dual role for glycoprotein IIb-IIla (integrin $\alpha_{110} \beta_{3}$ ) mediated by fibrinogen and glycoprotein Ib-von Willebrand factor. J. Biol. Chem. 267 (1992) 11300-11306.

24 C.J. Jen, H.I. Chen, K.C. Lai, S. Usami. Changes in cytosolic calcium concentrations and cell morphology in single platelets adhered to fibrinogen-coated surface under flow. Blood 87 (1996) 3775-3782.

25. M. Ikeda, H. Ariyoshi, J. Kambayashi, M. Sakon, T. Kawasaki, M. Monden. Simultaneous digital imaging analysis of cytosolic calcium and morphological change in platelets activated by surface contact. J. Cell Biochem. 61 (1996) 292-300.

26. H.A.M. Andree, M.C.A. Stuart, W.Th. Hermens, C.P.M. Reutelingsberger, H.C. Hemker, P.M. Frederik, G.M. Willems. Clustering of lipid-bound annexin V may explain its anticoagulant effect. J. Biol. Chem. 267 (1992) 17907-17912.

27. M. Kalafatis, N.A. Swords, M.D. Rand, K.G. Mann. Membrane-dependent reactions in blood coagulation: role of the vitamin K-dependent enzyme complexes. Biochim. Biophys. Acta 1227 (1994) 113-129.

28. J.M. Pasquet, J. Dachary-Prigent, A.T. Nurden. Calcium influx is a determining factor of calpain activation and microparticle formation in platelets. Eur. J. Biochem. 239 (1996) 647-654. 


\section{Chapter 3}

Contribution of Platelet-derived Factor Va to Thrombin

Generation on Immobilized Collagen- and Fibrinogen-

\section{Adherent Platelets}

Jacob J. Briedé, Johan W. M. Heemskerk, Cornelis van 't Veer, H. Coenraad Hemker and Theo Lindhout

Thrombosis and Haemostasis 85 (2001), 509-513 


\section{Summary}

Adhesion of platelets to immobilized collagen induces the expression of anionic phospholipids, e.g. phosphatidylserine (PS), in the outer leaflet of the plasma membrane of these platelets. In contrast, of the platelets that adhere to immobilized fibrinogen only a small sub-population representing $10 \pm 3 \%$ of the total population of the fibrinogen-adherent platelets has exposed PS as probed by annexin V binding. Although the presence of PS is thought to be critical for thrombin generation at the platelet surface, no information is available about the effect of this differential PS exposure on the ability of adherent platelets to support thrombin generation. Perfusion of the fibrinogen- or collagen-adherent platelets with solutions containing factor $\mathrm{Xa}$ and prothrombin resulted in thrombin generation that i) increased linear during the first perfusion minutes, ii) was about two-fold faster at collagen-adherent than at fibrinogen-adherent platelets and iii) was for more than $98 \%$ restricted to the surface of the adherent platelets. It appeared that the lower thrombin generating capacity of fibrinogen-adherent platelets is not due to a lower overall surface density of PS, but is caused by lower amounts of platelet-bound factor Va. Firstly, in both cases thrombin generation could be completely attenuated with antibodies against human factor $\mathrm{Va}$, and secondly, in the presence of an excess of exogenous plasma-derived factor $\mathrm{Va}$ similar initial rates of thrombin formation were measured for collagen- and fibrinogenadherent platelets. Our findings suggest a unique role for immobilized collagen in maintaining haemostasis. 


\section{Introduction}

After vessel wall damage, collagen fibers present in the sub-endothelium become exposed to the blood stream. Thrombus formation is initiated by platelets that adhere to these collagen fibers. Interactions between these adherent platelets and other platelets then result in the formation of a haemostatic plug (reviewed in (1)). At the same time thrombin, a plasma protease, is generated which converts the soluble plasma protein fibrinogen into insoluble fibrin strands. The fibrin network then stabilizes this primary haemostatic plug. Sufficient amounts of thrombin to accomplish fibrin formation are only generated when the serine protease factor $\mathrm{Xa}$ is assembled with the non-enzymatic cofactor $\mathrm{Va}$ at a membrane that contains anionic phospholipids $(2,3)$. In blood, approximately $20 \%$ of the non-activated form of this essential cofactor, factor $V$, is stored in the alpha-granules of platelets (4) and becomes released and activated when platelets are exposed to a sub-nanomolar concentration of thrombin (5); the other $80 \%$ is found in plasma. Yet, patients with normal plasma factor $\mathrm{V}$ levels, but reduced platelet-derived factor $\mathrm{V}$ content, appear to have an increased bleeding tendency $(6,7)$, which might point at an important role of platelet factor $V$ in maintaining normal haemostasis. It is postulated that the ratio of platelet-derived factor $V$ over plasma-derived factor $V$ within a platelet-rich thrombus increases to about 100 -fold (8). The validity of this assumption remains, however, to be proven.

Activated platelets are also an important source of procoagulant anionic phospholipid membranes. In resting platelets negatively charged phospholipids are solely present in the inner leaflet of the plasma membrane, but when platelets in suspension are exposed to a combination of thrombin and collagen they appear at the outer leaflet of the plasma membrane (9). However, whether anionic phospholipids are the sole binding and catalytic sites for the prothrombinase complex at activated platelets is still a matter of debate. Studies that compared the regulation of thrombin generation on synthetic phospholipids with that on activated platelets indicate that in addition to the anionic phospholipid membrane constituents specific receptor-like membrane components for factor $\mathrm{Va}(10)$, factor $\mathrm{Xa}(11,12)$ and prothrombin $(13)$ are likely to play a role in prothrombin activation.

We note that in spite of the detailed information that has been gathered on prothrombin activation in platelet suspensions much less is known about the factors that determine thrombin generation at the surface of adherent platelets in a flowthrough system. The latter experimental set up is probably more relevant to the in vivo situation. Previous studies from our group have indicated that the procoagulant response of platelets as triggered by adhesion to immobilized fibrinogen and collagen quantitatively differs. Whereas adhesion of platelets to immobilized collagen induced PS exposure and release of P-selectin in the absence of thrombin, these reactions 
were almost absent in platelets that adhere to immobilized fibrinogen (14). The objective of this study was to assess whether these marked difference in procoagulant responses have consequences for the ability of these platelets to support thrombin generation and if so, whether this could be attributed to a difference in PS exposure or platelet factor V release and activation. The experimental set up to address these questions consists of a flow-through system in which washed platelets were adhered to immobilized collagen or fibrinogen prior to their exposure to a flowing buffer containing factor $\mathrm{Xa}$ and prothrombin, but no factor $\mathrm{Va}$.

\section{Materials and Methods}

Materials. Bovine serum albumin (BSA), bovine fibrinogen (fraction I, type IV), and apyrase were from Sigma (St. Louis, USA). S2238, a chromogenic substrate for thrombin, was obtained from Chromogenix (Mölndal, Sweden). Human factor Xa and human prothrombin were prepared and quantified as described (15). Human factor $\mathrm{Va}$ was kindly donated by Dr. G. Tans, Department of Biochemistry, Maastricht University, Maastricht, The Netherlands. Human $\alpha$-thrombin was prepared as described elsewhere (16). Horm collagen was a product of Nycomed (Munich, Germany). Oregon Green 488-labeled annexin V (OG-annexin V) was a product of NeXins Research (Hoeven, The Netherlands). Sheep anti-human factor V IgG and nonimmune purified sheep IgG were purchased from Kordia (Leiden, The Netherlands). The synthetic peptide $S^{123}$ PGKPGNQNSKNEPP ${ }^{137}$ duplicating the factor Xa binding site of the effector cell protease receptor-1 (EPR-1) (18) and a mouse mAb directed against this peptide were a kind gift of $\mathrm{Dr}$. N. Senden (Department of Surgery, Maastricht University, Maastricht, The Netherlands). FITClabeled goat anti-mouse lgG was obtained from Molecular Probes (Leiden, The Netherlands).

Isolation of platelets. Suspensions of washed platelets were prepared as described before (14). Briefly, blood was drawn from healthy donors, who had not taken anti-platelet drugs in the preceding two weeks. Platelet-rich plasma was prepared by centrifugation. The platelets were then sedimented from plasma by another centrifugation step, washed twice with HEPES buffer (10 mM HEPES, 136 $\mathrm{mM} \mathrm{NaCl}, 5 \mathrm{mM}$ glucose, $2.7 \mathrm{mM} \mathrm{KCl}, 2 \mathrm{mM} \mathrm{MgCl}, \mathrm{pH} 6.6$ ), containing $0.5 \mathrm{mg} / \mathrm{ml}$ BSA and apyrase $(0.1 \mathrm{U} / \mathrm{ml})$. Finally, the platelets were resuspended in HEPES buffer of the same composition, but adjusted to $\mathrm{pH} 7.45$. Platelets were counted on a Coulter counter (Coulter, Miama, USA), and suspensions were adjusted to $5 \times 10^{7}$ platelets/ml.

Preparation of fibrinogen- and collagen-coated cover slips with adherent platelet. Fibrinogen-coated glass cover slips were prepared as previously described (19). 
Cleaned cover slips were exposed for $15 \mathrm{~min}$ at room temperature to $10 \mathrm{mg} / \mathrm{ml}$ fibrinogen in saline solution $(154 \mathrm{mM} \mathrm{NaCl})$. Collagen-coated cover slips were prepared by spraying a solution of $100 \mu \mathrm{g} / \mathrm{ml}$ Horm collagen using a 100-GFX airbrush (Badger, Franklin Park, USA). The collagen-coated cover slips were allowed to dry on air before use. Fibrinogen- and collagen-coated cover slips were rinsed and incubated for $15 \mathrm{~min}$ with HEPES buffer $(\mathrm{pH} \mathrm{7.45)}$ to shield uncovered patches of glass with BSA before they were exposed to a platelet suspension. Non-adherent platelets were removed by rinsing 5 times with $250 \mu \mathrm{l} \mathrm{HEPES} \mathrm{buffer}(\mathrm{pH} 7.45)$. Phase contrast and epifluorescence microscopy. A cover slip with adherent platelets mounted in a rectangular flow chamber was placed on the stage of an inverted microscope (Diaphot 200, Nikon, Tokyo, Japan). The images were recorded with a VPM 6132 monochrome high-resolution charge-coupled device camera from Vista (Norbain, UK) that was connected to the arm of a 1:1 beam splitter. Quanticell 900 software (Visitech, Sunderland, UK) was used for analyzing the phase contrast images. Fluorescence images were made using light from a Xenon lamp passing a computer-controlled excitation and neutral density filter wheel, and reaching the objective of the inverted microscope through an UV-transparent liquid light guide and a dichroic long-pass filter. The emission light collected by $40 x$ quartz oil-immersion objective passed, via the second arm of the 1:1 beam splitter, a computer controlled emission filter wheel, and finally reached a low-light level intensified, charge-coupled device camera working at standard video rate (Photonic Sciences, Robertsbridge, UK). Oregon Green 488 and FITC fluorescence were observed with a $485 \mathrm{~nm}$ excitation filter (bandpass of $40 \mathrm{~nm}$ ), a $505 \mathrm{~nm}$ dichroic long-pass filter, and a $530 \mathrm{~nm}$ emission filter (bandpass of $30 \mathrm{~nm}$ ). Fluorescence images were digitized and averaged after subtraction of background images, and the resulting images were stored. The fluorescence images were off-line analyzed using Quanticell 700 software. Results represent the mean and standard deviation of three experiments.

Thrombin generation. Experiments under flow conditions were performed using a rectangular flow chamber that was described before (19). The flow chamber $(60 \mu \mathrm{l})$. that contained a cover slip with immobilized collagen or fibrinogen, was filled with a suspension of washed platelets and incubated at room temperature for 40 minutes. Non-adherent platelets were removed by rinsing the chamber with HEPES buffer $(\mathrm{pH}$ 7.45 ) at a flow rate of $300 \mu \mathrm{l} / \mathrm{min}$ for $10 \mathrm{~min}$. The flow chamber was then perfused $(100 \mu \mathrm{l} / \mathrm{min}$; wall shear rate of 50/s) with HEPES buffer ( $\mathrm{pH} 7.45)$ containing $3 \mathrm{mM}$ $\mathrm{CaCl}_{2}$, factor $\mathrm{Xa}$, prothrombin and, where indicated, factor $\mathrm{Va}$. Samples $(100 \mu \mathrm{l})$ were collected from the outlet of the flow chamber and added to cuvettes, containing $350 \mu \mathrm{l}$ Tris-EDTA buffer ( $50 \mathrm{mM}$ Tris- $\mathrm{HCl}, 175 \mathrm{mM} \mathrm{NaCl}, 20 \mathrm{mM}$ EDTA and $0.5 \mathrm{mg} / \mathrm{ml} \mathrm{BSA}$, $\mathrm{pH}$ 7.9) and assayed for thrombin using the chromogenic substrate $\mathrm{S} 2238$ as previously described $(20)$. The rate of thrombin generation in the flow reactor, $v_{t}$ (pmol/min), was calculated from $v_{t}=[1 l a]_{t} Q$, in which $[1 l a]_{t}$ is the thrombin 
concentration $(\mathrm{pmol} / \mathrm{ml})$ in the timed sample taken at the outlet of the flow reactor and $Q$ the volumetric flow rate $(\mathrm{ml} / \mathrm{min})$. To measure thrombin formation in the fluid phase, which could be associated with microparticles, samples of $50 \mu \mathrm{l}$ were collected at the outlet and incubated for an additional $10 \mathrm{~min}$ before Tris-EDTA buffer was added to stop prothrombin activation. The rate of thrombin formation in the fluid phase, $v_{t}$ (pmol/min), was calculated from $v_{f}=[11 \mathrm{la}]_{\mathrm{f}} \mathrm{V} / \mathrm{t}$ in which [lla $]_{\mathrm{f}}(\mathrm{pmol} / \mathrm{ml})$ is the amount of thrombin that was formed during the 10-min incubation time, $\mathrm{V}$ the volume of the flow chamber $(0.06 \mathrm{ml})$ and $\mathrm{t}$ the incubation time $(10 \mathrm{~min})$. The rate of thrombin generation at the surface of the adherent platelets, $v_{s}(\mathrm{pmol} / \mathrm{min})$, was then calculated from $v_{s}=v_{1}-v_{1}$.

Statistics. Data are shown as mean \pm SD $(n=3)$ unless otherwise stated.

\section{Results}

Extracellular calcium-induced translocation of anionic phospholipids in the membranes of fibrinogen- and collagen-adherent platelets. Washed platelets in HEPES buffer ( $\mathrm{pH} 7.45)$ were exposed to fibrinogen- or collagen-coated glass cover slips mounted in a flow chamber as described in "Material and Methods". Platelets in contact with fibrinogen developed pseudopodia, and a majority of them became fully spread. In contrast, platelets in contact with a collagen-coated cover slip all spread. After 40 minutes of incubation no further morphological changes were observed in both cases. The adherent platelets were exposed to a $\mathrm{CaCl}_{2}$-containing HEPES buffer ( $\mathrm{pH} 7.45)$ and platelet shape changes and PS exposure were analyzed by phase contrast microscopy and by the capability to bind OG-annexin V, respectively. In accordance with previous observations (21) most of the platelets did not change in morphology (Fig. 1A), but $10 \pm 3 \%$ of the fibrinogen-adherent platelets responded by vesiculation of the plasma membrane and binding of OG-annexin V (Fig. 1B). In contrast, most of the collagen-adherent platelets responded to the addition $\mathrm{CaCl}_{2}$ with a dramatic shape change. Within $10 \mathrm{~min}$ the platelets transformed from a fully spread to a balloon-shaped appearance (Fig. 1C) and all platelets bound annexin V (Fig. 1D). These data thus confirm our earlier observations (14) that extracellular calcium induces in some fibrinogen-, but virtually all collagen-adherent platelets translocation of PS from the inner leaflet to the outer leaflet of the platelet plasma membrane. 

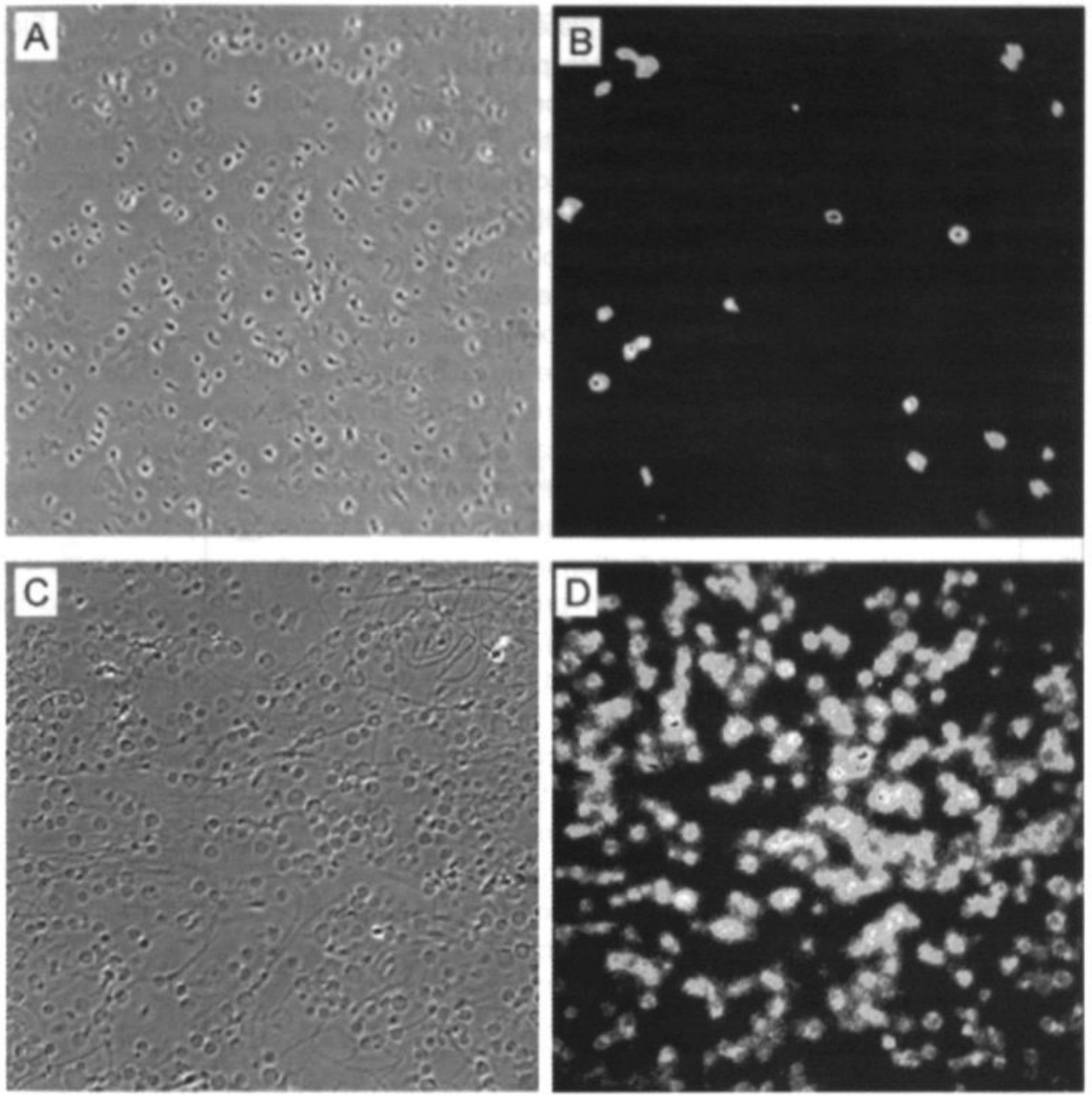

Figure 1 Morphology and OG-annexin $\mathbf{V}$ binding capacity of fibrinogen- and collagen-adherent platelets. Washed platelets in HEPES buffer $(\mathrm{pH} \mathrm{7.45)}$ were exposed to immobilized fibrinogen or collagen and incubated with $28 \mathrm{nM}$ OG-annexin $V$ and $3 \mathrm{mM} \mathrm{CaCl}$ as described in "Materials and Methods". Panels $\mathrm{A}$ and $\mathrm{B}$ represent phase contrast images and OG-fluorescence images, respectively, of fibrinogenadherent platelets. Those of collagen-adherent platelets are depicted in panels $C$ and $D$. The fibers in panel $\mathrm{C}$ are collagen. 
The influence of PS exposure on platelet-dependent thrombin generation. Flow chambers with adherent platelets were perfused at a flow rate of $100 \mu \mathrm{l} / \mathrm{min}$ with HEPES buffer $(\mathrm{pH} 7.45)$ containing factor $\mathrm{Xa}(0.05 \mathrm{nM})$, prothrombin $(100 \mathrm{nM})$ and $\mathrm{CaCl}_{2}(3 \mathrm{mM})$. Fig. 2A shows that during the first $10 \mathrm{~min}$ of the experiment the rate of thrombin production at the surface of collagen-adherent platelets increased about two-fold faster than at the surface of fibrinogen-adherent platelets. However, the steady state rates of thrombin production in the flow chamber with fibrinogen- or collagen-adherent platelets were about the same (1.0 and $1.2 \mathrm{pmol} / \mathrm{min}$, respectively). It is apparent that initially more prothrombinase is assembled at the collagen- than at the fibrinogen-adherent platelets. Yet, the question whether this difference is solely caused by the different overall surface density of PS cannot be answered at this point. One should think of the possibility that part of the prothrombinase activity is associated with microparticles shed into the solution by adherent platelets. However, whereas the rate of thrombin production in the chamber increased up to $1 \mathrm{pmol} / \mathrm{min}$, the average rate of thrombin production in the perfusion solution was less than 0.01 $\mathrm{pmol} / \mathrm{min}$. It is evident that thrombin production is almost totally confined to the surface of the adherent platelets (Fig. 2A). Alternatively, the overall surface density of PS on fibrinogen-adherent platelets could increase during the time of the experiment because of the platelet activating capability of in situ generated thrombin. However, during thrombin generation no gross increase in the number of annexin V-binding platelets was measured. We found that the percentage of platelets exposing PS in their outer leaflet of the plasma membrane increases from $10 \pm 3 \%$ before thrombin generation to $28 \pm 7 \%$ after $50 \mathrm{~min}$ of thrombin production. We recall that in contrast to fibrinogen-adherent platelets, all collagen-adherent platelets bound annexin $\mathrm{V}$ prior to their exposure to in situ generated thrombin. 


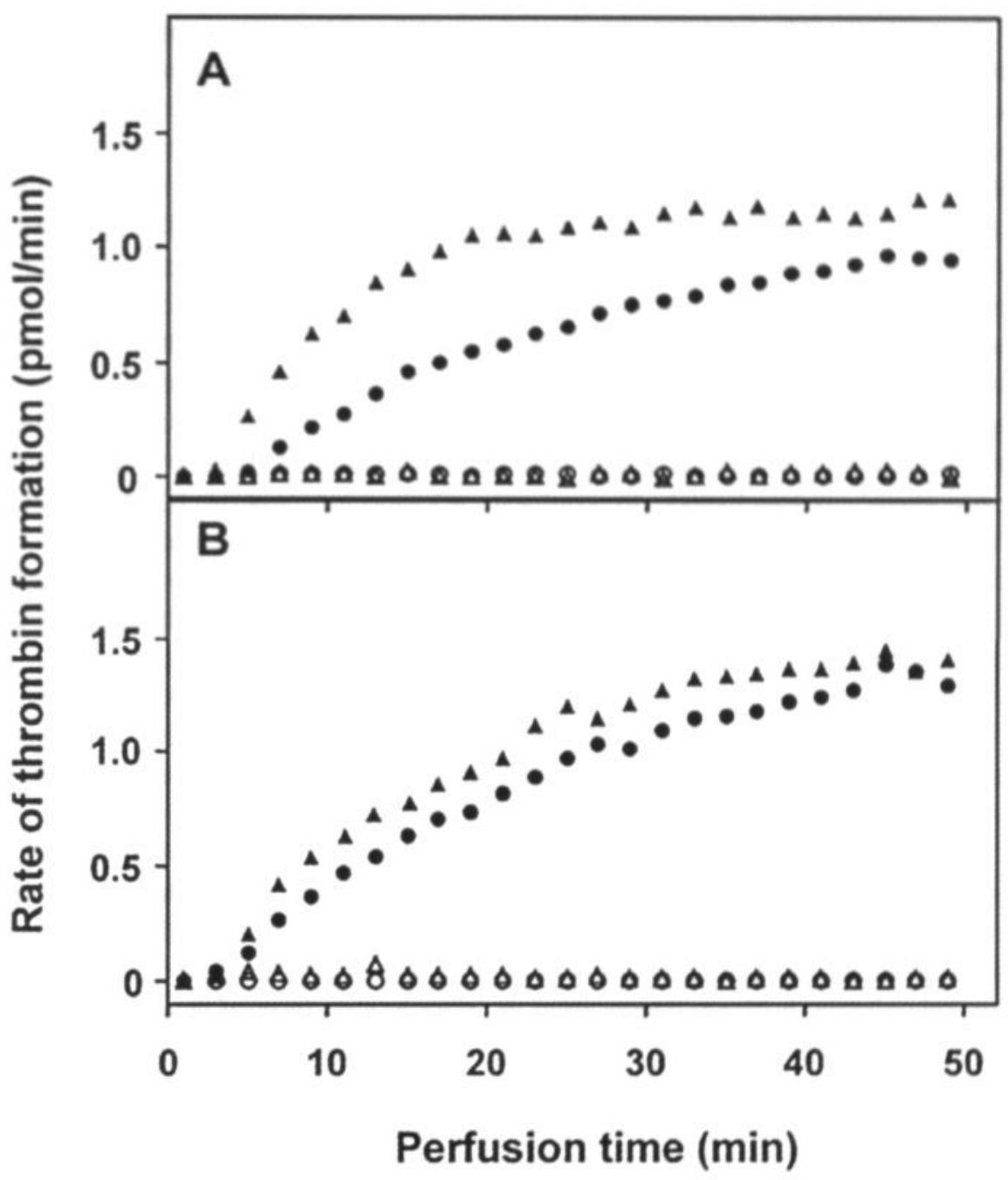

Figure 2 Thrombin formation on fibrinogen- or collagen-adherent platelets. A flow chamber containing collagen- or fibrinogen-adherent platelets was perfused with HEPES buffer ( $\mathrm{pH} 7.45$ ), supplemented with $3 \mathrm{mM} \mathrm{CaCl}_{2}, 0.05 \mathrm{nM}$ factor $\mathrm{Xa}$, and $100 \mathrm{nM}$ prothrombin in the absence (Panel A) or in the presence of $0.5 \mathrm{nM}$ factor Va (Panel B). The rate of thrombin generation at the surface of fibrinogen- $(\bullet)$ and collagen-adherent platelets $(\boldsymbol{\Lambda})$ was calculated from the rate of thrombin generation in the flow chamber and the rate of thrombin generation in the perfusion solution passing by the fibrinogen$(\mathrm{O})$ and collagen-adherent platelets $(\Delta)$ as described in Materials and Methods. 
Dependency of platelet-dependent thrombin generation on platelet factor Va. Because of the absence of exogenous factor $\mathrm{Va}$ in the perfusion solution in the previous experiments, the differential thrombin generating abilities between fibrinogen- and collagen-adherent platelets could be the result of limited amounts of platelet-bound factor $\mathrm{Va}$. To examine this possibility, a similar experiment as shown in Fig. $2 \mathrm{~A}$ was performed but with added plasma-derived factor $\mathrm{Va}(0.5 \mathrm{nM})$. Fig. $2 \mathrm{~B}$ shows the rate of thrombin production in flow chambers with collagen- or fibrinogen adherent platelets (closed symbols) and the rate of thrombin production in the perfusion solution (open symbols). It is seen that for collagen-adherent platelets, addition of plasma factor $\mathrm{Va}$ had no effect on the rate of thrombin production (compare Figs. 2A and 2B). In the absence and presence of plasma factor Va the rate of thrombin production linearly accelerated at the same rate $(0.09 \pm 0.02$ and $0.10 \pm$ $0.01 \mathrm{pmol} / \mathrm{min}^{2}$, respectively). In contrast, addition of plasma factor $\mathrm{Va}$ initially accelerated the rate of thrombin generation on fibrinogen-adherent platelets about twofold: from $0.04 \pm 0.01$ to $0.08 \pm 0.02 \mathrm{pmol} / \mathrm{min}^{2}$. It is clearly seen in Fig. $2 \mathrm{~B}$ that also in the presence of exogenous factor Va virtually all thrombin produced in the flow chamber originates from the surface of the fibrinogen- and collagen-adherent platelets. Thus, in the presence of plasma factor $\mathrm{Va}$ the rate of thrombin generation at the surface of fibrinogen-adherent platelets approaches the rate of thrombin production at the surface of collagen-adherent platelets in the absence of exogenous factor Va.

It is of interest to note that all courses of thrombin generation showed about similar steady state rates of thrombin production. The steady state of thrombin production could result from a transport-limited situation in which the rate of prothrombin activation is faster than the rate at which prothrombin is transported to the catalytic platelet surface. If true, then the steady state rate of thrombin production will depend on the prothrombin concentration in the perfusion solution. In accordance with an earlier observation (19) we found a linear increase in the steady state rate of thrombin production when the prothrombin concentration was increased from 20 to $200 \mathrm{nM}$.

To confirm our notion that platelet-bound factor $\mathrm{Va}$ is critical in factor $\mathrm{Xa}$ catalyzed prothrombin activation, experiments with anti-human factor $\mathrm{V}$ antibodies were performed. Fibrinogen-and collagen-adherent platelets were pre-activated for 15 min with human $\alpha$-thrombin $(10 \mathrm{nM})$ to activate platelet factor $V$. Thrombin was then removed by a 5-min perfusion with $\mathrm{CaCl}_{2}$-containing $\mathrm{HEPES}$ buffer $(\mathrm{pH} 7.45)$ and the platelets were incubated during $45 \mathrm{~min}$ with $0.4 \mathrm{mg} / \mathrm{ml}$ anti-factor $\mathrm{V} \mathrm{lgG}$. After unbound antibodies were removed from the flow chamber by flushing for $5 \mathrm{~min}$ with $\mathrm{CaCl}_{2}$ containing HEPES buffer, a perfusion was performed with factor Xa $(0.05 \mathrm{nM})$, prothrombin $(100 \mathrm{nM})$ and $\mathrm{CaCl}_{2}(3 \mathrm{mM})$. We found that incubation of thrombinactivated fibrinogen- and collagen-adherent platelets with anti-factor V IgG completely 
blocked thrombin generation. When the same experiment was performed with purified nonimmune sheep lgG $(0.4 \mathrm{mg} / \mathrm{ml})$ thrombin generation was comparable with that measured in the absence of IgG. To verify that anti-factor $V \lg$ specifically neutralized factor $\mathrm{Va}$ activity thrombin generation, experiments were performed in a well-defined buffer system. The reaction mixture consisted of synthetic phospholipid vesicles composed of $25 \mathrm{~mol} \%$ 1,2-dioleoyl-sn-glycero-3-phosphoserine and $75 \mathrm{~mol} \%$ 1,2-dioleoyl-sn-glycero-3-phosphocholine $(0.7 \mu \mathrm{M})$, human factor $\mathrm{Va}(0.4 \mathrm{nM}), 1 \mathrm{pM}$ human factor $\mathrm{Xa}, 200 \mathrm{nM}$ human prothrombin and $3 \mathrm{mM} \mathrm{CaCl}_{2}$ in $\mathrm{HEPES}$ buffer, $\mathrm{pH}$ 7.5. Prior to the start of the reaction with prothrombin the reaction mixture was incubated for $45 \mathrm{~min}$ at $37^{\circ} \mathrm{C}$ with either nonimmune sheep lgG $(0.4 \mathrm{mg} / \mathrm{ml})$ or sheep anti-human factor $V$ lgG $(0.4 \mathrm{mg} / \mathrm{ml})$. The rate of thrombin generation in the presence of the control IgG was $2.6 \mathrm{nM} / \mathrm{min}$, whereas no thrombin generation was detectable in the presence of anti-factor $V$ lgG.

Recent studies have indicated that the factor Xa binding site on thrombinactivated platelets could be a heterodimer that consists of factor Va and EPR-1 (11). Although the complete neutralization of platelet factor Va activity by anti-factor $\mathrm{V}$ IgG already points at an essential role of platelet factor $V a$ in the assembly of the prothrombinase complex, it cannot be ruled out that platelet EPR-1 is, by an as yet unknown mechanism, involved in thrombin generation. To detect EPR-1 on the surface of fibrinogen- and collagen-adherent platelets we used a mouse mAb raised against the peptide $\mathrm{S}^{123} \mathrm{PGKPGNQNSKNEPP}{ }^{137}$, which corresponds to the sequence of EPR-1 that interacts with factor Xa and that inhibits prothrombin activation (18). The binding of the monoclonal antibody was visualized utilizing FITC-labeled goat anti-mouse IgG. Control experiments showed no binding of this fluorescent-labeled antibody in the absence of mouse mAb against the EPR-1 peptide $\mathrm{S}^{123}-\mathrm{P}^{137}$. Only after incubation with thrombin $(10 \mathrm{nM})$ a sub-population of fibrinogen-adherent platelets expressed EPR-1 as detected by the mouse mAb against the EPR-1 peptide $\mathrm{S}^{123}-\mathrm{P}^{137}$ (Fig. 3). Collagen-adherent platelets, however, showed expression of EPR1 prior to their incubation with thrombin (data not shown). In contrast with earlier reports $(11,18)$ we could not detect an effect of the peptide $S^{123}-P^{137}(10 \mu \mathrm{g} / \mathrm{ml})$ and the mouse mAb against the EPR-1 peptide $S^{123}-P^{137}(80 \mu \mathrm{g} / \mathrm{ml})$ on cell-surface associated thrombin generation. It is our conclusion that EPR-1 is likely not involved in prothrombin activation at the surface of fibrinogen- or collagen-adherent platelets. 

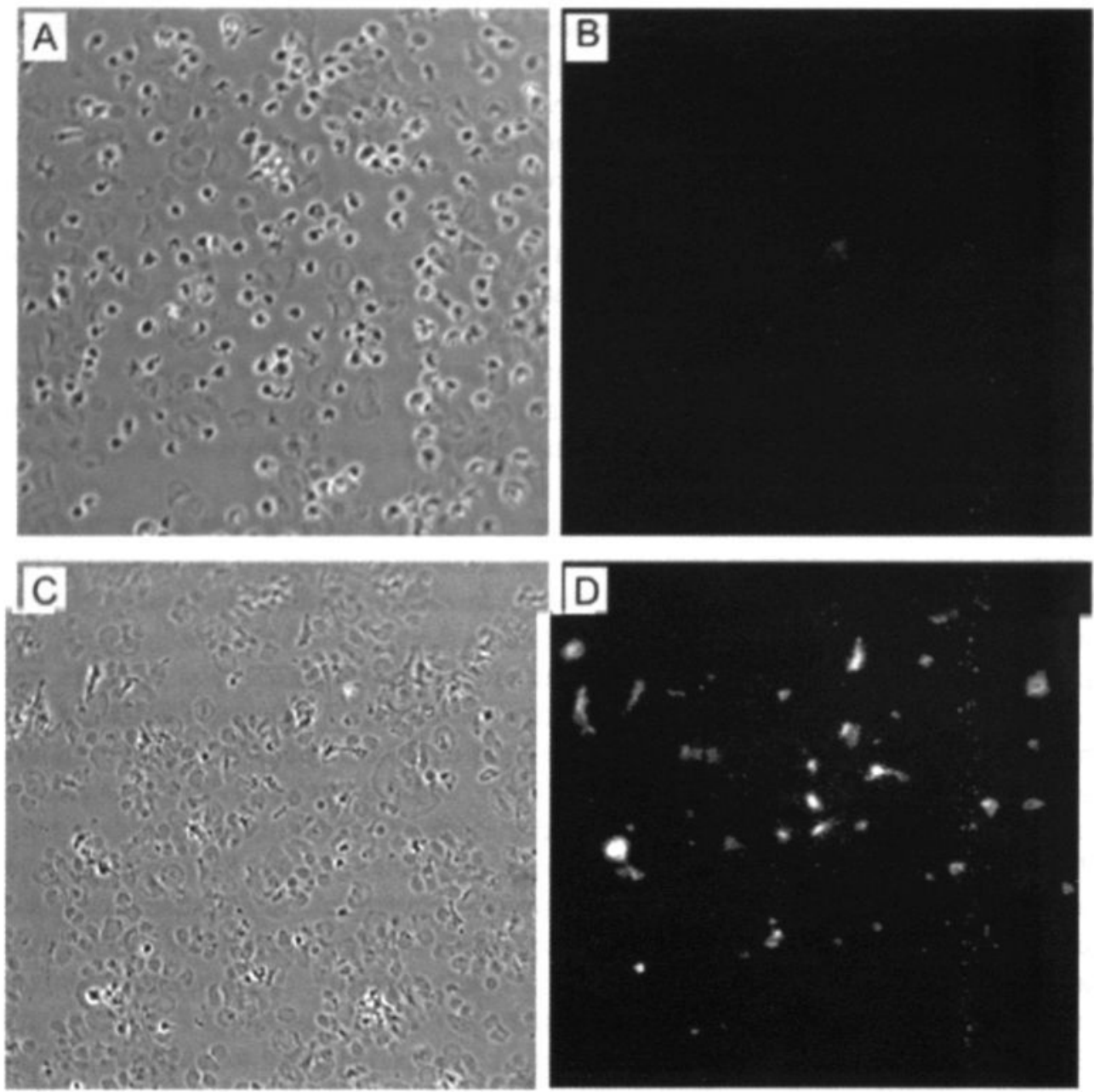

Figure 3. Binding of anti-EPR-1 monoclonal antibody to unstimulated and thrombin-stimulated fibrinogen-adherent platelets. Platelets were adhered to immobilized fibrinogen, as described in "Materials and Methods". The adherent platelets were incubated with $3 \mathrm{mM} \mathrm{CaCl}_{2}$ in the absence or presence of $10 \mathrm{nM}$ human $\alpha$-thrombin during $15 \mathrm{~min}$. Subsequently, the platelets were incubated with $80 \mu \mathrm{g} / \mathrm{ml}$ mouse antiEPR-1 mAb. After rinsing. FITC-labeled anti-mouse IgG $(20 \mu \mathrm{g} / \mathrm{ml})$ was added for 45 min. Excess of the second antibody was removed, and phase contrast as well as FITCfluorescence images of the same microscopic field ivere recorded from unstimulated ( $A$ and $\mathrm{B}$ ) and thrombin-stimulated platelets (C and D). 


\section{Discussion}

The findings of this study indicate that fibrinogen-adherent platelets are less supportive than collagen-adherent platelets in the assembly of the prothrombinconverting enzyme complex. The initially lower rate of thrombin production at the surface of fibrinogen-adherent platelets could be attributed to a lower overall surface density of platelets that have exposed anionic phospholipids. However, in the presence of exogenous plasma-derived factor $\mathrm{Va}$ the initial rate of thrombin production at fibrinogen-adherent platelets approached that found at the surface of collagen-adherent platelets. This finding indicates that the surface density of PS exposing platelets is not necessarily a limiting factor when sufficient amounts of (plasma) factor $\mathrm{Va}$ are available. It is apparent that the amount of factor $\mathrm{V}$ (a) released by fibrinogen-adherent platelets is too low to compensate for the lower PS surface density. This is in well agreement with earlier observations that the secretion reaction is much more pronounced in collagen- than in fibrinogen-adherent platelets (14). In this respect it is interesting to note that in situ formed thrombin had almost no effect on further thrombin formation. That is, the relatively small increase in the number of platelets that had exposed PS during the time course of thrombin generation did not enhance the rate of thrombin generation.

Optimal assembly of the functional prothrombinase complex at synthetic phospholipid membranes requires only the presence of anionic phospholipids. In contrast, several studies indicated the existence of specific membrane proteins that are involved in the assembly of prothrombinase on platelets $(10-13,22)$. In the present study we investigated the role of EPR-1 in platelet-dependent thrombin generation. It was postulated that both EPR-1 and membrane-bound factor Va are required to mediate factor $\mathrm{Xa}$ binding to activated platelets to form a functional prothrombinase complex $(11,12)$. We could confirm the critical role of platelet factor $\mathrm{Va}$ in platelet-dependent thrombin generation, but not that of EPR-1. That is, neutralizing antibodies against human factor $\mathrm{Va}$ completely blocked thrombin generation when adherent platelets were exposed to the perfusion solution that contained factor $\mathrm{Xa}$ and prothrombin. We also could confirm the presence of EPR-1 at the surfaces of collagen-adherent platelets utilizing a monoclonal antibody against the factor Xa-binding region of EPR-1. In contrast, fibrinogen-adherent platelets only expressed EPR-1 when they were activated with thrombin. Thrombin generation at the surface of thrombin activated platelets adhered to immobilized fibrinogen was, however, not inhibited by the monoclonal antibody directed against the factor $\mathrm{Xa}$ binding site of EPR-1 nor by the peptide $S^{123}-P^{137}$ that duplicates the factor $X a$ binding site of EPR-1. These results are not compatible with a significant contribution of platelet EPR-1 to the assembly of a functional platelet prothrombinase complex as suggested by others $(11,12)$. 
While this work was undertaken, Alberio et al (23) reported that a single agonist, e.g. thrombin, collagen or ionophore A23187, was unable to produce functionally relevant levels of surface-bound platelet factor $\mathrm{V}$ up on incubation with platelets in suspension. However, collagen in conjunction with thrombin did generate a subpopulation of platelets, representing $30 \%$ of the total population, that expressed very high levels of surface-bound factor $\mathrm{V}$. In addition, only this very same sub-population of platelets expose PS at their surface. We note intriguing differences between Alberio's and our study. Firstly, this study has demonstrated that virtually all platelets in direct contact with collagen bound annexin V, indicating that all platelets expose PS. Secondly, also fibrinogen-adherent platelets, in spite of the existence of a small sub-population of PS exposing platelets, fully support platelet-dependent thrombin generation when supplied with exogenous factor $\mathrm{Va}$. It is uncertain whether the reported difference between platelets in suspension and those adhered to immobilized collagen are of significant physiological relevance. However, it is of interest to note that adherent platelets apparently do not need a dual stimulation by thrombin to function as sites for the assembly of functional prothrombinase. Collagenadherent platelets, in addition, apparently have sufficient high levels of surface expressed factor $V$ to make thrombin generation independent on thrombin-activated plasma factor $\mathrm{V}$. These properties of collagen-adherent platelets could be of critical importance for the developing of a growing thrombus.

\section{ACKNOWLEDGEMENTS}

We are grateful to Dr. G.M. Willems of the Cardiovascular Research Institute Maastricht for fruitful discussion.

\section{References}

1. J.J. Sixma, G. Hindriks, H. Van Breugel, R. Hantgan R, P.G. de Groot. Vessel wall proteins adhesive for platelets. J. Biomater. Sci. Polym. 3 (1991) 17-26.

2. M.E. Nesheim, J.B. Taswell, K.G. Mann. The contribution of bovine Factor $V$ and Factor Va to the activity of prothrombinase. J. Biol. Chem. 254 (1979) 10952-10962.

3. J. Rosing, G. Tans, J.W. Govers Riemslag, R.F.A. Zwaal, H.C. Hemker. The role of phospholipids and factor Va in the prothrombinase complex. J. Biol. Chem. 255 (1980) 274283.

4. P.B. Tracy, L.L. Eide, E.J. Bowie,. K.G. Mann. Radioimmunoassay of factor $V$ in human plasma and platelets. Blood 60 (1982) 59-63. 
5. D. Baruch, H.C. Hemker, T. Lindhout. Kinetics of thrombin-induced release and activation of platelet factor V. Eur. J. Biochem. 154 (1986) 213-218.

6. P.B. Tracy, A.R. Giles, K.G. Mann, L.L. Eide, H. Hoogendoorn, G.E. Rivard. Factor V (Quebec): a bleeding diathesis associated with a qualitative platelet factor V deficiency. J. Clin. Invest. 74 (1984) 1221-1228.

7. C.M. Janeway, G.E. Rivard, P.B. Tracy, K.G. Mann. Factor V Quebec revisited. Blood 87 (1996) 3571-3578.

8. M.E. Nesheim, W.L. Nichols, T.L. Cole, J.G. Houston, R.B. Schenk, K.G. Mann, E.J. Bowie. Isolation and study of an acquired inhibitor of human coagulation factor V. J. Clin. Invest. 77 (1986) 405-415.

9. E.M. Bevers, P. Comfurius, R.F.A Zwaal. Changes in membrane phospholipid distribution during platelet activation. Biochim. Biophys. Acta 736 (1983) 57-66.

10. M.E. Nesheim, E. Furmaniak Kazmierczak, C. Henin, G. Cote. On the existence of platelet receptors for factor V(a) and factor VIII(a). Thromb. Haemost. 70 (1993) 80-86.

11. B.A. Bouchard, C.S. Catcher, B.R. Thrash, C. Adida, P.B. Tracy. Effector cell protease receptor-1, a platelet activation-dependent membrane protein, regulates prothrombinasecatalyzed thrombin generation. J. Biol. Chem. 272 (1997) 9244-9251.

12. P.J. Larson, R.M. Camire, D. Wong, N.C. Fasano, D.M. Monroe, P.B. Tracy, K.A. High. Structure/function analyses of recombinant variants of human factor Xa: Factor Xa incorporation into prothrombinase on the thrombin-activated platelet surface is not mimicked by synthetic phospholipid vesicles. Biochemistry 37 (1998) 5029-5038.

13. T.V. Byzova, E.F. Plow. Networking in the hemostatic system. Integrin $\alpha_{110} \beta_{3}$ binds prothrombin and influences its activation. J. Biol. Chem. 272 (1997) 27183-27188.

14. J.W.M. Heemskerk, W.M.J. Vuist, M.A.H. Feijge, C.P.M. Reutelingsperger, T. Lindhout. Collagen but not fibrinogen surfaces induce bleb formation, exposure of phosphatidylserine, and procoagulant activity of adherent platelets: evidence for regulation by protein tyrosine kinase dependent $\mathrm{Ca}^{2+}$ responses. Blood 90 (1997) 2615-2625.

15. D. Billy, H. Speijer, G.M. Willems, H.C. Hemker, T. Lindhout. Prothrombin activation by prothrombinase in a tubular flow reactor. J. Biol. Chem. 270 (1995) 1029-1034.

16. P. Schoen, T. Lindhout, J. Franssen, H.C. Hemker. Low molecular weight heparin-catalyzed inactivation of factor $\mathrm{Xa}$ and thrombin by antithrombin III: effect of platelet factor 4 . Thromb. Haemost. 66 (1991) 435-441.

17. F.B. Taylor, H. Hoogendoorn, A.C. Chang, G. Peer, M.E. Nesheim, R. Catlett, D.C. Stump, A.R. Giles. Anticoagulant and fibrinolytic activities are promoted, not retarded, in vivo after thrombin generation in the presence of a monoclonal antibody that inhibits activation of protein C. Blood 79 (1992) 1720-1728.

18. G.D. Ambrosini, D.C. Altieri. Molecular dissection of effector cell protease receptor-1 recognition of factor $\mathrm{Xa}$. Assignment of critical residues involved in antibody reactivity and ligand binding. J. Biol. Chem. 271 (1996) 1243-1248. 
19. D. Billy, J. Briedé, J.W.M. Heemskerk, H.C. Hemker, T. Lindhout. Prothrombin conversion under flow conditions by prothrombinase assembled on adherent platelets. Blood Coagul. Fibrinolysis 8 (1997) 168-174.

20. P. Schoen, T. Lindhout, G.M. Willems, H.C. Hemker. Continuous flow and the prothrombinasecatalyzed activation of prothrombin. Thromb. Haemost. 64 (1990) 542-547.

21. J.J. Briedé, J.W.M. Heemskerk, H.C. Hemker, T. Lindhout. Heterogeneity in microparticle formation and exposure of anionic phospholipids at the plasma membrane of single adherent platelets. Biochim. Biophys. Acta 1451 (1999) 163-172.

22. C.P. Hayward, E. Furmaniak Kazmierczak, A.M. Cieutat, J.C. Moore, D.F. Bainton, M.E. Nesheim, J.G. Kelton, G. Cote. Factor V is complexed with multimerin in resting platelet lysates and colocalizes with multimerin in platelet alpha-granules. J. Biol. Chem. 270 (1995) 19217 19224.

23. L. Alberio, O. Safa, K.J. Clemetson, C.T. Esmon, G.L. Dale. Surface expression and functional characterization of alpha-granule factor $\mathrm{V}$ in human platelets: effects of ionophore A23187. thrombin, collagen, and convulxin. Blood 95 (2000) 1694-1702. 


\section{Chapter 4}

\section{Regulation of Platelet Factor Va-dependent Thrombin}

\section{Generation by Activated Protein C at the Surface of}

\section{Collagen-adherent Platelets}

Jacob J. Briedé, Guido Tans, George M. Willems, H. Coenraad Hemker and Theo Lindhout

Journal of Biological Chemistry 276 (2001), 7164-7168 


\section{Summary}

Recent studies have indicated that factor Va bound to activated platelets is partially protected from inactivation by activated protein C (APC). To explore whether this sustained factor $\mathrm{Va}$ activity could maintain ongoing thrombin generation, the kinetics of platelet factor Va-dependent prothrombinase activity and its inhibition by APC were studied. In an attempt to mimic physiological relevant conditions, platelets were adhered to collagen type I-coated discs. These discs were then spun in solutions containing prothrombin and factor Xa either in the absence or presence of APC. The experiments were performed in the absence of platelet-derived microparticles, with thrombin generation and inhibition confined to the surface of the adherent platelets. APC completely inactivated platelet-associated prothrombinase activity with an overall second order rate constant of $3.3 \times 10^{6} \mathrm{M}^{-1} \mathrm{~s}^{-1}$, which was independent of the prothrombin concentration over a wide range around the apparent $K_{m}$ for prothrombin. Kinetic studies on prothrombinase assembled at a planar phospholipid membrane composed of $25 \mathrm{~mol} \%$ phosphatidylserine and $75 \mathrm{~mol} \%$ phosphatidylcholine revealed a similar second order rate constant of inhibition $\left(2.5 \times 10^{6} \mathrm{M}^{-1} \mathrm{~s}^{-1}\right)$. Collectively, these data demonstrate that ongoing platelet factor $\mathrm{Va}$ dependent thrombin generation at the surface of collagen-adherent platelets is effectively inhibited by APC. No differences were observed between the kinetics of APC inactivation of plasmaderived factor $\mathrm{Va}$ or platelet factor $\mathrm{Va}$ as part of the prothrombinase associated with respectively a planar membrane of synthetic phospholipids or collagen adherent platelets. 


\section{Introduction}

Activated protein C (APC) is a serine protease that inhibits thrombin formation by limited proteolysis of the non-enzymatic cofactors factor Va and factor VIIla of the prothrombin and the factor $\mathrm{X}$ activating enzyme complex, respectively. Efficient proteolysis of the cofactors requires the presence of membranes that contain anionic phospholipids, calcium ions and protein S. In the presence of membranes that contain negatively charged phospholipids, plasma factor Va is inactivated by APC-catalyzed cleavage of its heavy chain at $\operatorname{Arg}^{306}$ and $\operatorname{Arg}^{506}(1,2)$. The cleavage at $\mathrm{Arg}^{506}$ is relatively rapid and yields a reaction intermediate that still retains partial cofactor activity in prothrombin activation. The slower cleavage at position $\mathrm{Arg}^{306}$ results in complete loss of cofactor activity (3). The rapid cleavage at $\mathrm{Arg}^{506}$ is inhibited when factor $\mathrm{Va}$ is in complex with factor $\mathrm{Xa} \mathrm{(4-8).}$

Recently, it was reported that in contrast to synthetic phospholipid membranes, thrombin-activated platelets partially protect platelet-derived and plasma-derived factor Va from inactivation by APC. Thrombin-activated platelets appeared to slow down the cleavage at $\operatorname{Arg}^{506}(9)$. It was speculated that activated platelets express a membrane component(s) in addition to anionic phospholipids that specifically binds factor Va resulting in a factor Va molecule with an apparent APC resistant phenotype (10). This protection of APC-catalyzed inactivation of factor Va was not observed in the presence of microparticles or synthetic phospholipid vesicles (9). One of the questions that remain to be answered is how platelets influence APC-dependent factor $\mathrm{Va}$ inactivation once factor $\mathrm{Va}$ is assembled in the prothrombinase complex at the plasma membrane of activated platelets.

The purpose of the present study was to establish the kinetics of APCdependent inhibition of ongoing prothrombin activation at the plasma membrane of platelets adhered to immobilized collagen. To account for transport limitations of reactants, the experiments were conducted under well-defined flow conditions on a rotating disc. Our findings indicate no difference in the kinetics of APC-dependent inactivation of prothrombinase at the membrane of activated, collagen-adherent, platelets compared with that at the surface of a planar phospholipid membrane.

\section{Materials and Methods}

Materials. Bovine serum albumin (BSA), bovine fibrinogen and apyrase were from Sigma (St. Louis, Al). S2238, a chromogenic substrate for thrombin, was obtained from Chromogenix (Mölndal, Sweden). Human factor Xa, human prothrombin and bovine factor Va were prepared and quantified as described before (11). Native type I collagen fibrils were extracted from bovine achilles tendon in the 
absence of proteases using $0.5 \mathrm{M}$ acetic acid and precipitated with $1.7 \mathrm{M} \mathrm{NaCl}$, as described (12). Human $\alpha$-thrombin was prepared as previously described (13). Human activated protein C (APC) was purchased from Kordia (Leiden, The Netherlands). 1,2-Dioleoyl-sn-glycero-3-phosphocholine (DOPC) and 1,2-dioleoyl-snglycero-3-phosphoserine (DOPS) were obtained from Avanti Polar Lipids (Alabaster, USA). All other reagents used were of analytical grade.

Platelets. Suspensions of human washed platelets were prepared as described before (14). Briefly, blood was drawn from healthy volunteers, who had not taken any anti-platelet medication in the preceding two weeks. Platelet-rich plasma was prepared by centrifugation. The platelets were then sedimented by centrifugation, washed twice with HEPES buffer ( $10 \mathrm{mM}$ HEPES, $136 \mathrm{mM} \mathrm{NaCl}, 5 \mathrm{mM}$ glucose, 2.7 $\mathrm{mM} \mathrm{KCl}, 2 \mathrm{mM} \mathrm{MgCl}, 1 \mathrm{mg} / \mathrm{ml}$ BSA and $0.1 \mathrm{U} / \mathrm{ml}$ apyrase, $\mathrm{pH} 6.6$ ). Finally, the platelets were resuspended in HEPES buffer adjusted to $\mathrm{pH} 7.45$ (buffer A). Platelets were counted on a Coulter counter (Coulter, Miami, USA) and the suspensions were adjusted to $5 \times 10^{7}$ platelets $/ \mathrm{ml}$.

The rotating disc device. Rotating disc experiments were performed in a device as described before (15). Briefly, a circular glass cover slip with a diameter of $20 \mathrm{~mm}$ (Menzel Gläser, Braunschweig, Germany), is rotated at $63 \mathrm{rad} / \mathrm{s}$ at the bottom of a cylindrical reaction vessel containing reactants in $3 \mathrm{ml}$ buffer $A$. This angular velocity results in a wall shear rate of $3681 \mathrm{~s}^{-1}$ at the edge of the rotating disc. The reaction vessel was pretreated for 1 hour with $20 \mathrm{mg} / \mathrm{ml} \mathrm{BSA}$ in buffer A.

Preparation of discs with collagen-adherent platelets. Circular glass cover slips with a diameter of $20 \mathrm{~mm}$ were cleaned with a 1:1 mixture of ethanol (96 vol\%) and $\mathrm{HCl}(37 \mathrm{vol} \%)$ and subsequently rinsed with deionized water. The discs were coated with collagen by incubating the cover slips for 3 hours with $300 \mu \mathrm{l}$ of $0.5 \mathrm{mg} / \mathrm{ml}$ collagen type I in $0.5 \mathrm{M}$ acetic acid. Coated discs were extensively rinsed with $40 \mathrm{mM}$ phosphate buffer $(\mathrm{pH} 7.4)$ containing $0.15 \mathrm{M} \mathrm{NaCl}$ and stored in this buffer until use. Inspection of the discs by phase-contrast microscopy showed a homogeneous distribution of the collagen fibrils over the glass surface. The collagen-coated discs were incubated for 15 min with buffer $A$, followed by a 40 min incubation at room temperature with $300 \mu \mathrm{l}$ of a suspension of washed platelets. Non-adherent platelets were removed by rinsing with buffer $A$.

Preparation of phospholipid-coated discs. Spinning circular glass cover slips (63 $\mathrm{rad} / \mathrm{s}$ ) were exposed for $20 \mathrm{~min}$ to $20 \mu \mathrm{M}$ vesicles composed of $25 \mathrm{~mol} \%$ DOPS and $75 \mathrm{~mol} \%$ DOPC, prepared as described before (16). Fluid phase vesicles were removed by flushing $5 \mathrm{~min}(10 \mathrm{ml} / \mathrm{min})$ with buffer $A$. The phospholipid-coated discs were then transferred to a reaction vessel containing $3 \mathrm{ml}$ buffer $A$ for further experimentation. 
Thrombin generation at rotating discs. Discs with collagen-adherent platelets or coated with a phospholipid membrane were spun at $63 \mathrm{rad} / \mathrm{s}$ in $3 \mathrm{ml}$ buffer A containing $3 \mathrm{mM} \mathrm{CaCl}{ }_{2}$. Factor $\mathrm{Xa}$ and, when indicated, factor $\mathrm{Va}$ were added and thrombin generation was started after $3 \mathrm{~min}$ by the addition of prothrombin. Timed samples $(10 \mu \mathrm{l})$ were taken and transferred to cuvettes with $440 \mu \mathrm{l}$ Tris buffer $(50 \mathrm{mM}$ Tris- $\mathrm{HCl}, 175 \mathrm{mM} \mathrm{NaCl}, 0.5 \mathrm{mg} / \mathrm{ml}$ BSA, pH 7.9) containing $20 \mathrm{mM}$ EDTA. Thrombin was assayed by the addition of $2.4 \mathrm{mM} \mathrm{S} 2238(50 \mu \mathrm{l})$ to the cuvette. The change in optical density was monitored at $405 \mathrm{~nm}$. The thrombin concentrations in the samples were calculated from a standard curve obtained with known amounts of the enzyme. All procedures were performed at $37^{\circ} \mathrm{C}$.

Assay for procoagulant microvesicles. Samples $(10 \mu \mathrm{l})$ from the reaction vessel were added to cuvettes containing factor $\mathrm{Xa}$, factor $\mathrm{Va}$ and $3 \mathrm{mM} \mathrm{CaCl}$ in $137 \mu \mathrm{l}$ Tris buffer. After a 3-min incubation, thrombin generation was started by the addition of 3 $\mu \mathrm{l}$ prothrombin. The final concentrations were: $1 \mathrm{pM}$ factor $\mathrm{Xa}, 0.5 \mathrm{nM}$ factor $\mathrm{Va}$ and $200 \mathrm{nM}$ prothrombin. Thrombin generation was stopped after $5 \mathrm{~min}$ by the addition of Tris-EDTA buffer and assayed as described. A reference curve was constructed using different phospholipid vesicle (25 mol\% DOPS/75 mol\% DOPC) concentrations and was linear up to $1 \mu \mathrm{M}$.

Kinetic data analysis of time courses of APC-dependent inactivation of prothrombinase._The rate of thrombin generation at the surface of the rotating disc decreases in time especially when prothrombin concentrations were used below the apparent $\mathrm{K}_{\mathrm{m}}$ for prothrombin. Thrombin generation in the presence of APC was therefore corrected for substrate depletion by assuming an APC-independent pseudo first order rate constant of inactivation, $\mathbf{k}_{1}$, utilizing the equation

$$
[\text { thrombin }]_{t}=V_{0}\left(1-e^{-k_{1} t}\right) / k_{1}
$$

in which [thrombin], is the thrombin concentration at time $t$, and $V_{0}$ the initial rate of thrombin formation. Inhibition of prothrombin activation in the presence of APC was analyzed according to

$$
[\text { thrombin }]_{t}=[\text { thrombin }]_{1}+V_{0} e^{-k_{1} t_{i}}\left(1-e^{-\left(k_{2}+k_{1}\right)\left(t-t_{1}\right)}\right) /\left(k_{2}+k_{1}\right) \quad \text { for } t>t_{1}
$$

with $t_{i}$ the time at which APC was added to the reaction and $k_{2}$ the APC-dependent pseudo first order rate constant of prothrombin activation inhibition. Values for $V_{0}, k_{1}$ and $k_{2}$ were estimated by a least square fit of equations 1 and 2 to the experimental data obtained from thrombin generation experiments performed in the absence or presence of APC. 


\section{Results}

Thrombin formation at the plasma membrane of collagen-adherent platelets. Platelet adhesion on immobilized collagen in the presence of extracellular calcium is accompanied by shedding of microparticles and exposure of negatively charged phospholipids in the outer leaflet of the plasma membrane (14). These microparticles may provide a procoagulant surface that supports prothrombin activation and thus could complicate our study on the kinetics of APC-dependent inactivation of prothrombin activation at the surface of collagen-adherent platelets. Therefore, initially experiments were conducted to establish the extent of microvesiculation, their contribution to prothrombin activation and, when necessary, to redesign the experiment in such a way that the contribution of microparticles to prothrombin activation would be negligible.

Cover slips with collagen-adherent platelets were spun in buffer $\mathrm{A}$ and after 12 $\min \mathrm{CaCl}_{2}(3 \mathrm{mM})$ was added. Samples were taken from the reaction vessel and assayed for procoagulant vesicles. Fig. 1 shows that immediately after the addition of calcium the concentration of solution phase procoagulant phospholipid increased and reached a maximum after $30-40$ minutes.

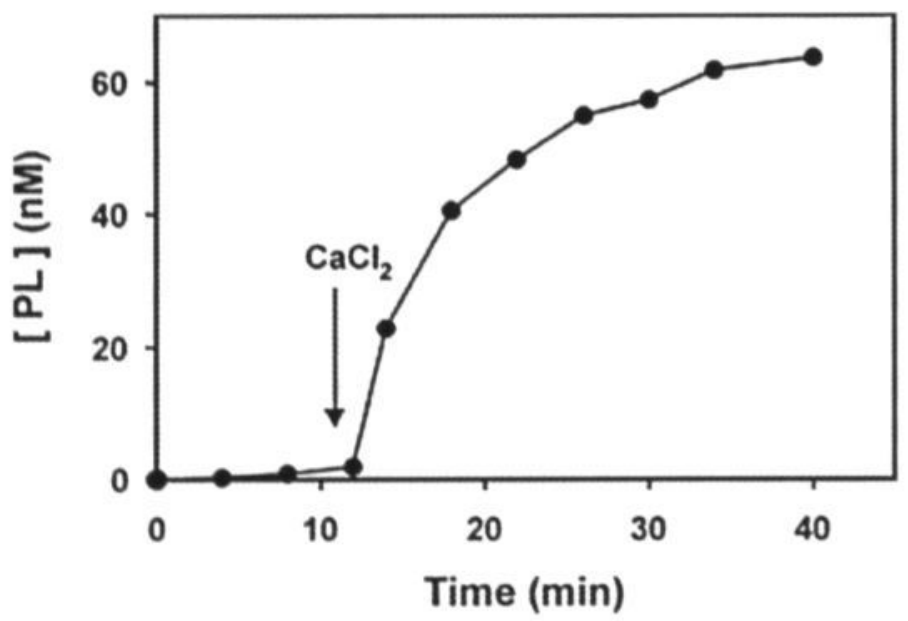

Figure 1 Extracellular calcium-induced shedding of procoagulant microvesicles. A collagen-coated circular glass cover slip with adherent platelets was spun at $63 \mathrm{rad} / \mathrm{s}$ in a calcium-free buffer $\mathrm{A}(\mathrm{pH} 7.4)$. At the time indicated (arrow) $3 \mathrm{mM}$ $\mathrm{CaCl}_{2}$ was added. Timed samples were taken and assayed for procoagulant activity as described under "Materials and Methods". 
To investigate the relative contributions of these microparticles and the collagenadherent platelets to prothrombin activation, factor Xa (50 pM) followed 3 min later by prothrombin $(100 \mathrm{nM})$ were added to the reaction vessel. Immediately after the addition of prothrombin an aliquot $(100 \mu \mathrm{l})$ was taken from the reaction vessel, transferred to a test tube and incubated at $37^{\circ} \mathrm{C}$. Timed samples were taken from both the reaction vessel and the test tube and assayed for thrombin activity. The rates of thrombin generation were $2.2 \mathrm{nM} / \mathrm{min}$ and $1.3 \mathrm{nM} / \mathrm{min}$ in the reaction vessel and test tube, respectively, demonstrating that microvesicles and adherent platelet contributed about equally to thrombin generation (Fig. 2). In the second step of this experiment the reaction vessel was flushed during $5 \mathrm{~min}(10 \mathrm{ml} / \mathrm{min})$ with buffer $A$ containing $3 \mathrm{mM} \mathrm{CaCl}_{2}$ to remove microparticles. After the re-addition of factor $\mathrm{Xa}$ ( 50 pM) followed by prothrombin (100 nM) no thrombin generation could be detected in the fluid phase. This finding indicates that procoagulant microparticles were absent and that thrombin generating activity was now solely confined to the spinning surface with collagen-adherent platelets (Fig. 2).

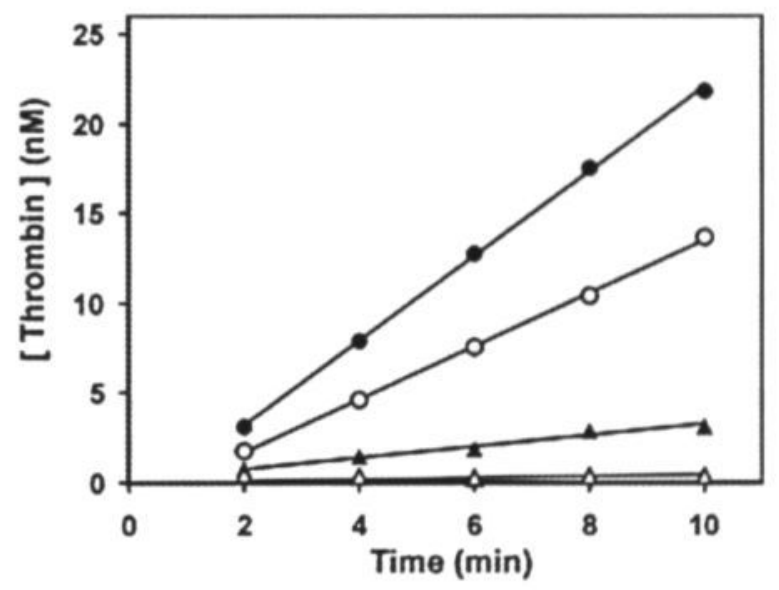

Figure 2 Platelet surface and microvesicle-associated thrombin generation. A collagen-coated cover slip with adherent platelets was spun at $63 \mathrm{rad} / \mathrm{s}$ during $30 \mathrm{~min}$ in buffer $\mathrm{A}$ containing $3 \mathrm{mM} \mathrm{CaCl}_{2}$. Factor $\mathrm{Xa}(50 \mathrm{pM})$ was added, followed by prothrombin $(100 \mathrm{nM})$ to start thrombin generation. Immediately after the addition of prothrombin an aliquot $(100 \mu \mathrm{l})$ was taken and incubated at $37^{\circ} \mathrm{C}$. Timed samples were taken from both the rotating disc reaction vessel and the removed aliquot to determine respectively the rate of total thrombin generation $(\bullet)$ and the rate of fluid phase thrombin generation $(\mathrm{O})$. After 10 min the reaction vessel was flushed with $3 \mathrm{mM} \mathrm{CaCl}_{2}$-containing buffer $\mathrm{A}$ for 5 $\mathrm{min}$ at $10 \mathrm{ml} / \mathrm{min}$. Factor $\mathrm{Xa}(50 \mathrm{pM})$ and prothrombin $(100 \mathrm{nM})$ were re-added. An aliquot $(100 \mu \mathrm{l})$ was taken from the reaction vessel and further incubated at $37^{\circ} \mathrm{C}$. Timed samples from the reaction vessel $(\mathbf{\Lambda})$ as well as from the incubation mixture $(\Delta)$ were assayed for thrombin. 
The rate of thrombin generation $(0.3 \mathrm{nM} / \mathrm{min})$ was, however, lower than the rate of thrombin generation at the spinning surface before the removal of microparticles $(0.9$ $\mathrm{nM} / \mathrm{min}$ ). The combined results of three similar experiments showed that the rinsing step decreased the surface-associated thrombin production by $59 \% \pm 10 \%$ (mean \pm SD). This loss of activity is most likely due to a loss of platelet associated factor $\mathrm{Va}$ activity since addition of plasma-derived factor $\mathrm{Va}(1 \mathrm{nM})$ resulted in an increase in the rate of thrombin generation from $0.3 \mathrm{nM} / \mathrm{min}$ to $1.8 \mathrm{nM} / \mathrm{min}$. All further experiments were performed with discs containing collagen-adherent platelets that were first spun for $30 \mathrm{~min}$ at $63 \mathrm{rad} / \mathrm{s}$ in buffer $\mathrm{A}$ containing $3 \mathrm{mM} \mathrm{CaCl} \mathrm{C}_{2}$ and then flushed with the same buffer for $5 \mathrm{~min}$ at $10 \mathrm{ml} / \mathrm{min}$ to remove microparticles prior to thrombin generation.

Optimization of thrombin generation at the plasma membrane of collagenadherent platelets. Fig. 3 shows the initial rates of thrombin generation at a fixed prothrombin concentration $(100 \mathrm{nM})$ as a function of the factor Xa concentration. The apparent dissociation constant, $K_{d}$, of surface-bound factor $\mathrm{Xa}$ is described by the simple single site binding isotherm

$$
\mathrm{V}_{\mathrm{obs}}=\mathrm{V}_{\max }[\mathrm{Xa}] /\left([\mathrm{Xa}]+\mathrm{K}_{\mathrm{d}}\right)
$$

with $\mathrm{V}_{\mathrm{obs}}$ the initial rate of thrombin formation, [Xa] the factor $\mathrm{Xa}$ concentration, and $V_{\max }$ the initial rate of thrombin generation at saturating factor $X a$ concentration. The value for the apparent $K_{d}$ estimated by fitting this equation to the data from two similar experiments is $3.5 \pm 0.9 \mathrm{pM}$ (estimated value $\pm 1 \mathrm{SEE}$ ). Further experiments were performed at a saturating concentration of factor $\mathrm{Xa}(50 \mathrm{pM})$.

Fig. 4 shows the prothrombin dependency of thrombin generation at the surface of collagen adherent platelets in the presence of $50 \mathrm{pM}$ factor $\mathrm{Xa}$. The data could be adequately described by the Michaelis-Menten equation

$$
\mathrm{V}_{\mathrm{obs}}=\mathrm{V}_{\max }\left[\text { prothrombin] } /\left([\text { prothrombin }]+\mathrm{K}_{\text {m.app }}\right)\right.
$$

in which $V_{\max }$ is the initial rate of thrombin formation at saturating prothrombin concentration, [prothrombin] the prothrombin concentration in free solution, and $\mathrm{K}_{\mathrm{m} \text {.app }}$ is the apparent Michaelis constant. The solid line in Fig. 4 represents the best fit of this equation to the experimental data. The combined result of two similar experiments yielded a $K_{\text {m.app }}$ of $42 \pm 5 \mathrm{nM}$ (estimated value $\pm 1 \mathrm{SEE}$ ). 


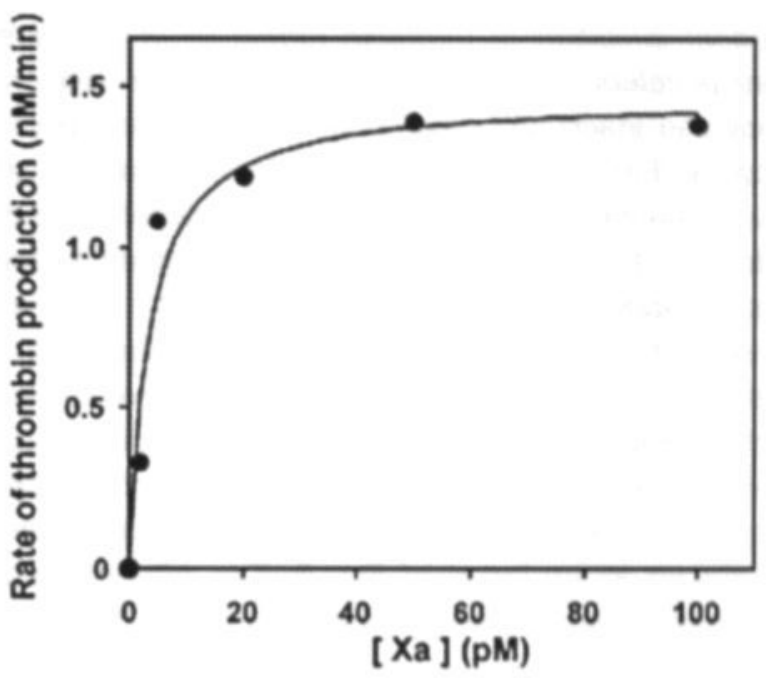

Figure 3 Rate of thrombin formation at collagen-adherent platelets as a function of the factor $\mathrm{Xa}$ concentration. A disc with collagen-adherent platelets was spun in buffer $\mathrm{A}$ containing $3 \mathrm{mM} \mathrm{CaCl}$ and $100 \mathrm{nM}$ prothombin. The initial rates of thrombin formation were measured for increasing concentrations of factor $\mathrm{Xa}$. The solid line is the result of the fit procedure described under "Results".

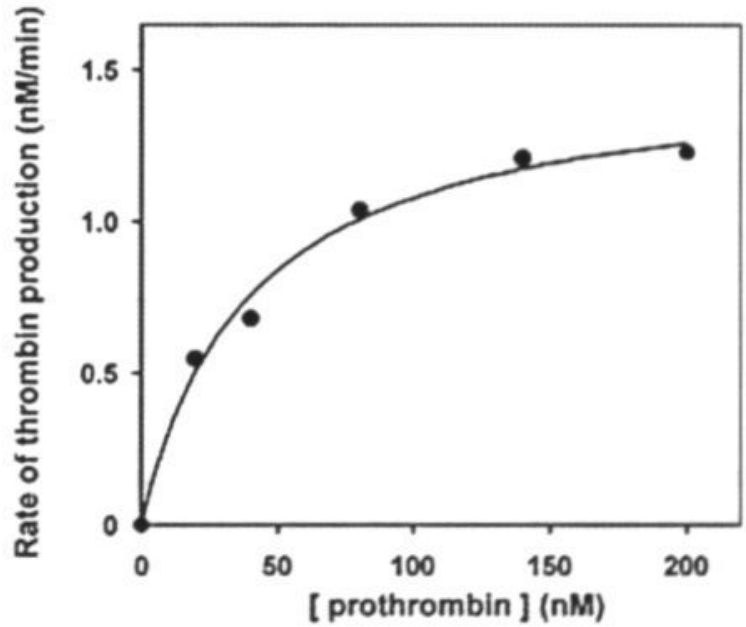

Figure 4 Rate of thrombin formation at collagen-adherent platelets as a function of the prothrombin concentration. A disc with collagen-adherent platelets was spun in buffer $\mathrm{A}$ containing $3 \mathrm{mM} \mathrm{CaCl} 2$ and $50 \mathrm{pM}$ factor $\mathrm{Xa}$. The initial rates of thrombin formation were measured for increasing concentrations of prothrombin. The solid line is the result of the fit procedure described under "Results". 
APC-dependent inhibition of thrombin formation at the plasma membrane of collagen-adherent platelets during ongoing prothrombin activation. The results of a typical prothrombinase inactivation experiment at the surface of collagen-adherent platelets are shown in Fig. 5. The first $8 \mathrm{~min}$ of the experiment was performed in the absence of APC to enable the determination of the initial rate of thrombin formation, $V_{0}$. Upon the addition of APC, the rate of thrombin formation rapidly decreased. To visualize the concentration-dependent effect of APC, a considerable inter-disc variation in the rate of thrombin generation $(0.5-1.2 \mathrm{nM} / \mathrm{min})$ was corrected by setting the initial rates in the absence of APC to the same value. The total time courses of thrombin generation in the absence or presence of APC were analyzed by a least squares fit according to equation 1 and 2 as described in experimental procedures. The first order rate constant of inhibition as a function of the APC concentration is shown as an insert of Fig. 5. The APC-dependent inactivation of prothrombinase obtained from these data was $3.3 \times 10^{6} \mathrm{M}^{-1} \mathrm{~s}^{-1}$.

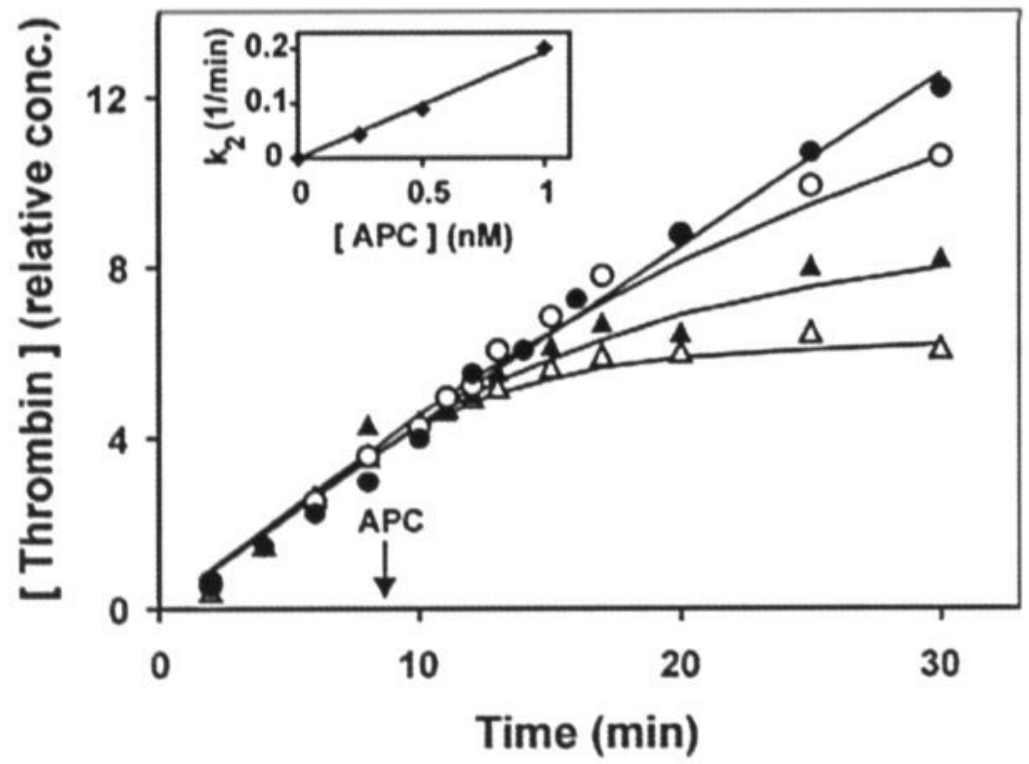

Figure 5 APC-dependent inactivation of prothrombinase activity associated with collagen-adherent platelets. Discs with collagen-adherent platelets were spun in buffer A containing $3 \mathrm{mM} \mathrm{CaCl}, 50 \mathrm{pM}$ factor $\mathrm{Xa}$ and $100 \mathrm{nM}$ prothrombin. Timed samples were removed and assayed for thrombin. At the indicated time (arrow) a small aliquot of buffer $(\bullet), 0.25 \mathrm{nM}(\mathrm{O}), 0.5 \mathrm{nM}(\mathbf{\Delta})$ or $1 \mathrm{nM}$ APC $(\Delta)$ was added. The initial rates of thrombin formation in the absence of APC were set to the same value. The solid lines represent the best fit of equations 1 and 2 to the data. The first order rate constants of inhibition thus obtained are shown as a function of the APC concentration in the insert. 
To assess the influence of the prothrombin concentration on the inhibition of the prothrombinase activity, comparable inhibition experiments were performed at prothrombin concentrations ranging from $20-500 \mathrm{nM}$. The results presented in Table 1 show that varying the prothrombin concentration did not influence the pseudo first order rate constant of inactivation of platelet-associated prothrombinase activity.

The inhibition of prothrombinase activity by APC at a platelet surface was compared with that at a rotating planar phospholipid membrane composed of 25 mol\% DOPS and $75 \mathrm{~mol} \%$ DOPC. The experimental conditions for thrombin generation and inhibition were the same as described for collagen-adherent platelets. However, besides factor $\mathrm{Xa}(50 \mathrm{pM})$ and prothrombin $(100 \mathrm{nM})$ also plasma factor $\mathrm{Va}$ $(10 \mathrm{pM})$ was added. Typical thrombin generation curves in the absence or presence of APC are shown in Fig. 6. Thrombin generation was analyzed by a least squares fit of equation 1 and 2 to the data. A plot of the first order rate constants of inactivation as a function of the APC concentration is shown as an insert of Fig. 6. Linear regression to these data yielded a second order rate constant of inhibition of prothrombin activation of $2.5 \times 10^{6} \mathrm{M}^{-1} \mathrm{~s}^{-1}$. 


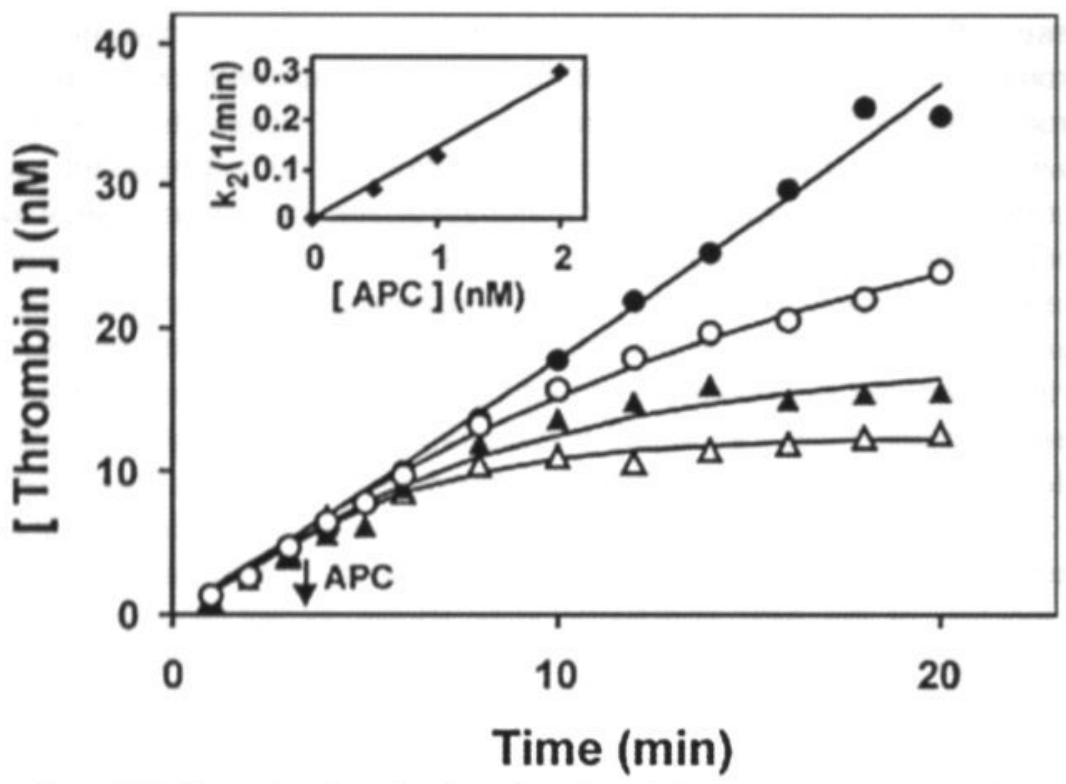

Figure 6 APC-dependent inactivation of prothrombinase activity associated with a synthetic phospholipid membrane. Rotating discs with planar phospholipid membranes composed of $25 \mathrm{~mol} \%$ DOPS and $75 \mathrm{~mol} \%$ DOPC were spun in buffer A containing $\mathrm{CaCl}_{2}(3 \mathrm{mM})$, factor $\mathrm{Xa}(100 \mathrm{pM})$ and factor $\mathrm{Va}(10 \mathrm{pM})$. After $5 \mathrm{~min}$ thrombin generation was started by the addition of prothrombin $(100 \mathrm{nM})$. At the indicated time (arrow) a small aliquot of buffer $(\bullet), 0.5 \mathrm{nM}(\mathrm{O}), 1 \mathrm{nM}(\mathbf{\Delta})$ or $2 \mathrm{nM}$ APC $(\Delta)$ was added. Timed samples were removed and assayed for thrombin. The solid lines represent the best fit of equations 1 and 2 to these data. The first order rate constants of inhibition thus obtained are shown as a function of the APC concentration in the insert.

Table 1 Effect of prothrombin concentration on APC-catalyzed inhibition of prothrombinase activity. Discs with collagen-adherent platelets were spun in buffer $A$ containing $3 \mathrm{mM} \mathrm{CaCl}_{2}, 50 \mathrm{pM}$ factor $\mathrm{Xa}$ and indicated prothrombin concentrations. After $3 \mathrm{~min} 0.5 \mathrm{nM}$ APC was added and the pseudo first order rate constants of inhibition by APC were calculated by fitting the thrombin generation data as described in experimental procedures.

\begin{tabular}{cc}
\hline $\begin{array}{c}\text { Prothrombin concentration } \\
(\mathrm{nM})\end{array}$ & $\begin{array}{c}\text { Rate constant of inhibition } \\
\left(\mathrm{min}^{-1}\right)\end{array}$ \\
\hline 20 & 0.07 \\
50 & 0.07 \\
100 & 0.08 \\
200 & 0.05 \\
500 & 0.07 \\
\hline
\end{tabular}




\section{Discussion}

It is generally believed that upon vessel wall injury the adhesion of platelets to exposed collagen stimulates thrombus formation. The interaction between platelets and immobilized collagen induces release of the content of the $\alpha$-granula, exposure of anionic phospholipids and shedding of microvesicles. As a result, highly reactive procoagulant platelets and microvesicles are generated where factor Va from $\alpha$ granula $(17,18)$ and anionic phospholipids (12) provide the essential accessory factors for the prothrombin converting enzyme factor $\mathrm{Xa}$.

This study focuses on the role of APC as an inhibitor of ongoing thrombin generation at the surface of collagen-adherent platelets. To account for the transportlimited supply of substrate at these surfaces $(19,20)$ and to approach the in vivo situation of thrombin formation under flow conditions, activation and inactivation experiments were performed utilizing saturating factor $\mathrm{Xa}$ and prothrombin concentrations in a previously described rotating disc device (15, 20-22).

Thrombin generation at the surfaces of collagen-adherent platelets. Initial experiments confirmed that platelet adhesion to collagen in the presence of extracellular calcium resulted in the formation of microparticles. As a matter of fact, about $60 \%$ of total thrombin generation could be attributed to prothrombinase associated with these microparticles. Because this study was aimed to focus on ongoing thrombin generation at adherent platelets, subsequent experiments were performed after the microparticles were removed from the reaction system.

To further characterize the kinetics of thrombin generation at the surfaces of collagen adherent platelets, the dependency on the factor $\mathrm{Xa}$ and prothrombin concentration was determined. The apparent $\mathrm{K}_{\mathrm{d}}$ for factor $\mathrm{Xa}$ on collagen-adherent platelets was $3.5 \mathrm{pM}$. We note that this $\mathrm{K}_{d}$ value is determined in the presence of a fixed prothrombin concentration $(100 \mathrm{nM})$ but in the absence of both microvesicles and exogenous factor $\mathrm{Va}$. Much higher apparent $\mathrm{Kd}$ values for factor $\mathrm{Xa}$ have been reported for thrombin-activated platelets in suspension $\left(K_{d}=142 \mathrm{pM}\right)(24)$ and for von Willebrand factor-adherent platelets $\left(K_{d}=4 \mathrm{nM}\right)(25)$ but the value found here is in close agreement with the value of $1 \mathrm{pM}$ reported for the interaction of factor $\mathrm{Xa}$ with planar phospholipid surface composed of $25 \%$ PS/75 \% PC and containing preabsorbed factor Va (23).

The prothrombin concentration in the solution required to obtain a half-maximal rate of thrombin generation was $42 \mathrm{nM}$. This apparent $\mathrm{K}_{\mathrm{m}}$ value is lower than the value reported for vesicles in suspension $\left(K_{m}=100 \mathrm{nM}\right)(26)$ but higher than the values of $5 \mathrm{nM}$ and $7 \mathrm{nM}$ for phospholipid bilayers in a tubular flow system (11) and for prothrombin activation experiments on rotating discs (20), respectively. However, the values reported for the tubular flow reactor were obtained after correction for prothrombin depletion near the catalytic surface. If the same correction is made here, 
a $\mathrm{K}_{m}$ value of $14 \mathrm{nM}$ would be obtained. Interestingly, the plasma prothrombin concentration is more than 100-fold higher, meaning that inhibitors like antithrombin will have no chance to successfully compete with prothrombin for the active site of prothrombinase $(27,28)$. It is, therefore, unlikely that proteinase inhibitors like antithrombin can regulate platelet-associated prothrombinase activity.

APC-dependent inhibition of ongoing thrombin generation at adherent platelets. It has been shown that platelets greatly accelerate the rate APC-dependent inactivation of factor $\mathrm{Va}$ by providing a negatively charged phospholipid surface (29). However, it has also been reported that platelets show an APC resistant phenotype. That is, in spite of the presence of APC, platelet-derived factor Va activity is sustained on the surface of thrombin activated platelets $(9-10,30-31)$. The present report demonstrates that APC inhibits platelet-associated prothrombinase activity in a monoexponential way with a second order rate constant of inactivation of $3.3 \times 10^{6} \mathrm{M}^{-1} \mathrm{~s}^{-1}$. This value is in excellent agreement with the second order rate constant of inhibition $\left(2.5 \times 10^{6} \mathrm{M}^{-1} \mathrm{~s}^{-1}\right)$ found for prothrombinase associated with a planar synthetic phospholipid membrane composed of $25 \mathrm{~mol} \%$ PS $/ 75 \mathrm{~mol} \%$ PC. Moreover, the inhibition rates reported here for ongoing thrombin generation are also very close to the reported (32) rate constant for APC-catalyzed cleavage at $\mathrm{Arg}^{306}$ in plasmaderived factor $\mathrm{Va}\left(\mathrm{k}=6.5 \times 10^{6} \mathrm{M}^{-1} \mathrm{~s}^{-1}\right)$.

Thus, in the experimental set up of the present study, which mimics physiological relevant conditions, we observed complete inactivation by APC of the prothrombin-converting activity of the factor Va-factor Xa complex bound to collagenadherent platelets. Moreover, no differences were found between the first order rate constant of inactivation of prothrombinase assembled at collagen-adherent platelets and at a synthetic phospholipid membrane. In contrast, Camire et al (9) found different kinetics for the inactivation of factor $\mathrm{Va}$ at platelets and synthetic phospholipid membranes, with a slower, and most importantly, incomplete inactivation of factor $\mathrm{Va}$ at the membrane of platelets. We note that these investigators used thrombin-activated platelets and that the decline of factor Va cofactor activity was assayed from timed samples as prothrombinase activity using a high factor $\mathrm{Xa}$ concentration. Thrombin, however, has been demonstrated to be a rather weak agonist to induce exposure of negatively charged phospholipids (PS) in the outer leaflet of the platelet plasma membrane $(14,33)$. In addition, Camire et al (9) prevented thrombin-activated platelets from aggregation by using the RGDS peptide and did not stir the platelet suspension. It was recently reported that these conditions prevents thrombin-induced exposure of PS (34). In view of the stimulating role of negatively charged phospholipids on the kinetics of the cleavage of factor $V$ at $\mathrm{Arg}^{306}$ (32), it is tempting to speculate that under their experimental conditions insufficient platelets provide the suitable surface to bind factor Va and to stimulate APC activity. Although this notion would explain the finding that part of the factor Va escaped from 
inactivation, it is contradicted by their observation that exogenous plasma-derived factor $\mathrm{Va}$ added to a thrombin-activated platelet suspension was rapidly inactivated (9).

Recently, it was reported that prothrombin dramatically inhibits the ability of APC to inactivate factor $\mathrm{Va}$, but scarcely inhibits the inactivation of factor $\mathrm{Va}_{\text {Leiden }}$ (35). Moreover, it was suggested that prothrombin inhibits both the cleavage at $\mathrm{Arg}^{506}$ and at $\mathrm{Arg}^{306}$. In contrast, our experiments clearly demonstrate that the rate of inactivation of platelet-bound prothrombinase by APC is not slowed down even under conditions that result in full saturation of the prothrombinase complex with its substrate prothrombin (cf. Fig. 4, Table 1). At present we have no explanation for these deviating results.

In summary, our data show that APC is an efficient inhibitor of plateletdependent thrombin generation. The half-life time of prothrombinase in the presence of $1 \mathrm{nM} \mathrm{APC}$ and under the conditions of the experiment is $5 \mathrm{~min}$. Whereas it has been reported that platelet-bound factor $\mathrm{Va}$ is resistant to APC, our results clearly indicate that platelet-bound factor $\mathrm{Va}$, as part of the prothrombinase complex, is inactivated by APC with a rate that is comparable with that found on a membrane of synthetic phospholipids. Sustained platelet-derived factor $\mathrm{Va}$ cofactor activity therefore could be less critical than proposed $(9,10)$.

\section{References}

1. M. Kalafatis, M.D. Rand, K.G. Mann. The mechanism of inactivation of human factor $V$ and human factor Va by activated protein C. J. Biol. Chem. 269 (1994) 31869-31880.

2. G. Tans, G.A. Nicolaes, J. Rosing. Regulation of thrombin formation by activated protein C: effect of the factor V Leiden mutation. Semin. Hematol. 34 (1997) 244-255.

3. G.A. Nicolaes, G. Tans, M.C. Thomassen, H.C. Hemker, I. Pabinger, K. Varadi, H.P. Schwarz, J. Rosing. Peptide bond cleavages and loss of functional activity during inactivation of factor Va and factor VaR506Q by activated protein C. J. Biol. Chem. 270 (1995) 21158-21166.

4. P.C. Comp, C.T. Esmon. Activated protein C inhibits platelet prothrombin-converting activity. Blood 54 (1979) 1272-1281.

5. F.J. Walker, P.W. Sexton, C.T. Esmon. The inhibition of blood coagulation by activated Protein C through the selective inactivation of activated Factor V. Biochim. Biophys. Acta 571 (1979) 333-342.

6. M.E. Nesheim, W.M. Canfield, W. Kisiel, K.G. Mann. Studies of the capacity of factor Xa to protect factor Va from inactivation by activated protein C. J. Biol. Chem. 257 (1982) 1443-1447.

7. K. Suzuki, J. Stenflo, B. Dahlback, B. Teodorsson. Inactivation of human coagulation factor V by activated protein C. J. Biol. Chem. 258 (1983) 1914-1920. 
8. J. Rosing, L. Hoekema, G.A. Nicolaes, M.C. Thomassen, H.C. Hemker, K. Varadi, H.P. Schwarz, G. Tans. Effects of protein $\mathrm{S}$ and factor $\mathrm{Xa}$ on peptide bond cleavages during inactivation of factor Va and factor VaR506Q by activated protein C. J. Biol. Chem. 270 (1995) 27852-27858.

9. R.M. Camire, M. Kalafatis, P. Simioni, A. Girolami, P.B. Tracy. Platelet-derived factor $\mathrm{Va} / \mathrm{Va}$ (Leiden) cofactor activities are sustained on the surface of activated platelets despite the presence of activated protein C. Blood 91 (1998) 2818-2829.

10. J. Taube, N. McWilliam, R. Luddington, C.D. Byrne, T. Baglin. Activated protein C resistance: effect of platelet activation, platelet-derived microparticles, and atherogenic lipoproteins. Blood 93 (1999) 3792-3797.

11. D. Billy, H. Speijer, G. Willems, H.C. Hemker, T. Lindhout. Prothrombin activation by prothrombinase in a tubular flow reactor. J. Biol. Chem. 270 (1995) 1029-1034.

12. J.W.M. Heemskerk, P. Siljander, W.M.J. Vuist, G. Breikers, C.P.M. Reutelingsperger, M.J. Barnes, C.G. Knight, R. Lassila, R.W. Farndale. Function of glycoprotein VI and integrin alpha(2)beta(1) in the procoagulant response of single, collagen-adherent platelets. Thromb. Haemos. 81 (1999) 782-792.

13. Schoen, T. Lindhout, J. Franssen, H.C. Hemker. Low molecular weight heparin-catalyzed inactivation of factor $\mathrm{Xa}$ and thrombin by antithrombin III: effect of platelet factor 4 . Thromb. Haemost. 66 (1991) 435-441.

14. J.W.M. Heemskerk, W.M.J. Vuist, M.A.H. Feijge, C.P.M. Reutelingsperger, T. Lindhout. Collagen but not fibrinogen surfaces induce bleb formation, exposure of phosphatidylserine, and procoagulant activity of adherent platelets: Evidence for regulation by protein tyrosine kinase dependent $\mathrm{Ca}^{2+}$ responses. Blood 90 (1997) 2615-2625.

15. I. Salemink, J. Franssen, G.M. Willems, H.C. Hemker, T. Lindhout. Inhibition of tissue factorfactor VIla-catalyzed factor $\mathrm{X}$ activation by factor $\mathrm{Xa-tissue}$ factor pathway inhibitor. A rotating disc study on the effect of phospholipid membrane composition. J. Biol. Chem. 274 (1999) 28225-28232.

16. J. Rosing, H.M. Bakker, M.C. Thomassen, H.C. Hemker, G. Tans. Characterization of two forms of human factor Va with different cofactor activities. J. Biol. Chem. 268 (1993) 2113021136.

17. D.D. Monkovic, P.B. Tracy. Functional characterization of human platelet-released factor $V$ and its activation by factor Xa and thrombin. J. Biol. Chem. 265 (1990) 17132-17140.

18. L. Alberio, O. Safa, K.J. Clemetson, C.T. Esmon, G.L. Dale. Surface expression and functional characterization of alpha-granule factor $\mathrm{V}$ in human platelets: effects of ionophore A23187. thrombin, collagen, and convulxin. Blood 95 (1999) 1694-1702.

19. H.A. Andree, P.B. Contino, D. Repke, R. Gentry, Y. Nemerson. Transport rate limited catalysis on macroscopic surfaces: the activation of factor $\mathrm{X}$ in a continuous flow enzyme reactor. Biochemistry 33 (1994) 4368-4374.

20. G.M. Willems, P.L. Giesen, W.T. Hermens. Adsorption and conversion of prothrombin on a rotating disc. Blood 82 (1993) 497-504. 
21. F.R. Shu, G.S. Wilson. Rotating ring-disk enzyme electrode for surface catalysis studies. Anal. Chem. 48 (1976) 1679-1686.

22. J.F. Castner, L.B. Wingard, Jr. Mass transport and reaction kinetic parameters determined electrochemically for immobilized glucose oxidase. Biochemistry 23 (1984) 2203-2210.

23. P.L. Giesen, G.M. Willems, H.C. Hemker, W.T. Hermens. Membrane-mediated assembly of the prothrombinase complex. J. Biol. Chem. 266 (1991) 18720-18725.

24. P.J. Larson, R.M. Camire, D. Wong, N.C. Fasano, D.M. Monroe, P.B. Tracy, K.A. High. Structure/function analyses of recombinant variants of human factor Xa: Factor Xa incorporation into prothrombinase on the thrombin-activated platelet surface is not mimicked by synthetic phospholipid vesicles. Biochemistry 37 (1998) 5029-5038.

25. N.A. Swords,K.G. Mann. The assembly of the prothrombinase complex on adherent platelets. Arterioscler. Thromb. 13 (1993) 1602-1612.

26. J. Rosing, G. Tans, J.W. Govers Riemslag. R.F.A. Zwaal, H.C. Hemker. The role of phospholipids and factor $\mathrm{Va}$ in the prothrombinase complex. J. Biol. Chem. 255 (1980) 274283.

27. D. Billy, H. Speijer, T. Lindhout, H.C. Hemker, G.M. Willems. Inhibition of prothrombinase at macroscopic lipid membranes: competition between antithrombin and prothrombin. Biochemistry 34 (1995) 13699-13704.

28. H. Speijer, D. Billy, G. Willems, H.C. Hemker, T. Lindhout. Inhibition of prothrombinase by antithrombin-heparin at a macroscopic surface. Thromb. Haemost. 73 (1995) 648-653.

29. G. Tans, J. Rosing. M.C. Thomassen, M.J. Heeb, R.F. Zwaal, J.H. Griffin. Comparison of anticoagulant and procoagulant activities of stimulated platelets and platelet-derived microparticles. Blood 77 (1991) 2641-2648.

30. J. Sidelmann, J. Gram, O.D. Pedersen, J. Jespersen. Influence of plasma platelets on activated protein C resistance assay. Thromb. Haemost. 74 (1995) 993-994.

31. R. Shizuka, T. Kanda, H. Amagai, I. Kobayashi. False-positive activated protein C (APC) sensitivity ratio caused by freezing and by contamination of plasma with platelets. Thromb. Res. 78 (1995) 189-190.

32. L. Hoekema, G.A. Nicolaes, H.C. Hemker, G. Tans, J. Rosing. Human factor Va1 and factor Va2: properties in the procoagulant and anticoagulant pathways. Biochemistry 36 (1997) 3331 3335.

33. E.M. Bevers, P. Comfurius, R.F.A. Zwaal. Changes in membrane phospholipid distribution during platelet activation. Biochim. Biophys. Acta 736 (1983) 57-66.

34. D. Dörmann, K.J. Clemetson, B.E. Kehrel. The GPIb thrombin-binding site is essential for thrombin-induced platelet procoagulant activity. Blood 96 (2000) 2469-2478.

35. M.D. Smirnov, O. Safa, N.L. Esmon, C.T. Esmon. Inhibition of activated protein C anticoagulant activity by prothrombin. Blood 94 (1999) 3839-3846. 



\section{Chapter 5}

\section{Von Willebrand Factor Stimulates Thrombin-induced}

\section{Exposure of Procoagulant Phospholipids on the Surface of}

\section{Fibrin-adherent Platelets}

Jacob J. Briedé, Johan W. M. Heemskerk, Simone J. H. Wielders, Dominique Baruch, H. Coenraad Hemker and Theo Lindhout 


\section{Summary}

Previous studies have indicated that fibrin plays a functional role in platelet-dependent thrombin generation. The precise mechanism by which fibrin induces the exposure of procoagulant phospholipids in the outer leaflet of the platelet plasma membrane is however unknown. For this study fibrin was deposited from plasma on a tissue factorcoated glass coverslip. Platelet adhesion, changes in cytosolic free calcium concentration $\left(\left[\mathrm{Ca}^{2+}\right]\right)$ ) and exposure of anionic phospholipids under conditions of low and high shear stress were visualized using epifluorescence video microscopy in real time. Studies performed under conditions of low shear stress (wall shear rate of $50 \mathrm{~s}$ $\left.{ }^{1}\right)$ demonstrate that 1) non-activated platelets do not adhere to fibrin; 2) thrombinactivated platelets adhere independent of $\mathrm{vWf},\left[\mathrm{Ca}^{2+}\right]$ is elevated up to $0.2 \mu \mathrm{M}$ and only a few platelets expose anionic phospholipids. Under conditions of high shear stress $\left(1000 \mathrm{~s}^{-1}\right)$ it was observed that 1) fibrin-bound $\mathrm{vWf}$, platelet glycoprotein (GP) Ib and integrin $\alpha_{410} \beta_{3}$ are essential to firmly adhere platelets on fibrin; 2 ) the $\left[\mathrm{Ca}^{2+}\right]$ is not increased $(0.05 \mu \mathrm{M})$; and 3 ) thrombin, but not the PAR-1 specific ligand, SFLLRN, increases $\left[\mathrm{Ca}^{2+}\right]_{3}$ about 20-fold and induces exposure of anionic phospholipids in $85 \pm$ $14 \%$ of the adherent platelets. Under low shear stress, botrocetin effectively induced similar effects as observed under high shear stress. Collectively, these findings indicate that vWf-GP lb mediated adhesion to fibrin potentiates in platelets the thrombin-induced flux of intracellular calcium and thereby initiates the scrambling of procoagulant phospholipids from the inner to the outer leaflet of the platelet plasma membrane. 


\section{Introduction}

Thrombus formation at an injured vessel wall involves platelet adhesion, platelet activation and fibrin formation. Previous studies have provided evidence that fibrin, besides physically entrapping platelets (1), may also be involved in signal pathways that result in the exposure of anionic phospholipids at the plasma membrane of platelets $(2,3)$. The presence of these anionic phospholipids is thought to be of physiological importance because of their critical role in maintaining thrombin generation at the surface of a developing thrombus (4).

Platelets adhere to fibrin by molecular mechanisms that vary with the surface shear rate. At low shear rates platelet adhesion is mediated by integrin $\alpha_{410} \beta_{3}$ but platelet adhesion to fibrin at high shear rates involves a multi-step mechanism. Platelet glycoprotein (GP) lb and fibrin-bound von Willebrand factor (vWf) serve to tether the platelets as a prerequisite for an irreversible, integrin $\alpha_{1 b} \beta_{3}$-mediated, adhesion to fibrin $(5,6)$. GP Ib is probably also involved in the secondary phase of platelet adhesion. It has been shown that signaling across GP Ib-IX induces activation of integrin $\alpha_{1 \mathrm{~b}} \beta_{3}(7,8)$. This in turn is a prerequisite for solute phase fibrinogenplatelet interaction and probably also for the adhesion of platelets to fibrin $(9,10)$.

Recently, conflicting reports appeared on the role for GP lb in the development of procoagulant platelets. Béguin et al (3) concluded from their work in platelet rich plasma that vWf supports thrombin generation by two mechanisms: one that involves integrin $\alpha_{\mathrm{lb}} \beta_{3}$ but not fibrin and another that is dependent on both fibrin and GP Ib. Dörmann et al (11) studied the thrombin-dependent expression of procoagulant activity in suspensions of gel-filtered platelets. These investigators concluded that the GP lb binding site for thrombin, but not that for vWf, has a key role in the exposure of procoagulant phospholipids on the platelet surface, implying that vWf does not function in this response. It was further concluded that besides GP Ib also plateletplatelet contact, integrin $\alpha_{41 b} \beta_{3}$ and activation of protease-activated receptor 1 (PAR1) are essential for the exposure of procoagulant phospholipids (11). In contrast, Andersen et al (12) reported that PAR1 is the primary mediator of thrombin-stimulated platelet procoagulant activity. Evidently, these discrepancies may be due in part to the widely divergent experimental conditions under which these investigations were performed. For instance, involvement of vWf is only to be expected when experiments are conducted under conditions of high shear stress.

To address the contribution of vWf to the initiation of exposure of procoagulant phospholipids, we have conducted flow experiments with suspensions of washed platelets under varying shear conditions in the absence and presence of vWf and/or thrombin. To address the role of fibrin in this process, a native fibrin layer, deposited from flowing platelet free plasma on a glass coverslip coated with tissue factor, was used as the substrate for platelet adhesion and activation. This study demonstrates 
that fibrin-bound platelets exposed procoagulant phospholipids at their surfaces only in the presence of thrombin and when platelet adhesion was mediated by vWf and GP $\mathrm{lb}$, i.e. under high shear stress or at low shear stress in the presence of botrocetin.

\section{Materials and Methods}

Materials. Unfractionated heparin and bovine serum albumin (BSA, Sigma, St. Louis, USA); chromogenic substrate for thrombin, S2238 (Chromogenix, Mölndal, Sweden); D-Phe-Pro-Arg chloromethylketone (PPACK, Calbiochem, San Diego, USA); 1,2-dioleoyl-sn-glycero-3-phosphocholine (DOPC) and 1,2-dioleoyl-sn-glycero3-phosphoserine (DOPS, Avanti Polar Lipids, Alabaster, USA); calcein acetoxymethyl ester and fura-2 acetoxymethylester (Molecular Probes, Leiden, The Netherlands) and botrocetin (Kordia, Leiden, The Netherlands) were purchased from commercial sources as indicated. All other reagents used were of analytical grade.

Proteins and antibodies. Recombinant human tissue factor was a kind gift of Dr. Y. Nemerson (Mount Sinai School of Medicine, New York, USA) and was relipidated as described before (13). An affinity purified polyclonal rabbit anti-vWf antibody was obtained from the Central Laboratory of the Red Cross (Amsterdam, The Netherlands). Monovalent Fab fragments of a monoclonal antibody directed against GP Ib (6B4 Fab) described previously (14) were a kind gift of Dr. H. Deckmyn (Laboratory for Thrombosis Research, Kortrijk, Belgium). Fluorescein isothiocyanate (FITC) labeled swine anti-rabbit IgG was from DAKO A/S (Glostrup, Denmark). Purified vWf and a monoclonal antibody (MoAb 9) directed against the platelet $\alpha_{41 t} \beta_{3}$ binding site on vWf were described before (15). Oregon Green 488-labeled Annexin V came from Nexins Research (Hoeven, The Netherlands). The source of the platelet $\alpha_{410} \beta_{3}$ receptor blocker abciximab was as described (16). Human $\alpha$-thrombin was prepared as previously described (17). The specific protease-activated receptor 1 (PAR1) ligand SFLLRN, was obtained from Bachem (Bubendorf, Switzerland).

Platelets. Suspensions of washed platelets were prepared as described before (18). Briefly, blood was drawn from healthy volunteers, who had not taken any antiplatelet medication in the preceding two weeks. Platelet-rich plasma was prepared by centrifugation. Where indicated, platelet-rich plasma was incubated with $2.5 \mu \mathrm{M}$ calcein acetoxymethyl ester or $3 \mu \mathrm{M}$ fura-2 acetoxymethyl ester in the presence of 1 $\mathrm{U} / \mathrm{ml}$ apyrase $45 \mathrm{~min}$ at $37^{\circ} \mathrm{C}$. The platelets were then sedimented by centrifugation, washed twice with HEPES buffer pH 6.6 (10 mM HEPES, $136 \mathrm{mM} \mathrm{NaCl}, 5 \mathrm{mM}$ glucose, $2.7 \mathrm{mM} \mathrm{KCl}, 2 \mathrm{mM} \mathrm{MgCl}, 1 \mathrm{mg} / \mathrm{ml} \mathrm{BSA}$ and apyrase $(0.1 \mathrm{U} / \mathrm{ml})$. Finally, the platelets were resuspended in HEPES buffer adjusted to $\mathrm{pH}$ 7.4. Platelets were counted (Coulter, Miami, USA) and the suspensions were adjusted to $3.0 \times 10^{8}$ platelets $/ \mathrm{ml}$. 
Preparation of fibrin-covered glass coverslips. A fibrin layer was prepared as originally described by Remijn et al (19). Briefly, a cleaned glass coverslip was placed in a flow chamber (20). The depth of the slit of the chamber was either 50 or $200 \mu \mathrm{m}$. The chambers were filled with $0.3 \mathrm{nM}$ tissue factor embedded in $30 \mu \mathrm{M}$ DOPS (25 $\mathrm{mol} \%) /$ DOPC $(75 \mathrm{~mol} \%)$ vesicles and incubated for $20 \mathrm{~min}$. Non-bound vesicles were removed by flushing the chambers with Tris-buffer $(50 \mathrm{mM}$ Tris, $175 \mathrm{mM} \mathrm{NaCl}$, $\mathrm{pH}$ 7.9). Subsequently, the flow chambers were perfused (shear rate of $20 \mathrm{~s}^{-1}$ ) with plasma that was diluted 5-fold with Tris-buffer containing $1 \mathrm{U} / \mathrm{ml}$ heparin and $3 \mathrm{mM}$ $\mathrm{CaCl}_{2}$. After $20 \mathrm{~min}$, when a network of fibrin strands was formed, the flow chambers were flushed with Tris-buffer to remove plasma proteins. The fibrin layer contained thrombin and vWf. After a rinse with HEPES buffer and 30-min incubation with S2238 $(0.2 \mathrm{mM})$ a small but significant increase in the optical density at $405 \mathrm{~nm}$ was observed. A 10-min incubation with PPACK $(50 \mu \mathrm{M})$ resulted in complete neutralization of the amidolytic activity. Therefore, unless otherwise indicated, fibrin layers were prior to their use treated with PPACK to inactivate fibrin-bound thrombin activity. Fibrin-bound vWf could be visualized after incubation with a primary polyclonal rabbit anti-human vWf antibody $(10 \mu \mathrm{g} / \mathrm{ml}$ during $60 \mathrm{~min})$ and a secondary FITC-labeled swine anti-rabbit antibody (1:50 dilution during $60 \mathrm{~min}$ ). Incubation of the fibrin layer with purified plasma-derived human vWf $(10 \mu \mathrm{g} / \mathrm{ml})$ during $180 \mathrm{~min}$, followed by a rinse with HEPES buffer, and immuno-staining resulted in a 2 -fold increase in fluorescence intensity, indicating that the original fibrin layer was not saturated with plasma-derived vWf. All procedures were performed at room temperature.

Scanning electron microscopy. Glass coverslips with fibrin layers were incubated during one hour with $2.5 \%$ glutaraldehyde in $0.15 \mathrm{M} \mathrm{NaCl}$ buffered with 0.1 $\mathrm{M}$ phosphate, $\mathrm{pH} 7.4$ (PBS). The chamber was rinsed with PBS and the fibrin was dehydrated through a graded ethanol series. The dried sample was then sputtercoated with gold (Bio-Rad SC500, Veenendaal, the Netherlands) and observed with a scanning electron microscope (Personal SEM, R.J. Lee Instruments, Trafford, USA).

Platelet flow studies. The flow chamber with coverslip was connected via silicone tubing (inner diameter $1 \mathrm{~mm}$ ) to a syringe filled with washed platelets $(3.0 \mathrm{x}$ $10^{8}$ platelets $/ \mathrm{ml}$ ) in HEPES buffer containing $3 \mathrm{mM} \mathrm{CaCl}_{2}$. Perfusion experiments under low shear stress conditions (wall shear rate of $50 \mathrm{~s}^{-1}$ ) were performed at 100 $\mu \mathrm{l} / \mathrm{min}$ in flow chambers with a slit depth of $200 \mu \mathrm{m}$. Perfusion experiments under high shear stress conditions (wall shear rate of $1000 \mathrm{~s}^{-1}$ ) were performed at $125 \mu \mathrm{l} / \mathrm{min}$ in flow chambers with a slit depth of $50 \mu \mathrm{m}$. All procedures were performed at room temperature.

Preactivation of platelets. To activate platelets with thrombin prior to their perfusion, the inlet of the flow chamber was connected to two syringes; one containing the platelet suspension $\left(3.8 \times 10^{8}\right.$ platelets $/ \mathrm{ml}$ in HEPES buffer containing 
$3 \mathrm{mM} \mathrm{CaCl} 2$ ) and the other containing $0.5 \mu \mathrm{M}$ thrombin in HEPES buffer. The pumpdriven syringes were set at flow rates of 80 and $20 \mu \mathrm{l} / \mathrm{min}$, respectively.

Botrocetin-induced platelet adhesion. Washed platelets $\left(3.8 \times 10^{8} / \mathrm{ml}\right)$ were labeled with calcein (adhesion studies) or with fura-2 (measurement of intracellular calcium) as above described. Fibrin-coated coverslips in a flow chamber with slit depth of $200 \mu \mathrm{m}$ were incubated stationary for 3 hours at room temperature with purified human vWf $(10 \mu \mathrm{g} / \mathrm{ml})$ and then incubated with botrocetin $(5 \mathrm{U} / \mathrm{ml} ; 30 \mathrm{~min})$. Prior to the perfusion (flow rate $100 \mu \mathrm{l} / \mathrm{min}$ ) with a suspension of washed platelets non-bound $v W f$ and botrocetin were removed during a 5 min perfusion with HEPES buffer at a flow rate of $100 \mu \mathrm{l} / \mathrm{min}$.

Phase contrast and fluorescence microscopy. Phase contrast and fluorescent real-time images were recorded as described before (18). Briefly, the flow chamber was placed on the stage of an inverted microscope (Diaphot 200, Nikon, Tokyo, Japan). Phase contrast and fluorescence images are recorded via a 40x quartz oilimmersion objective coupled to a high-resolution and a low-light level intensified, charge-coupled device camera, respectively. Oregon Green 488, calcein and FITC fluorescence were observed with a $485 \mathrm{~nm}$ excitation filter (bandpass of $40 \mathrm{~nm}$ ), a $505 \mathrm{~nm}$ dichroic long-pass filter, and a $530 \mathrm{~nm}$ emission filter (bandpass of $30 \mathrm{~nm}$ ). Four fluorescence images were taken every 10 seconds, digitized and averaged after subtraction of background images, and the resulting images were stored. Image analysis was performed off-line using Quanticell 700/900 software (Visitech, Sunderland, UK). The platelet adhesion results are expressed as the percentage of total area covered by calcein-loaded platelets calculated from at least 5 different microscopic fields in 3 independent experiments. Exposure of anionic phospholipids at the surfaces of adherent platelets was, unless otherwise stated, expressed as the percentage of all platelets that bound Oregon Green-labeled annexin $V$ in at least 5 different microscopic fields in 3 independent experiments. Fura- 2 fluorescence, as a probe for intracellular calcium concentration, was measured with alternating 340 and $380 \mathrm{~nm}$ excitation filters (bandpass $15 \mathrm{~nm}$ ), a $400 \mathrm{~nm}$ dichroic mirror and a $510 \mathrm{~nm}$ emission filter (bandpass $40 \mathrm{~nm}$ ). Four fluorescence images were taken every 3 seconds, averaged, background subtracted and ratio images were calculated. Calibration of fluorescence ratio to molar concentrations of intracellular calcium was according to Grynkiewicz et al (21). 


\section{Results}

Characterization of the fibrin layer. For this study we adapted an earlier reported method that allows fibrin formation from flowing plasma at a controlled rate (19). Realtime imaging by phase contrast microscopy showed the formation of a thin fibrin layer within $10 \mathrm{~min}$ when 5 -fold diluted, recalcified, platelet free plasma, containing $1 \mathrm{U} / \mathrm{ml}$ heparin, was passed through a flow chamber (wall shear rate of $20 \mathrm{~s}^{-1}$ ) with inserted tissue factor-coated glass coverslip. The use of non-heparinized plasma resulted in the formation of an occluding fibrin clot. Fibrin formation was tissue factor-driven because no fibrin was formed when the glass coverslip was coated with phospholipid vesicles without tissue factor. Further characterization by scanning electron microscopy showed a nearly complete coverage of the area with fibrin strands that varied in thickness from 0.1 to $0.3 \mu \mathrm{m}$. The thicker fibrin strands were aligned in the direction of the flow (Fig. 1).

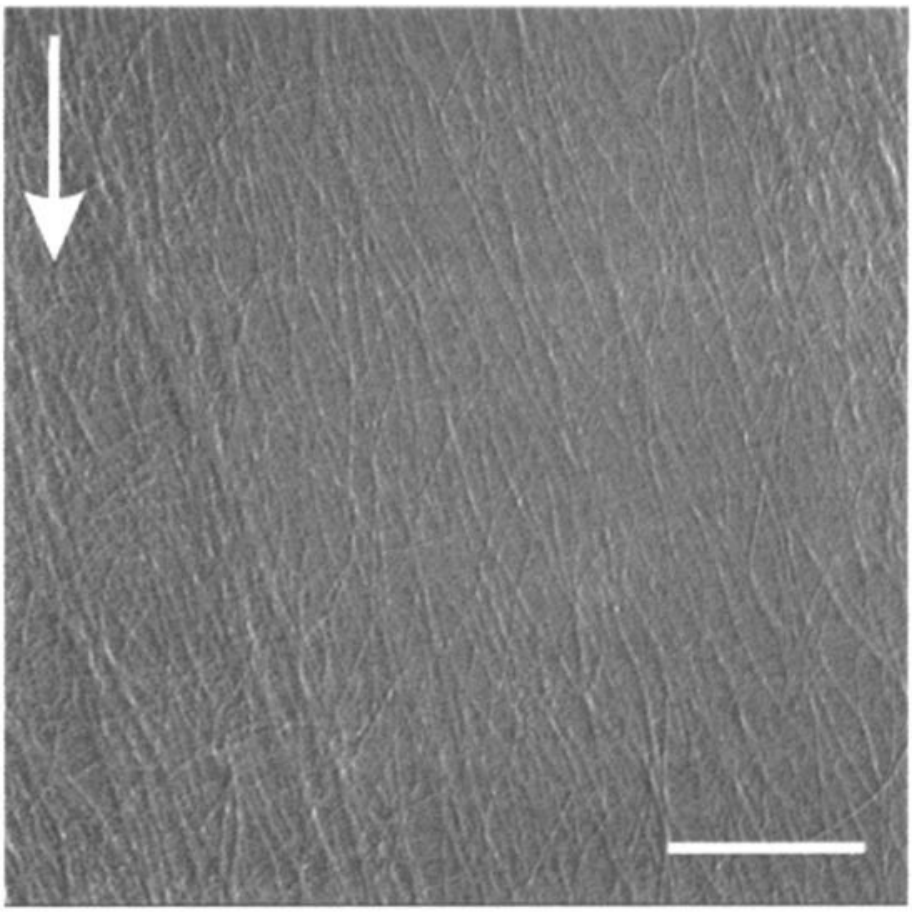

Figure 1 Scanning electron micrograph of fibrin layer. A flow chamber containing a TF-coated glass coverslip was perfused for $20 \mathrm{~min}$ with 5-fold diluted platelet-free plasma, containing $1 \mathrm{U} / \mathrm{ml}$ heparin, and subsequently rinsed with HEPES buffer. The arrow indicates the direction of flow. Bar represents $10 \mu \mathrm{m}$. 
Platelets that adhere to fibrin at low shear rates are not procoagulant. Nonactivated platelets hardly adhere on fibrin at a surface shear rate of $50 \mathrm{~s}^{-1}$ (Fig. 2A; closed circles). After a 10-min perfusion the area coverage was $3 \pm 2 \%$ (mean $\pm S D$; $n=15$ ). Phase contrast images showed that the few platelets that adhered formed pseudopodia but did not fully spread. Preincubation of the fibrin layer with PPACK ( 50 $\mu \mathrm{M})$ completely prevented platelet adhesion (Fig. 2A; open circles), suggesting that fibrin-bound thrombin promotes platelet adhesion. Indeed, platelet adhesion increased when the platelets were mixed with thrombin $(0.1 \mu \mathrm{M})$ just before the entrance of the flow chamber (Fig. 2A; open triangles). Ten minutes after the flow starts $12 \pm 7 \%$ (mean $\pm S D ; n=15$ ) of the total area was covered with platelets. Phase contrast images (Fig. 2B) showed that in addition to single adherent platelets also small aggregates (5-20 platelets) attached to the fibrin surface.

To investigate whether vWf was involved in the adhesion of thrombin-activated platelets on fibrin under low shear stress conditions, fibrin layers were preincubated with a polyclonal rabbit anti-human vWf antibody $(10 \mu \mathrm{g} / \mathrm{ml} ; 3$ hours) prior to the passage of thrombin-activated platelets through the flow chamber. The area coverage, $27 \pm 19 \%$ (mean $\pm S D ; n=15$ ) was similar to that for non-treated fibrin, indicating that under conditions of low shear stress the adhesion of thrombin-activated platelets on fibrin is not mediated by vWf.

Intracellular free calcium concentrations $\left[\mathrm{Ca}^{2+}\right]$; of the fibrin-adherent platelets were measured during $10 \mathrm{~min}$, directly following their adhesion to fibrin, to investigate the effects of adhesion- and thrombin-activation on calcium signaling. In a representative experiment the average $\left[\mathrm{Ca}^{2+}\right]$; calculated from the fluorescence ratios was $0.2 \pm 0.1 \mu \mathrm{M}$ (mean $\pm \mathrm{SD} ; \mathrm{n}=8$ ) and did not vary with time. This is significantly higher than the $\left[\mathrm{Ca}^{2+}\right]$, of resting platelets in suspension in the absence of thrombin $(0.05 \mu \mathrm{M})$.

Of the thrombin-activated platelets that adhered to fibrin (Fig. 2B), only a few platelets bound annexin V (Fig. 2C). Overall, $11 \pm 8 \%$ (mean $\pm S D ; n=30$ ) of the adherent platelets bound annexin V. Incubation of fibrin prior to the adhesion of thrombin-activated platelets with a polyclonal antibody to vWf had no effect on the percentage of platelets that bound annexin V, $13 \pm 5 \%$ (mean $\pm S D ; n=30)$. 

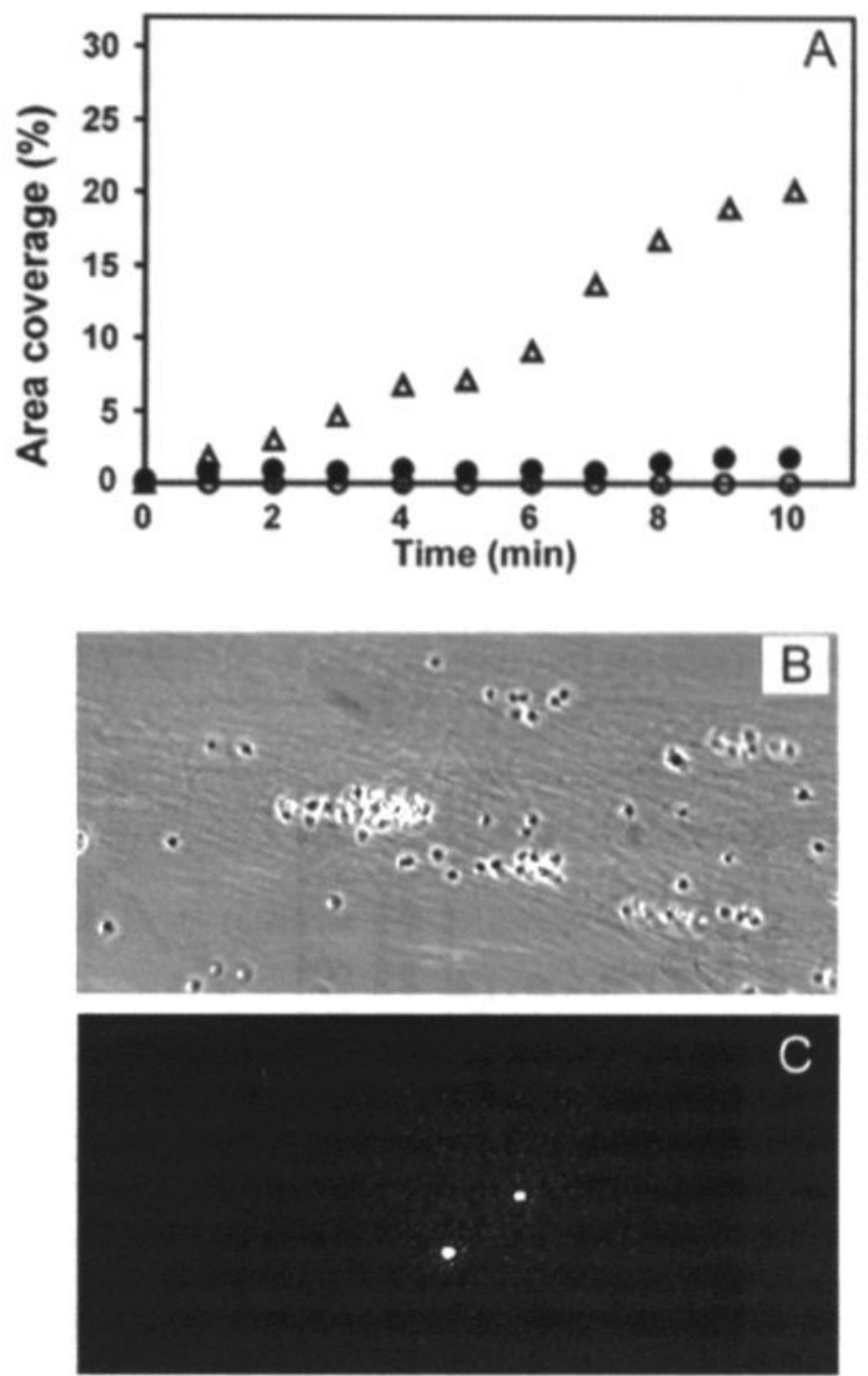

Figure 2 Platelet adhesion to fibrin under low shear stress. Panel A: fibrin layers were incubated for 3 hours with HEPES buffer $(\bullet)$ or $50 \mu \mathrm{M}$ PPACK $(\mathrm{O}, \Delta)$. Calceinloaded washed platelets $\left(3.9 \times 10^{8}\right.$ cells $\left./ \mathrm{ml}\right)$ in HEPES buffer containing $3 \mathrm{mM} \mathrm{CaCl}_{2}$ were mixed with HEPES buffer $(\bullet, 0)$ or thrombin $(\Delta$, final concentration $0.1 \mu \mathrm{M})$ just before the entrance of the flow chamber as described in Methods. The platelets passed through the flow chamber at a shear rate of $50 \mathrm{~s}^{-1}$. Fluorescence images were captured at different time intervals and analyzed off-line for the area covered with fluorescence. Panel B: phase contrast image of fibrin layer after $10 \mathrm{~min}$ perfusion with thrombinactivated platelets. Panel C: fluorescence image of sample shown in panel B after incubation with Oregon Green-labeled annexin V. 
Platelets that adhere vWf dependently at a low shear rate become procoagulant after thrombin treatment. To obtain vWf-mediated platelet adhesion under low shear rate conditions platelets were passed through a flow chamber with a fibrin layer that was incubated with vWf and botrocetin. Ten minutes after the start of the flow $11 \pm$ $4 \%$ (mean $\pm S D ; n=10$ ) of the area was covered with platelets. In contrast, the surface coverage was $<1 \%$ when the same experiment was performed in the presence of anti-vWf antibodies (data not shown). Measurements of intracellular calcium showed that fibrin-adherent platelets had a low $\left[\mathrm{Ca}^{2+}\right]$; of about $0.07 \mu \mathrm{M}$ (starting point in Fig. $3 \mathrm{~A})$. The percentage of platelets that bound annexin $V$ was also very low, namely 1.3 $\pm 2.3 \%$ (mean $\pm S D ; n=20$ ) of adherent platelets (starting point in Fig. 3B). Passing a thrombin solution $(0.1 \mu \mathrm{M})$ through the flow chamber resulted in a transiently increased $\left[\mathrm{Ca}^{2+}\right]_{1}$ (Fig. $3 \mathrm{~A}$ ) concomitantly with an increase in the percentage of platelets that bound annexin V (Fig. 3B). Already after 10 min $57 \pm 23 \%$ (mean \pm SD; $n=20$ ) of the adherent platelets bound annexin $V$.
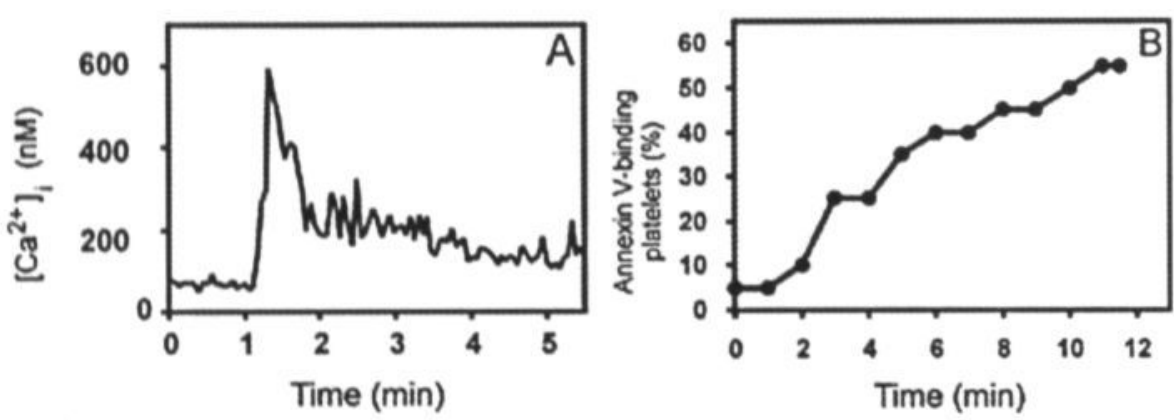

Figure 3 Calcium response and exposure of anionic phospholipids of platelets that adhered to fibrin in the presence of vWf and botrocetin at a low shear rate. Fura-2 loaded platelets $\left(3.0 \times 10^{8}\right.$ cells/ml) in HEPES buffer containing $3 \mathrm{mM} \mathrm{CaCl}_{2}$ were passed through a flow chamber containing a fibrin layer incubated for 3 hours with vWf $(10 \mu \mathrm{g} / \mathrm{ml})$ and botrocetin $(5 \mathrm{U} / \mathrm{ml})$. Wall shear rate was $50 \mathrm{~s}^{-1}$. Panel A: 10 minutes after the start of flow with platelet suspension, HEPES buffer containing $3 \mathrm{mM} \mathrm{CaCl}_{2}$ and 0.1 $\mu \mathrm{M}$ thrombin was passed through the flow chamber and fura-2 fluorescence ratio images were captured every 10 seconds. The $\left[\mathrm{Ca}^{2+}\right]$, of 5 single platelets were averaged and plotted against the perfusion time (panel A). Panel B: 10 minutes after the start of flow with platelet suspension, HEPES buffer containing $3 \mathrm{mM} \mathrm{CaCl}_{2}, 1 \mu \mathrm{g} / \mathrm{ml}$ Oregon Greenlabeled annexin $\mathrm{V}$ and thrombin $(0.1 \mu \mathrm{M})$ was passed through the flow chamber and Oregon Green fluorescence images were captured every minute. The percentage of adherent platelets that bound annexin $\mathrm{V}$ was calculated off-line. 
Shear-induced and vWf-mediated adhesion potentiates thrombin-enhanced exposure of procoagulant phospholipids. Platelet adhesion to fibrin under high shear stress conditions (surface shear rate of $1000 \mathrm{~s}^{-1}$ ) was dependent on vWf-GP $\mathrm{Ib}$ and integrin $\alpha_{410} \beta_{3}$ interactions because platelet adhesion was completely abolished when the fibrin layer was pretreated with the polyclonal anti-human vWf antibody $(10 \mu \mathrm{g} / \mathrm{ml})$ or MoAb $9(20 \mu \mathrm{g} / \mathrm{ml})$ against the integrin $\alpha_{410} \beta_{3}$ binding site on vWf or when platelets were pretreated with Fab fragments of MoAb $6 B 4(10 \mu \mathrm{g} / \mathrm{ml})$ that selectively blocks the vWf binding site on GP lb or integrin $\alpha_{110} \beta_{3}$ antagonist abciximab $(20 \mu \mathrm{g} / \mathrm{ml})$. Incubation of the fibrin layer with exogenous plasma-derived vWf increased the area covered with platelets from $55 \pm 4 \%$ to $75 \pm 7 \%$ (mean $\pm S D ; n=15$ ). The results of representative experiments are shown in Fig. 4. This finding confirms the notion that fibrin-adherent platelets withstand high shear forces because of multivalent interactions of several platelet receptors with (vWf-bound) fibrin $(5,6,9)$.

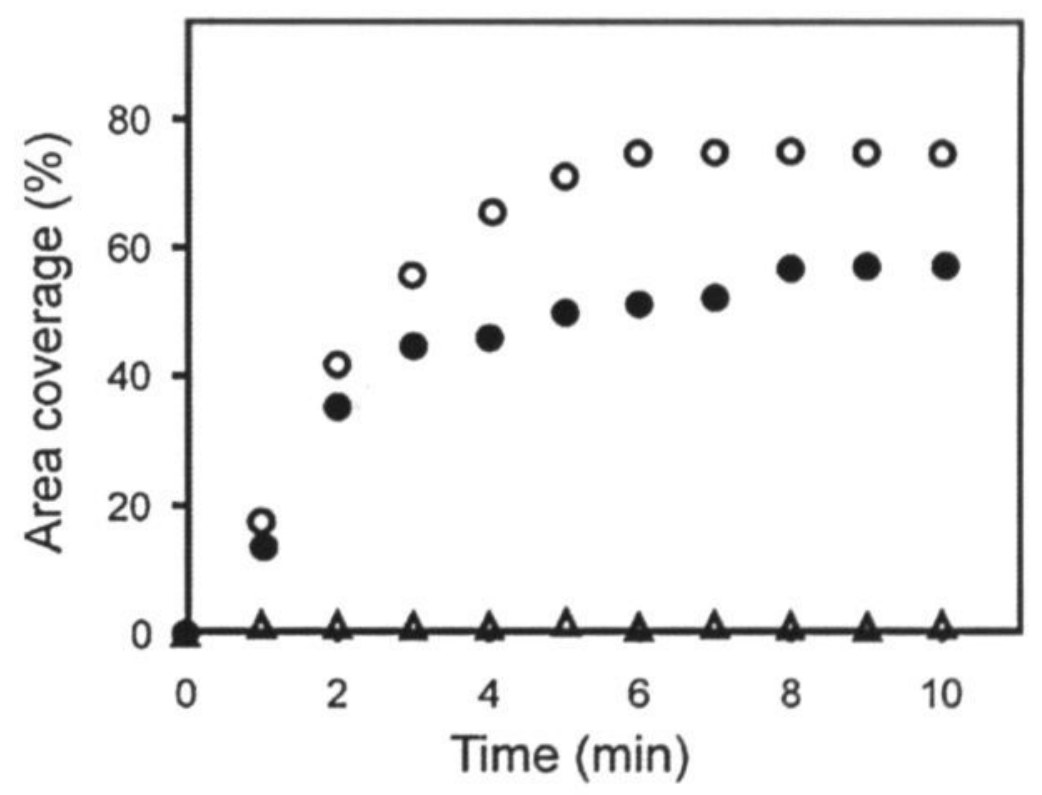

Figure 4 Platelet adhesion to fibrin under conditions of high shear stress. Calcein-loaded washed platelets $\left(3.0 \times 10^{8}\right.$ cells $\left./ \mathrm{ml}\right)$ in HEPES buffer containing $3 \mathrm{mM}$ $\mathrm{CaCl}_{2}$ were passed through a flow chamber containing a fibrin-coated glass coverslip at a wall shear rate of $1000 \mathrm{~s}^{-1}$. The fibrin layers were incubated for 3 hours with HEPES buffer (closed circle), $10 \mu \mathrm{g} / \mathrm{ml} \mathrm{vWf}(\mathrm{O})$ or $10 \mu \mathrm{g} / \mathrm{ml}$ polyclonal anti-vWf antibody $(\Delta)$. 
Importantly, none of these interactions activated the platelets nor initiated the exposure of procoagulant phospholipids: $\left[\mathrm{Ca}^{2+}\right]$ of adherent platelets $(0.05 \mu \mathrm{M})$ was not elevated and only $2 \pm 2 \%$ (mean $\pm S D ; n=20$ ) of the adherent platelets bound annexin V. Passage of thrombin $(0.1 \mu \mathrm{M})$ through the flow chamber, however, transiently increased $\left[\mathrm{Ca}^{2+}\right]$ to peak values of $1.1 \mu \mathrm{M}$ (Fig. 5A) and initiated the exposure of procoagulant phospholipid (Fig. 5B-D). Analysis of the fluorescence images of randomly chosen microscopic fields $10 \mathrm{~min}$ after the flow started showed that $85 \pm 14 \%$ (mean $\pm S D ; n=30$ ) of the adherent platelets bound annexin V. By varying the thrombin concentration it was found that a thrombin concentration of $5 \mathrm{nM}$ was sufficient to induce annexin $\mathrm{V}$ binding sites within $10 \mathrm{~min}$ in $50 \%$ of all adherent platelets.
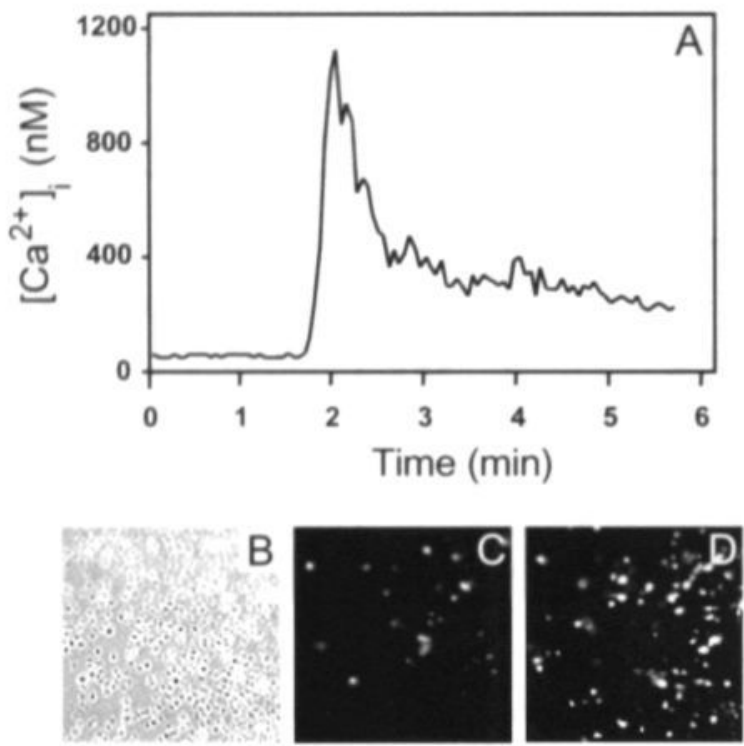

Figure 5 Thrombin-induced calcium response and exposure of anionic phospholipids of platelets that adhered to fibrin under conditions of high shear stress. Fura-2 loaded platelets $\left(3.0 \times 10^{8}\right.$ cells $\left./ \mathrm{ml}\right)$ in HEPES buffer containing $3 \mathrm{mM}$ $\mathrm{CaCl}_{2}$ were passed through flow chamber containing a fibrin layer incubated for 3 hours with vWf $(10 \mu \mathrm{g} / \mathrm{ml})$. Wall shear rate was $1000 \mathrm{~s}^{-1}$. Panel A: 10 minutes after the start of flow with platelet suspension. HEPES buffer containing $0.1 \mu \mathrm{M}$ thrombin was passed through the flow chamber and fura-2 fluorescence ratio images were captured every 10 seconds. The $\left[\mathrm{Ca}^{2+}\right]$, of 5 single platelets were averaged and plotted against the perfusion time. Panel B show phase contrast image of the fibrin layer 10 minutes after the start of flow with platelet suspension. The perfusion was then continued with HEPES buffer containing $1 \mu \mathrm{g} / \mathrm{ml}$ Oregon Green-labeled annexin $V$ and thrombin $(0.1 \mu \mathrm{M})$ Oregon Green fluorescence images were captured after $1 \mathrm{~min}$ (panel C) and $10 \mathrm{~min}$ (panel D). 
Because of the uncertainties about the role of PAR1 in the thrombin-induced procoagulant response of fibrin-adherent platelets $(11,12)$, the same experiments as described for thrombin were performed with SFLLRN, a specific PAR1 ligand. Fig. 6A demonstrates that as soon as the fibrin-adherent platelets were exposed to the perfusion solution containing $150 \mu \mathrm{M}$ SFLLRN, $\left[\mathrm{Ca}^{2+}\right]$ transiently increased to peak values of about $0.25 \mu \mathrm{M}$ (Fig. 6A). This response is significantly lower than the response seen with thrombin (Fig. 5A). In contrast, unlike thrombin, SFLLNR did not induce exposure of procoagulant phospholipids as could be inferred from the absence of annexin V-binding platelets (Fig. 6B). Moreover, incubation of the platelets with thrombin after the treatment with SFLLRN increased the number of platelets that bound annexin $\mathrm{V}$ with only $10 \%$. This finding is compatible with the notion that SFLLRN desensitizes the thrombin-induced procoagulant response of platelet in suspension (11).

\section{Discussion}

Numerous studies utilizing either platelet rich plasma or suspensions of washed platelets have indicated that thrombin is involved in the development of platelet procoagulant activity (for a review see ref. 22), though the opinions about the primary platelet receptors and ligands involved in this process are still the subjects of considerable debate. The discrepancies could origin from substantial differences in the experimental designs. More interestingly, the diversity in concepts could also point at a complicated process that can be triggered by several modulators depending on the settings of the experimental systems.

This study investigated specifically the role of vWf and thrombin in generating platelet procoagulant activity by varying the flow conditions and using platelets that interact with a physiological fibrin layer derived from flowing plasma. Fibrin was selected as the adhesive substrate because of its proposed role as adhesive protein in the development of a growing thrombus $(5,6,9)$ and its anticipated function in the vWf mediated generation of platelet procoagulant activity $(2,3)$.

Platelet adhesion to fibrin. For this platelet adhesion study we used a novel way to prepare fibrin strands close to the in vivo situation, namely by tissue factor-driven thrombin generation in flowing platelet poor plasma. We found that resting platelets do not adhere to fibrin under conditions of low shear stress. Substantial platelet adhesion was found when the platelets were pre-activated with thrombin. In contrast, non-activated platelets do adhere to fibrin under conditions of high shear stress provided that fibrin-bound vWf is present. These observations confirm the notion that activation of integrin $\alpha_{41 b} \beta_{3}$ is required for platelet adhesion to fibrin $(23,24)$ but contradicts another study (6) reporting that the affinity for fibrin of integrin $\alpha_{41 b} \beta_{3}$ on 

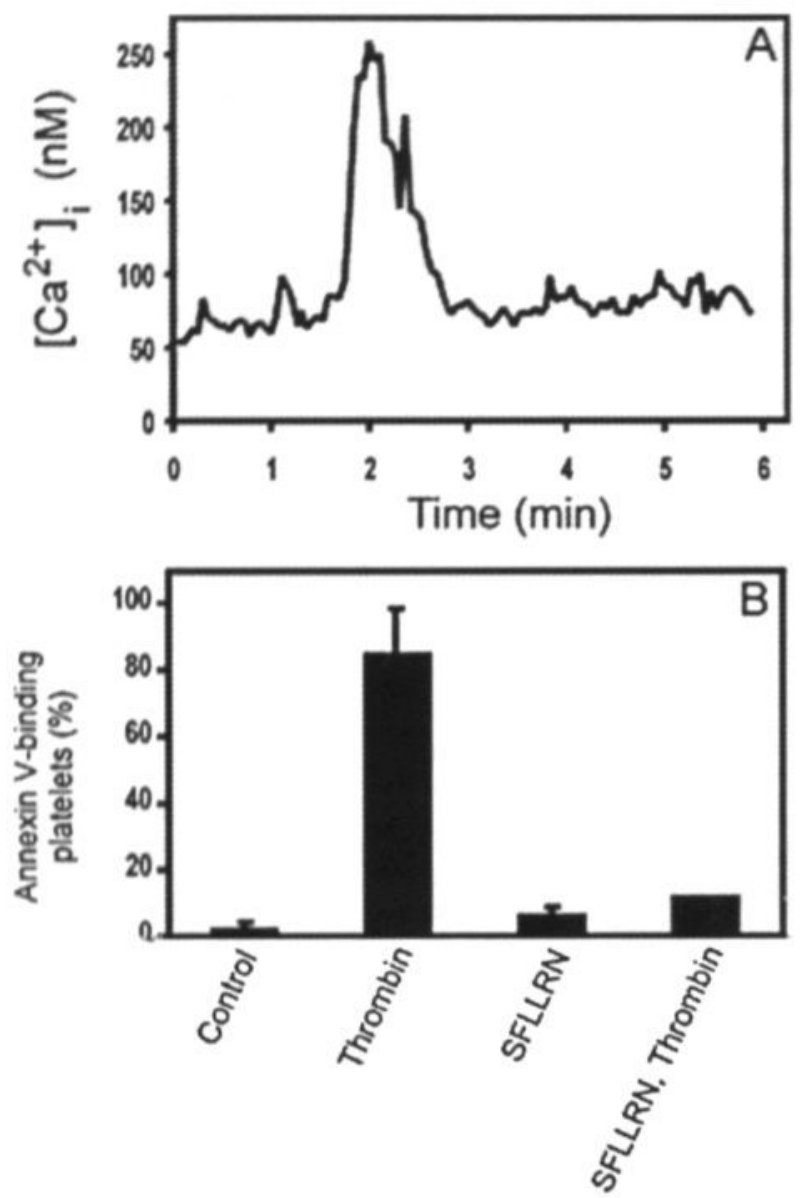

Figure 6 PAR1 agonist-induced calcium response and exposure of anionic phospholipids of platelets that adhered to fibrin under conditions of high shear stress. Fura-2 loaded platelets $\left(3.0 \times 10^{8}\right.$ cells $\left./ \mathrm{ml}\right)$ in HEPES buffer containing $3 \mathrm{mM}$ $\mathrm{CaCl}_{2}$ were passed (wall shear rate $1000 \mathrm{~s}^{-1}$ ) through a flow chamber containing a fibrin layer. After 10 min HEPES buffer containing $150 \mu \mathrm{M}$ PAR1 agonist was perfused through the flow chamber and fura-2 fluorescence ratio images were captured every 10 seconds. The average $\left[\mathrm{Ca}^{2+}\right]$, of 5 single platelets is shown (panel A). Panel B depicts the percentage of adherent platelets that bound annexin $V$ after incubation with HEPES buffer, $0.1 \mu \mathrm{M}$ thrombin or $150 \mu \mathrm{M}$ SFLLRN and $150 \mu \mathrm{M}$ SFFLRN followed by a 10-min incubation with $0.1 \mu \mathrm{M}$ thrombin. All incubation mixtures contained $1 \mu \mathrm{g} / \mathrm{ml}$ Oregon Green-labeled annexin $\mathrm{V}$ and $3 \mathrm{mM} \mathrm{CaCl}_{2}$. The percentage of platelets binding annexin $\mathrm{V}$ was calculated off-line from the fluorescence and phase contrast images captured after $10 \mathrm{~min}$ of incubation. The data represent the mean of 5 randomly chosen microscopic fields. 
non-stimulated platelets is strong enough to support optimal adhesion. Because immobilized fibrinogen is an adhesive substrate for non-activated platelets $(10,18)$ the differences in findings could be explained by different amounts of fibrinogen in the fibrin strand preparations (25). It has been reported that vWF must first bind to platelets before it can interact with fibrin and promote platelet adhesion (6). This study, however, demonstrated that fibrin layers formed from plasma contain sufficient amounts of vWf to support shear-induced platelet adhesion and provided further evidence that both GP Ib and integrin $\alpha_{410} \beta_{3}$ are involved in irreversible platelet adhesion on fibrin under flow conditions. We found that besides the MoAb 6B4 directed against the vWf binding site on GP lb, also the integrin $\alpha_{110} \beta_{3}$ antagonist, abxicimab, and MoAb 9 directed against the integrin $\alpha_{110} \beta_{3}$ binding site on vWf, inhibited shear-induced platelet adhesion to fibrin.

Adhesion-induced platelet responses under low shear stress conditions. Thrombin-induced adhesion of platelets to fibrin is associated with an increase of platelet intracellular calcium, but this increase is apparently too small to induce exposure of procoagulant phospholipids at the platelet surface (Table 1). This observation clearly rebuts the importance of thrombin as a potent initiator of the procoagulant activity in unstirred (12) and stirred (11) platelet suspension. Our finding is however compatible with the notion that this action of thrombin needs ancillary platelet activators, like collagen (4). Alternatively, we could surmise that the thrombininduced procoagulant response is down regulated by platelet-fibrin interaction. The absence of a transient increase of the intracellular calcium concentration in the fibrinadherent platelets supports the notion of a poor response of these platelets to thrombin. We recall that the flowing platelet suspension was exposed to thrombin shortly before it entered the flow chamber and that only adherent platelets were analyzed for their annexin $\mathrm{V}$ binding properties. In conclusion, 1) platelets have to be activated, e.g. with thrombin, for adhesion to fibrin under conditions of low shear stress, 2) fibrin-bound platelets showed a relatively small increase in intracellular calcium, and 3) only a small population of these platelets bind annexin $V$ (Table 1).

Von Willebrand factor-mediated platelet procoagulant activity. Shear stress- or botrocetin-induced adhesion was not accompanied with an increased intracellular free calcium concentration or exposure of annexin $\mathrm{V}$ binding sites on the platelet surface. Thrombin, however, induced a transient increase in the intracellular calcium concentration of the adherent platelets followed by the exposure of annexin $\mathrm{V}$ binding sites. Thus this study clearly demonstrates that vWf-mediated adhesion of platelets to fibrin is a prerequisite for thrombin to expose annexin $V$ binding sites at the surfaces of these platelets (Table 1). It also could explain the observation of a vWf-mediated increase in thrombin generation in platelet rich plasma (3). 
Table 1. Summarizing data. The experimental conditions and measurements of platelet adhesion (expressed as percentage of surface covered with platelets). procoagulant response (expressed as percentage of adherent platelets that bound annexin V) and intracellular calcium concentration were described in "Results". Fibrin layers were preincubated with PPACK and vWf.

\begin{tabular}{|l|c|c|c|c|c|c|}
\hline $\begin{array}{l}\text { Experimental } \\
\text { conditions }\end{array}$ & \multicolumn{2}{|c|}{ Adhesion } & \multicolumn{2}{c|}{$\begin{array}{l}\text { Procoagulant } \\
\text { response }\end{array}$} & \multicolumn{2}{|c|}{$\left[\mathrm{Ca}^{2+}\right] \mathrm{i}$} \\
(shear rate + addition) & \multicolumn{2}{|c|}{$(\%)$} & \multicolumn{2}{|c|}{$(\%)$} & \multicolumn{2}{c|}{$(\mu \mathrm{M})$} \\
\hline & & + thrombin & & + thrombin & & + thrombin \\
\hline $50 \mathrm{~s}^{-1}$ & $<1$ & $12 \pm 7$ & $\mathrm{na}^{* *}$ & $11 \pm 8$ & 0.05 & 0.20 \\
\hline $50 \mathrm{~s}^{-1}+$ anti-vWf & $<1$ & $27 \pm 9$ & na & $13 \pm 5$ & $\mathrm{nd}$ & $\mathrm{nd}$ \\
\hline $50 \mathrm{~s}^{-1}+$ botrocetin & $11 \pm 5$ & $\mathrm{nd}^{*}$ & $1 \pm 2$ & $57 \pm 23$ & 0.07 & 0.60 \\
\hline $1000 \mathrm{~s}^{-1}$ & $75 \pm 7$ & $54 \pm 13$ & $2 \pm 2$ & $85 \pm 14$ & 0.07 & 0.80 \\
\hline $1000 \mathrm{~s}^{-1}+$ anti-vWf & $<1$ & $<1$ & na & na & na & na \\
\hline
\end{tabular}

- nd, not determined

** na, insignificant platelet adhesion

A number of intriguing issues regarding the role of vWf, fibrin and thrombin in signaling for platelet responses remain however to be addressed. In particular the role of GP $\mathrm{lb}$ in this process is of interest because it contains a vWf and a thrombin binding site. Whether GP Ib or PAR1 is the primary mediator for the thrombin-initiated procoagulant response of platelets in suspension is also still a matter of debate (11, 12). This study could not attribute a significant role for PAR1 in the procoagulant response of fibrin-adherent platelets, albeit that the PAR1 agonist SFLLRN transiently increased the intracellular calcium concentration as reported for platelet in suspension (12) and desensitized fibrin-adherent platelets for a later activation by thrombin as previously reported (11). Several studies have indicated that the interaction of GP lb with either vWf or thrombin causes a signal transduction that results in activation of integrin $\alpha_{110} \beta_{3}(7,8,26)$. Interestingly, integrin $\alpha_{411} \beta_{3}$ antagonists have been reported to inhibit the induction of platelet procoagulant activity (27-29). It was therefore suggested that vWf-mediated fibrinogen-integrin $\alpha_{11 t} \beta_{3}$ interaction, could be linked to the development of procoagulant platelets (30). However, our study made it clear that under conditions of high shear stress vWf-mediated adhesion of platelets to fibrin alone is not sufficient to initiate platelet procoagulant activity. These platelets had to be activated with thrombin to initiate the scrambling of procoagulant 
phospholipids in the platelet plasma membrane. To date, there is little information on a synergistic signaling mechanism that comprises vWf-GP $\mathrm{lb}$ and thrombin-GP $\mathrm{lb}$ interactions. However, intracellular calcium mobilization and transmembrane calcium influx resulting in a sufficiently high intracellular calcium concentration are assumed to be key reactions in this process (31). In this context it is noteworthy to mention that integrin $\alpha_{410} \beta_{3}$-mediated adhesion of platelets to fibrin may cause a down regulation of calcium signaling through thrombin (32). It is apparent that shear-induced binding of fibrin-bound vWf to GP Ib does not negatively affect a thrombin-dependent calcium signaling. This synergistic effect of vWf, fibrin and thrombin to generate catalytic platelet surfaces is an attractive concept for explaining the formation of a stable thrombus under conditions of high shear stress.

\section{References}

1. R.S. Brown, S. Niewiarowski, G.J. Stewart, M. Millman. A double-isotope study on incorporation of platelets and red cells into fibrin. J. Lab. Clin. Med. 90 (1977) 130-140.

2. R. Kumar, S. Béguin, H.C. Hemker. The effect of fibrin clots and clot-bound thrombin on the development of platelet procoagulant activity. Thromb. Haemost. 74 (1995) 962-968.

3. S. Béguin, R. Kumar, I.M.L.W. Keularts, U. Seligsohn, B.S. Coller, H.C. Hemker. Fibrindependent platelet procoagulant activity requires GPIb receptors and von Willebrand factor. Blood 93 (1999) 564-570.

4. E.M. Bevers, P. Comfurius, J.L. van Rijn, H.C. Hemker, R.F.A. Zwaal. Generation of prothrombin-converting activity and the exposure of phosphatidylserine at the outer surface of platelets. Eur. J. Biochem. 122 (1982) 429-436.

5. R.R. Hantgan, G. Hindriks, R.G. Taylor, J.J. Sixma, P.G. de Groot. Glycoprotein Ib, von Willebrand factor, and glycoprotein Ilb:Illa are all involved in platelet adhesion to fibrin in flowing whole blood. Blood 76 (1990) 345-353.

6. S.C. Endenburg, R.R. Hantgan, L. Lindeboom-Blokzijl. H. Lankhof, W.G. Jerome, J.C. Lewis, J.J. Sixma, P.G. de Groot. On the role of von Willebrand factor in promoting platelet adhesion to fibrin in flowing blood. Blood 86 (1995) 4158-4165.

7. B. Savage, S.J. Shattil, Z.M. Ruggeri. Modulation of platelet function through adhesion receptors. A dual role for glycoprotein IIb-IIla (integrin $\alpha_{410} \beta_{3}$ ) mediated by fibrinogen and glycoprotein Ib-von Willebrand factor. J. Biol. Chem. 267 (1992) 11300-11306.

8. Y. Zaffran, S.C. Meyer, E. Negrescu, K.B. Reddy, J.E.B. Fox. Signaling across the platelet adhesion receptor glycoprotein $\mathrm{Ib}-\mathrm{IX}$ induces $\alpha_{10} \beta_{3}$ activation both in platelets and a transfected Chinese hamster ovary cell system. J. Biol. Chem. 275 (2000) 16779-16787.

9. C.J. Jen, J.S. Lin. Direct observation of platelet adhesion to fibrinogen- and fibrin-coated surfaces. Am. J. Physiol. 261 (1991) H1457-1463. 
10. B. Savage, Z.M. Ruggeri. Selective recognition of adhesive sites in surface-bound fibrinogen by glycoprotein Ilb-Illa on nonactivated platelets. J. Biol. Chem. 266 (1991) 11227-11233.

11. D. Dörmann, K.J. Clemetson, B.E. Kehrel. The GPIb thrombin-binding site is essential for thrombin-induced platelet procoagulant activity. Blood 96 (2000) 2469-2478.

12. H. Andersen, D.L. Greenberg, K. Fujikawa, W.F. Xu, D.W. Chung, E.W. Davie. Proteaseactivated receptor 1 is the primary mediator of thrombin-stimulated platelet procoagulant activity. Proc. Natl. Acad. Sci. USA. 96 (1999) 11189-11193.

13. I. Salemink, J. Franssen, G.M. Willems, H.C. Hemker, T. Lindhout. Inhibition of tissue factorfactor Vlla-catalyzed factor $\mathrm{X}$ activation by factor $\mathrm{Xa-tissue}$ factor pathway inhibitor. A rotating disc study on the effect of phospholipid membrane composition. J. Biol. Chem. 274 (1999) 28225-28232.

14. N. Cauwenberghs, M. Meiring, S. Vauterin, V. van Wyk, S. Lamprecht, J.P. Roodt, L. Novák, J. Harsfalvi, H. Deckmyn, H. F. Kotzé. Antithrombotic effect of platelet glycoprotein Ib-blocking monoclonal antibody Fab fragments in nonhuman primates. Arterioscler. Thromb. Vasc. Biol. 20 (2000) 1347-1353.

15. H. Depraetere, N. Ajzenberg, J.P. Girma, C. Lacombe, D. Meyer, H. Deckmyn, D. Baruch. Platelet aggregation induced by a monoclonal antibody to the A1 domain of von Willebrand factor. (1998) 91 Blood 3792-3799.

16. B.S. Coller, K.M. Anderson, H.F. Weisman. The anti-GPIlb-llla agents: fundamental and clinical aspects. Haemostasis 26 (1996) Supplement 4 285-293.

17. P. Schoen, T. Lindhout, J. Franssen, H.C. Hemker. Low molecular weight heparin-catalyzed inactivation of factor $\mathrm{Xa}$ and thrombin by antithrombin III: effect of platelet factor 4 . Thromb. Haemost. 66 (1991) 435-441.

18. J.W.M. Heemskerk, W.M.J. Vuist, M.A.H. Feijge, C.P.M. Reutelingsperger, T. Lindhout. Collagen but not fibrinogen surfaces induce bleb formation, exposure of phosphatidylserine, and procoagulant activity of adherent platelets: Evidence for regulation by protein tyrosine kinase dependent $\mathrm{Ca}^{2+}$ responses. Blood 90 (1997) 2615-2625.

19. J.A. Remijn, J.J. Sixma, P.G. de Groot. Fibrin formation under conditions of flow results in fibrin fibers carried along by flow and deposited downstream to preabsorbed fibrinogen [Abstract]. Thromb. Haemost. Supplement August (1999) 41

20. D. Billy, J. Briedé, J.W.M. Heemskerk, H.C. Hemker, T. Lindhout. Prothrombin conversion under flow conditions by prothrombinase assembled on adherent platelets. Blood Coagul. Fibrinolysis 8 (1997) 168-174.

21. G. Grynkiewicz, M. Poenie, R.Y. Tsien. A new generation of $\mathrm{Ca}^{2+}$ indicators with greatly improved fluorescence properties. J. Biol. Chem. 260 (1985) 3440-3450.

22. R.F.A. Zwaal, P. Comfurius, E.M. Bevers. Lipid-protein interactions in blood coagulation. Biochim. Biophys. Acta 1376 (1998) 433-453.

23. R.R. Hantgan, R.G. Taylor, J.C. Lewis. Platelets interact with fibrin only after activation. Blood 65 (1985) 1299-1311. 
24. M.W. Sanders, C.M.A. Nieuwenhuys, M.A.H. Feijge, M. Rook, S. Béguin, J.W.M. Heemskerk. The procoagulant effect of thrombin on fibrin(ogen)-bound platelets. Haemostasis. 28 (1998) 289-300.

25. M. Jirouskova, J.E. Dyr, J. Suttnar, K. Holada, B. Tmkova. Platelet adhesion to fibrinogen, fibrin monomer, and fibrin protofibrils in flowing blood: the effect of fibrinogen immobilization and fibrin formation. Thromb. Haemost. 78 (1997) 1125-1131.

26. L. Yap, S.C. Hughan, S.L. Cranmer, W.S. Nesbitt, M.M. Rooney, S. Giuliano, S. Kulkami, S.M. Dopheide, Y. Yuan, H.H. Salem, S.P. Jackson. Synergistic adhesive interactions and signaling mechanisms operating between platelet glycoprotein $\mathrm{lb} / \mathrm{IX}$ and integrin $\alpha_{40} \beta_{3}$. Studies in human platelets and transfected Chinese hamster ovary cells. J. Biol. Chem. 275 (2000) 41377-41388.

27. J.C. Reverter, S. Béguin, H. Kessels, R. Kumar, H.C. Hemker, B.S. Coller. Inhibition of plateletmediated, tissue factor-induced thrombin generation by the mouse/human chimeric 7E3 antibody. Potential implications for the effect of c7E3 Fab treatment on acute thrombosis and "clinical restenosis". J. Clin. Invest. 98 (1996) 863-874.

28. I.M.L.W. Keularts, S. Béguin, C. de Zwaan, H.C. Hemker. Treatment with a GPIlb/lla antagonist inhibits thrombin generation in platelet rich plasma from patients. Thromb. Haemost. 80 (1998) 370-371.

29. G. Dangas, A. Colombo. Platelet glycoprotein IIb/llla antagonists in percutaneous coronary revascularization. Am. Heart. J. 138 (1999) S16-23.

30. M.I. Furman, L.A. Krueger, A.L. Frelinger, M.R. Barnard, M.A. Mascelli, M.T. Nakada, A.D. Michelson. GPIIb-IIla antagonist-induced reduction in platelet surface factor V/Na binding and phosphatidylserine expression in whole blood. Thromb. Haemost. 84 (2000) 492-498.

31. F. Basse, J.G. Stout, P.J. Sims, T. Wiedmer. Isolation of an erythrocyte membrane protein that mediates $\mathrm{Ca}^{2 *}$-dependent transbilayer movement of phospholipid. J. Biol. Chem. 271 (1996) 17205-17210.

32. J.A. Rosado, E.M.Y Meijer, K. Hamulyak, I. Novakova, J.W.M. Heemskerk, S.O. Sage. Fibrinogen binding to the integrin $\alpha_{110} \beta_{3}$ modulates store-mediated calcium entry in human platelets. Blood In press. 
Chapter 6

General Discussion and Concluding Remarks 


\section{Thrombus formation: a complicated interplay between platelet reactions and activation of coagulation factors}

Thrombus formation on a damaged vessel wall is a complex process that starts with platelet-vessel wall interactions, followed by platelet-platelet interactions, platelet activation reactions and simultaneously occurring enzymatic reactions between plasma coagulation factors. The complexity of the process is further increased by the fact that all reactions take place at the interface between flowing blood and the developing thrombus at the vessel wall. Thrombus formation and embolization are therefore strongly influenced by blood flow: both processes are controlled by sheardependent cell-cell interactions and transport-limited kinetics of the enzymatic coagulation reactions at the catalytic platelet surface.

The aforementioned principles underlying thrombus formation has been the subject of imperative research. Initially, blood platelets and the coagulation system were studied separately as being two individual players in the thrombotic response to vessel wall injury. This resulted in a model in which the process was thought to proceed in two separate stages. During the first stage adhesion and aggregation of platelets takes place resulting in the fast arrest of blood loss. The formation of this primary haemostatic plug then induces a cascade of plasma protein reactions that ultimately results in the formation of the serine protease thrombin, which in turn converts the plasma protein fibrinogen into a network of fibrin strands that stabilizes the primary platelet plug.

Although the role of platelets in accelerating thrombin generation is already known for many decades, the mechanisms that turn resting platelets into procoagulant platelets still remain to be fully elucidated. Important progress was made when it was discovered that resting platelets could loose their asymmetric distribution of plasma membrane phospholipids and that especially the exposure of anionic phospholipids (PS) in the outer leaflet of the platelet plasma membrane correlated with a markedly enhanced thrombin generation (1). Thrombin in combination with collagen was found to be one of the strongest physiological relevant activators of the platelet membrane scrambling process. For the first time it could be postulated that adhesion of platelets to an extracellular matrix protein was not only important for the formation of a primary plug but also a pre-requisite for the formation of a catalytic platelet surface that supports thrombin formation. The role of platelet-platelet as well as platelet-matrix protein interactions in thrombin generation became even more evident when it was reported that platelet integrin receptor (GP Ilbllla) antagonists like abciximab (2) and vWf-GP Ib interaction (3) may also interfere with the exposure of procoagulant phospholipids by platelets. 


\section{Working hypothesis}

From the aforementioned investigations the picture emerge in which adhesion of (single) platelets to a damaged vessel wall induces the generation of highly reactive platelets. In these adherent platelets activated integrins are expressed that provide the focal points for platelet-platelet contacts and the phospholipid membrane (partially) looses its asymmetric phospholipid distribution, which in turn stimulates thrombin generation. It is therefore of interest to note that the antithrombotic action of the so-called anti-platelet drugs could also, if not primarily, be attributed to their anticoagulant effect. To test this hypothesis, further investigations on the adhesioninduced procoagulant response of platelets is needed. In particular, experiments with single adherent platelets under defined flow and reaction conditions, rather than using platelet suspensions in an undefined plasma milieu, have to be performed to find the conditions under which platelet adhesion leads to exposure of procoagulant phospholipids and by which mechanism. Once these answers are found, suggestions can be made for therapeutic interventions.

\section{Are fibrinogen- and collagen-adherent platelets procoagulant?}

The first objective of this study was to establish a reliable and reproducible method to visualize PS exposure on adherent platelets and to use such a surface in a kinetic study to analyze platelet-dependent thrombin generation under well-defined flow conditions (chapter 2 and 3). Resting platelets readily adhere to immobilized fibrinogen in the absence of extracellular calcium (chapter 2). Their heterogeneous morphologic appearance, ranging from a dendritic non-spread to fully spread shape, suggests different states of activation. However, the intracellular free calcium concentration $\left(\left[\mathrm{Ca}^{2+}\right]_{1}\right)$ remained as low as that of resting platelets. The question whether these platelets had exposed PS is somewhat difficult to answer. Binding of annexin $\mathrm{V}$ requires calcium and extracellular calcium induces platelet activation as could be inferred from a further morphological change and appearance of PS in a small (about $1 \%$ of all adherent platelets) population of fibrinogen-adherent platelets. To avoid influx of extracellular calcium econazole was used. The voltage-independent calcium channel blocker econazole inhibits capacitative calcium influx. In the presence of econazole and extracellular calcium none of the fibrinogen adherent platelets exposed PS. Thus, PS exposure in adherent platelets is mediated by elevated $\left[\mathrm{Ca}^{2+}\right]$, and for this elevation of $\left[\mathrm{Ca}^{2+}\right]$, the influx of extracellular calcium is necessary. These findings confirm an earlier report on platelets in suspension (4). The pathway by which elevation of $\left[\mathrm{Ca}^{2+}\right]$, causes PS exposure seems to be mediated by at least two mechanisms. Increased $\left[\mathrm{Ca}^{2+}\right]$, activates a protein called scramblase that accelerates the bidirectional movement of all phospholipids and elevated $\left[\mathrm{Ca}^{2+}\right]$, results in the inactivation of the aminophospholipid translocase activity thus preventing PS from being transported back to the inner leaflet of the membrane (5). 
But elevated $\left[\mathrm{Ca}^{2+}\right]$, will also activate the protease calpain that results in degradation of the membrane associated cytoskeletal proteins. The altered association of the proteolyzed membrane proteins with the plasma membrane facilitates platelet morphological changes like microvesiculation (6). We could demonstrate that calpain is involved in the generation of microparticles from adherent platelets, but not in PS exposure (chapter 2).

In contrast with fibrinogen-adherent platelets, platelets that adhere to immobilized collagen type I all expose PS in the presence of extracellular calcium (chapter 3). In addition, collagen-adherent platelets as well as ionomycin-activated fibrinogen-adherent platelets showed a balloon-like shape. In contrast, collagenactivated platelets in suspension showed a less pronounced procoagulant response compared to ionomycin-activated platelets $(1,7)$. Concomitantly with PS exposure, in these balloon-shaped platelets a marked increase of $700 \mathrm{nM}$ in $\left[\mathrm{Ca}^{2+}\right]$, was observed (chapter 2). Confocal microscopy showed a patch-like distribution of annexin $\mathrm{V}$ bound to the plasma membrane of these ionomycin-activated fibrinogen-adherent platelets, suggesting that PS is more or less patch-like distributed probably as a result of a lateral heterogeneous distribution of the molecules in the plasma membrane.

The marked difference in procoagulant response between fibrinogen- and collagen-adherent platelets is most likely the result of different signaling mechanisms via different platelet receptors. The adhesion of platelets to immobilized fibrinogen is mediated by the GP IIbllla receptor. Binding of fibrinogen to this receptor will induce outside-in signaling that results in platelet spreading, but not in PS exposure. The binding of platelets to collagen is via the GP lalla receptor and GP VI receptor. Signaling from the latter induces inside-out signaling resulting in extracellular calcium influx that finally leads to exposure of PS in the outer leaflet of the platelet plasma membrane (8).

\section{How relates PS exposure to the extent of thrombin generation at the surfaces of fibrinogen and collagen-adherent platelets under flow conditions?}

The question could then be addressed whether different PS surface densities, as observed for fibrinogen- and collagen-adherent platelets, have consequences for the kinetics of thrombin generation at such surfaces. In the presence of plasma-derived factor Va thrombin generation at the surface of fibrinogen-adherent platelets did not differ from that at the surface of collagen-adherent platelets in spite of the fact that in the former case less than $1 \%$ of the platelet had exposed PS. However, in the absence of plasma-derived factor $\mathrm{Va}$, the initial rate of thrombin generation was markedly reduced when compared to that in the presence of collagen-adherent platelets. In both cases thrombin generation was completely blocked by a polyclonal antibody that neutralized factor $\mathrm{Va}$ activity. The following conclusions can be drawn from these findings. PS is not a rate-limiting factor when saturating amounts of factor $\mathrm{Va}$ are available. Thus factor $\mathrm{Va}$ plays a critical role in thrombin generation. 
Moreover, collagen-adherent platelets express such amounts of platelet factor $\mathrm{Va}$ that thrombin generation at the surface of these platelets becomes independent of plasma-derived factor $\mathrm{Va}$. Platelet factor $\mathrm{V}$ is localized in the $\alpha$-granula which content is released after platelet activation and it is activated by thrombin into a protein that is electrophoretically indistinguishable from plasma factor Va (9). In contrast to this platelet factor $V$ activation, we found that in situ generated thrombin hardly influenced the number of fibrinogen-adherent platelets exposing PS. Thus generated thrombin is able to release and subsequently activate platelet factor $\mathrm{V}$, but thrombin alone is hardly capable to expose PS in platelets. This observation is further explored in the chapter that describes the role of fibrin and fibrin-bound vWf in PS exposure on the surface of adherent platelets.

Our findings also seem to contrast notions that functional prothrombinase assembled on platelets consists of other membrane components than PS. (platelet) factor Va, calcium and prothrombin. In particular, although we showed the presence of EPR-1 on collagen-adherent and thrombin-activated fibrinogen-adherent platelets. we could not demonstrate that EPR-1 was involved in prothrombinase assembly. Moreover, although it was postulated (10), a role for EPR-1 in factor Xa-induced cell signaling in various cell types was excluded $(11,12)$. In combination with the conclusion that EPR-1 is a unique property of specific cell lines only or that its published gene sequence is probably mixed up with that of survivin (13), makes the functional role of EPR-1 as a factor Xa receptor rather elusive.

Another important observation made in chapter 3 is that at a certain moment during thrombin generation a steady state rate of thrombin production is established. Similar steady state rates of thrombin production were observed on fibrinogen- and collagen-adherent platelets. Because the steady-state rate increased linearly with the prothrombin concentration, this steady-state thrombin production is a consequence of a transport-limited situation. That is, at a certain prothrombinase density, prothrombin will become depleted near the platelet surface in such a way that the amount of thrombin formed is limited by the transport rate of prothrombin towards the plateletbound prothrombinase complex. Thus, thrombin generation at the surfaces of adherent platelets (growing thrombus) will be highly dependent on the local blood flow rate.

\section{Does APC inhibit platelet-associated thrombin generation?}

The critical role platelet factor $\mathrm{Va}$ in prothrombinase assembly and thus thrombin generation on a surface of adherent platelets makes it an important target for the regulation of platelet associated thrombin generation. To study the inactivation of prothrombinase activity at the surface of adherent platelets we used a technique that allowed us to use well-defined conditions with respect to flow and transport of proteins towards or from the catalytic platelet surface, namely the rotating disc. Compared to the flow reactor, the uniformly accessibly surface of the rotating disc makes 
calculations concerning the transport of proteins towards or from the surfaces more easily. The $K_{m}$ value for prothrombin activation at the surface on collagen-adherent platelets was found to be $14 \mathrm{nM}$ (chapter 4). Importantly, this value is comparable with the values found on planar procoagulant phospholipid surfaces on a rotating disc (14).

Ongoing thrombin generation on the surface of collagen-adherent platelets was completely inhibited by activated protein C (APC). Platelet factor Va-dependent prothrombinase activity decayed in a mono-exponential way with a second order rate constant of inhibition that resembles that of prothrombinase assembled on a planar surface of synthetic procoagulant phospholipids. This finding contrasts that of other reports demonstrating that on the surface of thrombin-activated platelets, platelet- and plasma-derived factor $\mathrm{Va}$ is partially protected from inactivation (15). We note however that whereas our experiments were performed with collagen-adherent platelets that all have exposed PS, Camire et al (16) used a suspension of thrombin activated platelets. In view of the stimulating role that negatively charged phospholipids play in the kinetics of inactivation of factor Va by APC and the fact that thrombin activated platelets have a much less pronounced exposure of PS, we reasoned that the conflicting findings can be possibly explained by the differences in availability for catalytic surfaces. It must however be emphasized that results from experiments with platelet suspensions are not in line with our suggestion. It was shown that at the surface of thrombin-activated platelets in suspension plasmaderived factor Va was completely inactivated (16). Secondly, measuring activated partial thromboplastin times (APTT) others have shown (17) that there is a positive correlation between the concentration of platelet activator used and APC resistance. Moreover, platelet-dependent APC resistance increased using the platelet activators TRAP, collagen or ionomycin respectively, that also in this order stimulate the exposure of increasing amounts of negatively charged phospholipids (17). These authors speculated that platelets release a factor Va molecule with an APC-resistant phenotype or that platelets provide a membrane surface that delays inactivation by APC. It is apparent that for unknown reasons collagen-adherent platelets and thrombin-activated platelets in suspension show different APC-dependent inactivation profiles.

\section{A novel role for fibrin in the developing thrombus?}

At the site of an injured vessel wall, platelets initially adhere to subendothelial matrix proteins (i.e. collagen). At the same time tissue factor becomes exposed to blood and coagulation is started resulting in thrombin generation and deposition of fibrin strands. Fibrin-bound thrombin is capable to activate the coagulation factors V and VIII (18) and is thought to induce platelet procoagulant activity (19). In fibrin formation activated factor XIII functions to covalently crosslink fibrin. Moreover, it also crosslinks several plasma proteins to fibrin, like fibronectin and $\alpha$-2-plasmin inhibitor 
(20). Altogether it suggests that fibrin formation at the surface of a developing thrombus is critical to its growth.

To explore the role of fibrin in thrombus formation we first further developed a method (21), to form a layer of fibrin from flowing plasma. This fibrin layer is probably more physiological than fibrin made of mixing purified fibrinogen and thrombin (2225). Using this more or less native fibrin layer in a flow chamber we observed under low shear conditions that platelets have to be activated by thrombin to adhere, suggesting that GP IIbllla must be activated for this interaction. In this respect adhesion of platelets to fibrin differs from adhesion to immobilized fibrinogen. In spite of an increase in extracellular calcium in these thrombin-activated platelets exposure of PS was negligible. Thus, thrombin-activated platelets that adhere to fibrin via GP IIbIlla are not procoagulant. Neither are unstimulated platelets that adhere via vWf under high shear conditions. However, in contrast to immobilized fibrinogen and fibrin-bound platelets, vWf-mediated fibrin-bound-platelets do expose PS when incubated with a nanomolar concentration of thrombin. The notion that vWf-GP Ib interactions are involved in generating procoagulant platelets was supported by the results of experiments at a low shear rate in the presence of botrocetin. That GPIb is probably the only platelet receptor involved in this process is supported by the finding that PAR1 agonist SFLLRN was unable to mimic the effect of thrombin, thus indicating that the thrombin-induced PS exposure is not mediated by the thrombin receptor PAR1. Presently the mechanism by which the combined action of fibrinbound $v W f$ and thrombin induces the scrambling of the platelet membrane remains to be clarified. Collectively, our data suggest a number of clues. PS exposure is always associated with a strong and sustained increase in cytosolic calcium concentration (between 0.5 and $1.0 \mu \mathrm{M}$ ). Adhesion alone, even in case of thrombin-activated platelets under low shear rate conditions, does not sufficiently increase this intracellular calcium. Only when platelets adhere via vWf (botrocetin- or shearinduced) thrombin treatment results in sufficiently high intracellular calcium concentrations. Interestingly, it was recently suggested that the interaction between fibrinogen and platelet GP IIbllla down regulates the calcium response of these adherent platelets (26). In view of the synergistic role of fibrin-bound $\mathrm{VWf}$ and thrombin in PS exposure and increase in intracellular calcium, it is tempting to speculate that the calcium response is not down regulated when platelets adhere via vWf.

\section{Implications for understanding thrombosis and antithrombotic therapy.}

It is generally believed that in the onset of venous thrombosis the coagulation plays a crucial role, while in the onset of arterial thrombosis platelets are important (27). This reductionistic approach of the problem is clearly an oversimplification. Thrombus formation is a complex mechanism in which blood flow, platelet-vessel wall interactions, platelet-platelet interactions, platelet activation reactions and the pro- 
and anticoagulant reactions are intimately intertwined. It is apparent that aggregating platelets and fibrin form the main determinants in the formation of an obstructing thrombotic plug. The question then emerges which type of anticoagulant therapy will be the most beneficial in preventing thrombosis: an anti-platelet or an anti-thrombin therapy or a combination of both? On basis of the notion that the process of a developing thrombus, initiated after vessel wall damage or upon plaque rupture, encompasses the concerted action of both platelets and thrombin, it is evident that blocking one of these determinants will offer the possibility to successfully interfere with the process of ongoing thrombus formation. Anti-platelet drugs interfere at the level of platelet adhesion but most interestingly may also inhibit the conversion of platelets into catalytic surfaces. To what extent the (indirect) anti-thrombin activity of these drugs contributes to their antithrombotic activity is unknown. But it is becoming increasingly apparent that an effective antithrombotic therapy is achieved when the so-called anti-platelet drugs are combined with (direct) factor $\mathrm{Xa}$ and thrombin inhibitors that, unlike antithrombin-heparin, block the activity of factor $\mathrm{Xa}$ and thrombin bound to fibrin.

\section{References}

1. E.M. Bevers, P. Comfurius, J.L. van Rijn, H.C. Hemker, R.F.A. Zwaal. Generation of prothrombin-converting activity and the exposure of phosphatidylserine at the outer surface of platelets. Eur. J. Biochem. 122 (1982) 429-436.

2. M.I. Furman, L.A. Krueger, A.L. Frelinger, M.R. Barnard, M.A. Mascelli, M.T. Nakada, A.D. Michelson. GPIIb-IIla antagonist-induced reduction in platelet surface factor V/Na binding and phosphatidylserine expression in whole blood. Thromb. Haemost. 84 (2000) 492-498.

3. S. Béguin, R. Kumar, I. Keularts, U. Seligsohn, B.S. Coller, H.C. Hemker. Fibrin-dependent platelet procoagulant activity requires GPIb receptors and von Willebrand factor. Blood 93 (1999) 564-570.

4. J. Dachary-Prigent, J.M. Pasquet, J.M. Freyssinet, A.T. Nurden. Calcium involvement in aminophospholipid exposure and microparticle formation during platelet activation: a study using $\mathrm{Ca}^{2+}$-ATPase inhibitors. Biochemistry 34 (1995) 11625-11634.

5. R.F.A. Zwaal, A.J. Schroit. Pathophysiologic implications of membrane phospholipid asymmetry in blood cells. Blood 89 (1997) 1121-1132.

6. F. Bassé, P. Gaffet, A. Bienvenue. Correlation between inhibition of cytoskeleton proteolysis and anti-vesiculation effect of calpeptin during A23187-induced activation of human platelets: are vesicles shed by filopod fragmentation? Biochim. Biophys. Acta 1190 (1994) 217-224

7. H. Andersen, D.L. Greenberg. K. Fujikawa, W.F. Xu, D.W. Chung. E.W. Davie. Proteaseactivated receptor 1 is the primary mediator of thrombin-stimulated platelet procoagulant activity. Proc. Natl. Acad. Sci. USA 96 (1999) 11189-11193.

8. J.W.M. Heemskerk, P. Siljander, W.M.J. Vuist, G. Breikers, C.P.M. Reutelingsperger, M.J. Barnes, C.G. Knight, R. Lassila, R.W. Farndale. Function of glycoprotein VI and integrin $\alpha_{2} \beta$, in 
the procoagulant response of single, collagen-adherent platelets. Thromb. Haemost. 81 (1999) 782-792.

9. D.D. Monkovic, P.B. Tracy. Functional characterization of human platelet-released factor V and its activation by factor Xa and thrombin. J. Biol. Chem. 265 (1990) 17132-17140.

10. G. Ambrosini, D.C. Altieri. Molecular dissection of effector cell protease receptor-1 recognition of factor Xa. Assignment of critical residues involved in antibody reactivity and ligand binding. J. Biol. Chem. 271 (1996) 1243-1248.

11. N.H.M. Senden, T.M.A.A. Jeunhomme, J.W.M. Heemskerk, R. Wagenvoord, C. van 't Veer, H.C. Hemker, W.A. Buurman. Factor $\mathrm{Xa}$ induces cytokine production and expression of adhesion molecules by human umbilical vein endothelial cells. J. Immunol. 161 (1998) 4318 4324.

12. E. Camerer, J.A. Rottingen, E. Gjernes, K. Larsen, A.H. Skartlien, J.G. Iversen, H. Prydz. Coagulation factors VIla and Xa induce cell signaling leading to up-regulation of the egr-1 gene. J. Biol. Chem. 274 (1999) 32225-32233.

13. G.J.R. Zaman, E.M. Conway. The elusive factor Xa receptor: failure to detect transcripts that correspond to the published sequence of EPR-1. Blood 96 (2000) 145-148.

14. G.M. Willems, P.L. Giesen, W.T. Hermens. Adsorption and conversion of prothrombin on a rotating disc. Blood 82 (1993) 497-504.

15. R.M. Camire, E.S. Pollak, K. Kaushansky, P.B. Tracy. Secretable human platelet-derived factor $\checkmark$ originates from the plasma pool. Blood 92 (1998) 3035-3041.

16. R.M. Camire, M. Kalafatis, P. Simioni, A. Girolami, P.B. Tracy. Platelet-derived factor $\mathrm{Va} / \mathrm{Va}$ (Leiden) cofactor activities are sustained on the surface of activated platelets despite the presence of activated protein C. Blood 91 (1998) 2818-2829.

17. J. Taube, N. McWilliam, R. Luddington, C.D. Byrne, T. Baglin. Activated protein C resistance: effect of platelet activation, platelet-derived microparticles, and atherogenic lipoproteins. Blood 93 (1999) 3792-3797.

18. R. Kumar, S. Béguin, H.C. Hemker. The influence of fibrinogen and fibrin on thrombin generation--evidence for feedback activation of the clotting system by clot bound thrombin. Thromb. Haemost. 72 (1994) 713-721.

19. R. Kumar, S. Béguin, H.C. Hemker. The effect of fibrin clots and clot-bound thrombin on the development of platelet procoagulant activity. Thromb. Haemost. 74 (1995) 962-968.

20. P.G. Board, M.S. Losowsky, K.J. Miloszewski. Factor XIII: inherited and acquired deficiency. Blood Rev. 7 (1993) 229-242.

21. J.A. Remijn, J.J. Sixma, P.G. de Groot. Fibrin formation under conditions of flow results in fibrin fibers carried along by flow and deposited downstream to preabsorbed fibrinogen. Thromb. Haemost. supplement August 1999 (Abstract) 41.

22. C.J. Jen, J.S. Lin. Direct observation of platelet adhesion to fibrinogen- and fibrin-coated surfaces. Am. J. Physiol. 261 (1991) H1457-1463.

23. S.C. Endenburg, R.R. Hantgan, L. Lindeboom Blokzijl, H. Lankhof, W.G. Jerome, J.C. Lewis, J.J. Sixma, P.G. de Groot. On the role of von Willebrand factor in promoting platelet adhesion to fibrin in flowing blood. Blood 86 (1995) 4158-4165. 


\section{Chapter 6}

24. M. Jirouskova, J.E. Dyr, J. Suttnar, K. Holada, B. Tmkova. Platelet adhesion to fibrinogen, fibrin monomer, and fibrin protofibrils in flowing blood: the effect of fibrinogen immobilization and fibrin formation. Thromb. Haemost. 78 (1997) 1125-1131.

25. M.W. Sanders, C.M.A. Nieuwenhuys, M.A.H. Feijge, M. Rook, S. Béguin, J.W.M. Heemskerk. The procoagulant effect of thrombin on fibrin(ogen)-bound platelets. Haemostasis 28 (1998) 289-300.

26. J.A. Rosado, E.M.Y. Meijer, K. Hamulyak, I. Novaka, J.W.M. Heemskerk, S.O. Sage Fibrinogen binding to the integrin $\alpha_{110} \beta_{3}$ modulates store-mediated calcium entry in human platelets. Blood 2001 (In press).

27. S. Goto, S. Handa. Coronary thrombosis. Effects of blood flow on the mechanism of thrombus formation. Jpn. Heart J. 39 (1998) 579-596. 
Chapter 7

Nederlandse Samenvatting 


\section{Inleiding: De bloedstolling en de rol van bloedplaatjes}

Bij mensen circuleert het bloed in een gesloten systeem van bloedvaten om zo de weefsels en organen te voorzien van voedingsstoffen en om de gevormde afvalstoffen weer weg te voeren. Bloed kan worden onderverdeeld in twee fracties: Een cellulaire fractie bevattende de verschillende bloedcellen en een plasmafractie waarin zich onder andere de oplosbare eiwitten bevinden. De cellulaire fractie bestaat uit drie verschillende type cellen, namelijk de rode cellen (erythrocyten), die verantwoordelijk zijn voor het zuurstoftransport, de witte cellen (leukocyten), die een belangrijke rol spelen in de afweerreaktie. Wanneer een bloedvat beschadigt raakt dan spelen de bloedplaatjes (trombocyten), eigenlijk celfragmenten zonder kern, een hoofdrol in het proces dat optreedt na lekkage van het bloedvatstelsel: De bloedstolling. Het stollen van bloed is een nauw gereguleerd en gelokaliseerd proces waarin de bloedplaatjes en bloedeiwitten nauw samenwerken om zo de stolling te beperken tot de plaats van lekkage.

De bloedstolling wordt in gang gezet als door beschadiging de laag van endotheelcellen, die de binnenbekleding van de bloedvaten vormen, verdwijnen en het onderliggende subendotheel aan het bloed wordt blootgesteld. Bloedplaatjes bezitten op hun plasmamembraan allerlei specifieke receptoren die interacties aangaan met de verschillende matrixeiwitten die zich in subendotheliale laag bevinden. De adhesie van bloedplaatjes aan matrixeiwitten als bijvoorbeeld von Willebrand factor (vWf) en collageen heeft als gevolg dat de plaatjes geactiveerd worden. Andere bloedplaatjes zullen vastplakken aan deze initieel geadhereerde en geactiveerde bloedplaatjes, zodat een plaatjesaggregaat (de primaire hemostatische plug) wordt gevormd. Bij dit plakken van bloedplaatjes functioneren plasma-eiwitten zoals vWf en fibrinogeen als de plakeiwitten in plaatjesaggregatie.

Ook wordt op de plek van vaatwandbeschadiging een reeks enzymatische reakties, de stollingscascade, in gang gezet met het ultieme doel de omzetting van oplosbaar fibrinogeen in een polymeer netwerk van fibrinedraden dat de primaire hemostatische plug verder verstevigd. De reeks aan enzymreacties die plaatsvinden in de stollingscascade hebben een aantal gemeenschappelijke kenmerken. Zo wordt telkens een celmembraan-geassocieerd complex gevormd bestaande uit een serine protease samen met zijn cofactor. Zowel enzym als cofactor komen in niet-actieve vorm voor en dienen geactiveerd te worden, waarbij het complex zorgdraagt voor de activering van het enzym dat betrokken is bij de volgende stap in de reeks van enzymreacties. Enkel indien het enzym zich bevindt in een membraan-gebonden complex met zijn cofactor leidt dit tot efficiënte en ook gelocaliseerde activering van zijn substraat.

De stollingscascade begint als weefsel factor (tissue factor, TF) dat zich onder andere in de vaatwand bevindt, wordt blootgesteld aan het voorbijstromende bloed. 
Binding van het niet actieve plasma-eiwit factor VII aan TF heeft tot gevolg dat deze geactiveerd wordt tot de serine protease factor VIla. Dit TF:factor VIla complex activeert factor X en factor IX. Factor IXa in complex met de cofactor factor VIIIa (het tenase complex) activeert eveneens factor $\mathrm{X}$. Factor $\mathrm{Xa}$ vormt op zijn beurt een complex met zijn cofactor factor Va (het protrombinase complex). Dit protrombinase complex zet protrombine om in trombine. Eén van de belangrijkste activiteiten van dit centrale enzym in de bloedstolling is dat het fibrinogeen omzet in fibrinedraden. Daarnaast kan trombine binden aan verschillende receptoren op het plasmamembraan van bloedplaatjes en deze activeren.

Om de vorming van trombine te reguleren spelen een aantal trombine-activiteit en trombine-vorming remmende enzymen een belangrijke rol. Zo activeert trombine zelf het protein C systeem. Geactiveerd protein C (APC) samen met de cofactor protein S vormt ook een membraan-geassocieerd complex dat in staat is via gelimiteerde proteolyse van de cofactoren VIIla en Va de verdere vorming van trombine af te remmen.

Het plasmamembraan van geactiveerde bloedplaatjes functioneert als platform voor de assemblage van de bij de bloedstolling betrokken enzymcomplexen en zo hun werking optimaliseerd en lokaliseerd. Met name als dit membraan de asymmetrische verdeling van fosfolipiden over binnenste en buitenste laag verliest en het negatief geladen fosfolipid fosfatidylserine (PS) verschijnt in de buitenste monolaag. Voor het in dit proefschrift beschreven onderzoek is gebruik gemaakt van de eigenschap van het eiwit annexine $V$ dat specifiek bindt aan PS-exposerende membranen.

\section{Doel van het onderzoek}

Het doel van de studies beschreven in dit proefschrift was het bestuderen van de regulatie van trombinevorming aan het oppervlak van geadhereerde bloedplaatjes onder goed gedefinieerde stromingscondities. Daarvoor is gebruik gemaakt van de binding van bloedplaatjes aan geïmmobiliseerde eiwitten in de afwezigheid van andere bloedcellen en plasma-eiwitten, zodat ook de invloed van de matrixeiwitten zelf en plasma-eiwitten op de de activering van bloedplaatjes, het verlies van de fosfolipiden-asymmetrie en de regulatie van trombinevorming onderzocht konden worden. 


\section{Procoagulante respons van fibrinogeen- en collageen geadhereerde bloedplaatjes}

In hoofdstuk 2 zijn de gevolgen van de adhesie van bloedplaatjes aan geïmmobiliseerd fibrinogeen beschreven, toegespitst op de veranderingen in morfologie en inclusief de vorming van microvesicles, de relatie met calciumgeïnduceerde plaatjesactivatie en PS-expositie. Niet-geactiveerde bloedplaatjes in de afwezigheid van extracellulair calcium adheren aan geïmmobiliseerd fibrinogeen. $\mathrm{Er}$ konden twee morfologisch verschillende populaties van geadhereerde bloedplaatjes worden onderscheiden; waar namelijk de meerderheid volledig gespreid was, bleef ongeveer $10 \%$ in een niet-gespreide, dendritische vorm. De cytosolische calcium concentratie $\left(\left[\mathrm{Ca}^{2+}\right]_{1}\right)$ in de geadhereerde bloedplaatjes was even laag als die van niet-geactiveerde bloedplaatjes $(50 \mathrm{nmol} / \mathrm{l})$. Omdat voor de binding van annexine $\mathrm{V}$ de aanwezigheid van extracellulair calcium vereist is, is de vraag of fibrinogeengebonden bloedplaatjes PS exposeren in afwezigheid van extracellular calcium beantwoord door proeven te doen met de calcium-influx blokker econazole. Dit leerde ons dat geen van deze bloedplaatjes PS exposeerden. Echter in aanwezigheid van extracellulair calcium exposeerden $1 \%$ van de geadhereerde bloedplaatjes PS, gemedieerd door extracellulaire calcium influx en samengaand met de vorming van microvesicles. Versnelling van de calcium influx en PS expositie via een ionomycine behandeling leidde in dendritische plaatjes tot een verandering in een ballonvormige morfologie met een diameter van $2.0 \pm 0.7 \mu \mathrm{m}$ maar zonder verdere microvesicle formatie. In gespreide plaatjes leidde deze behandeling wel tot microvesicle formatie. Via inhibitie van de calpaïne activiteit werd duidelijk dat een destruktie van het cytoskelet betrokken is bij de verandering in de ballonvormige morfologie en microvesicle formatie maar niet bij PS expositie. De plaatjes met een ballonvormige morfologie vertoonden een sterk heterogene verdeling van de annexine $\mathrm{V}$ bindingsplaatsen. Niet-geactiveerde bloedplaatjes in afwezigheid van extracellulair calcium binden ook aan geïmmobiliseerd collageen (hoofdstuk 3). Echter nu leidt de toevoeging van extracellulair calcium direkt tot de verandering in de ballonvormige morfologie en het verschijnen van PS in de buitenste laag van het plasmamembraan. De verschillen in PS expositie van geïmmobiliseerd fibrinogeen- en collageengebonden plaatjes is een gevolg van de verschillende signaaltransduktie opgewekt door de binding van adhesie receptoren aan hun verschillende liganden. Binding van GP IIbIlla aan geïmmobiliseerd fibrinogeen leidt tot spreiding, maar niet tot PS expositie. Bloedplaatjes binden aan geïmmobiliseerd collageen via de GP lalla en GP VI receptor en resulteert in het verschijnen van PS in de buitenste laag van het plasmamembraan. 


\section{Relatie tussen PS expositie en trombinegeneratie aan het oppervlak van fibrinogeen- en collageen-geadhereerde plaatjes onder stromingscondities}

In hoofdstuk 3 zijn de verschillen in trombinegeneratie aan het oppervlak tussen fibrinogeen- en collageen-geadhereerde plaatjes onder stromingscondities onderzocht. De perfusie van fibrinogeen- of collageen-gebonden bloedplaatjes met factor Xa en protrombine resulteerde in trombinegeneratie die 1) lineair toeneemt gedurende de eerste perfusie minuten en 2) deze lineaire toename was ongeveer twee maal keer sneller op collageen-geadhereerde plaatjes vergeleken met fibrinogeen-geadhereerde bloedplaatjes en 3) vond voor meer dan $98 \%$ plaats aan het oppervlak van geadhereerde plaatjes. De lagere trombinegenererende capaciteit van fibrinogeen-gebonden plaatjes is niet zozeer het gevolg van de lagere PSdichtheid, maar door een lagere concentratie van plaatjes gebonden factor $\mathrm{Va}$. Trombinegeneratie kan namelijk volledig geremd worden door antilichamen gericht tegen humaan factor $\mathrm{Va}$ en in aanwezigheid van een overmaat plasma factor $\mathrm{Va}$ werden gelijke initiële snelheden van trombinevorming gevonden op collageen- en fibrinogeen-gebonden bloedplaatjes. PS is dus geen snelheids-limiterende factor als een verzadigde hoeveelheid factor $V a$ aanwezig is. En collageen-gebonden bloedplaatjes expresseren dus zoveel plaatjes factor $\mathrm{Va}$ dat trombinegeneratie aan het oppervlak van deze plaatjes onafhankelijk is van de aanwezigeid van plasma factor Va. Ook werd gevonden dat trombine alleen nauwelijks in staat is PS expositie te induceren, een observatie die verder uitgewerkt is in hoofdstuk 5.

Verder kan uit hoofdstuk 3 worden geconcludeerd dat het functionele protrombinase complex geassembleerd op het oppervlak van bloedplaatjes uit niet meer componenten bestaat dan PS, (plaatjes) factor Va, calcium en protrombine. Ondanks dat de aanwezigheid van de factor Xa receptor EPR-1 op het oppervlak van collageen-gebonden en trombine-geactiveerde fibrinogeen-gebonden plaatjes kon worden aangetoond, speelde deze receptor geen rol in de assemblage van het functionele protrombinase complex. Een andere belangrijke observatie in hoofdstuk 3 is dat bij een zekere protrombinase dichtheid een transport-gelimiteerde situatie ontstaat. De vorming van trombine wordt dan gelimiteerd door het transport van protrombine naar het plaatjes-gebonden protrombinase complex.

\section{Remming van bloedplaatjes-geassocieerde trombinegeneratie door APC}

In hoofdstuk 4 is de kinetiek van plaatjes factor Va-gemedieerde protrombinase activiteit en de remming hiervan door APC aan het opervlak van collageengeadhereerde bloedplaatjes onder stromingscondities bestudeerd. De studie is uitgevoerd op collageen-geadhereerde bloedplaatjes aanwezig op een roterende 
schijf, maar in afwezigheid van microvesicles. Onder deze omstandigheden werd vastgesteld dat voor het protrombinase complex de hoeveelheid protrombine die nodig is om een half-maximale snelheid van trombinevorming te krijgen $\left(K_{m}\right) 14 \mathrm{nM}$ bedraagt. In aanwezigheid van APC werd een complete inactivatie van het bloedplaatjes-geassocieerde protrombinase activiteit gevonden met een tweede orde remmingsconstante van $3.3 \times 10^{6} \mathrm{M}^{-1} \mathrm{~s}^{-1}$, welke onafhankelijk was van de protrombine concentratie wanneer deze gevarieerd werd in een breed concentratiebereik rond de $\mathrm{K}_{\mathrm{m}}$. Was het protrombinase complex geassembleerd op een procoagulant fosfolipiden membraanoppervlak ( $25 \mathrm{~mol} \%$ PS en $75 \mathrm{~mol} \% \mathrm{PC}$ ), dan werd een ongeveer vergelijkbare tweede orde remmingconstante van $2.5 \times 10^{6} \mathrm{M}^{-1} \mathrm{~s}^{-1}$ gevonden. Dus bloedplaatjes factor Va-gemedieerde trombine vorming wordt effectief geremd door APC met een vergelijkbare kinetiek als gevonden wordt voor plasma factor Va-gemedieerde trombinevorming op een procoagulant fosfolipiden oppervlak. Een opmerkelijke observatie was dat de remming van de activiteit van het plaatjes factor Va-gemedieerde protrombinase complex geassembleerd het oppervlak van collageen-geadhereerde bloedplaatjes door APC totaal was. Er werd onder deze omstandigheden geen partiële bescherming tegen inactivatie door APC gevonden wanneer factor Va zich op een bloedplaatjes oppervlak bevond, zoals eerder beschreven was. Een verklaring hiervoor zou de massale aanwezigheid van PS in buitenste laag van het plasmamembraan van geïmobiliseerd collageen-geadhereerde bloedplaatjes kunnen zijn.

\section{De procoagulante activiteit van fibrine-gebonden bloedplaatjes onder stromingscondities}

In hoofdstuk $\mathbf{5}$ is de rol van fibrine en fibrine-gebonden eiwitten in bloedplaatjes adhesie en de als gevolg van deze adhesie geïnduceerde veranderingen in $\left[\mathrm{Ca}^{2+}\right]$ en PS expositie onder lage en hoge afschuifspanning (shear stress) bestudeerd. Eerst is er een methode ontwikkeld om fibrine te vormen vanuit stromend plasma op een TFgecoat glasoppervlak. Vervolgens werd bij een lage shear stress $\left(50 \mathrm{~s}^{-1}\right)$ gevonden dat 1) niet-geactiveerde plaatjes binden niet aan fibrine; 2) trombine-geactiveerde plaatjes wel binden aan fibrine, de adhesie onafhankelijk is van fibrine-gebonden vWf, de adhesie resulteert in een verhoging van $\left[\mathrm{Ca}^{2+}\right]$, tot $0,2 \mu \mathrm{M}$ en dat maar $12 \%$ van de geadhereerde bloedplaatjes PS exposeren. Onder hoge shear stress condities (1000 $\mathrm{s}^{-1}$ ) werd gevonden dat 1) fibrine-gebonden vWf en de plaatjesreceptoren GP Ib en GP Ilbllla essentieel zijn voor binding; 2) deze adhesie niet leidt tot een verhoging van $\left[\mathrm{Ca}^{2+}\right]$ en 3) trombine-activering, maar niet de activering met de protease receptor-1 (PAR-1) specifieke ligand SFLLRN, leidt tot een 20 maal verhoging van $\left[\mathrm{Ca}^{2+}\right]$, en PS 
expositie in $85 \%$ van de geadhereerde plaatjes. In aanwezigheid van botrocetine werden deze laatste effecten ook onder lage shear stress condities gemeten.

\section{Conclusies}

De studies in dit proefschrift laten zien dat de vorming van een trombus een complex mechanisme is waarin de bloedstromingscondities, bloedplaatjes-vaatwand interacties, plaatjes-plaatjes interacties, plaatjes activatie reakties en de pro- en anticoagulante reakties nauw zijn verstrengeld. De gevolgen hiervan voor ons begrip van trombose en anti-trombotische therapieën zijn nader uitgewerkt in hoofdstuk 7. 



\section{List of Publications}

1. W.P. Vermeulen, J.J. Briedé, G. Bunt, J.A. Op den Kamp, R.J. Kraaijenhagen, B. Roelofsen. Enhanced $\mathrm{Mg}^{2 *}$-ATPase Activity in ghosts from HS erythrocytes and in normal ghosts stripped of membrane skeletal proteins may reflect enhanced aminophospholipid translocase activity. British journal of Haematology 90 (1995) 56-64.

2. W.P. Vermeulen, J.J. Briedé, B. Roelofsen. Manipulation of the phosphatidylethanolamine pool in the human red cell membrane affects its $\mathrm{Mg}^{2 *}$-ATPase activity. Molecular Membrane Biology 13 (1996) 95-102.

3. D. Billy, J.J. Briedé, J.W.M. Heemskerk, H.C. Hemker, T. Lindhout. Prothrombin conversion under flow conditions by prothrombinase assembled on adherent platelets. Blood Coagulation and Fibrinolysis 8 (1997) 168-174.

J.J. Briedé, J.W.M. Heemskerk, H.C. Hemker H.C., T. Lindhout. Heterogeneity in microparticle formation and exposure of anionic phospholipids at the plasma membrane of single adherent platelets. Biochimica et Biophysica Acta 1451 (1999) 163-172.

5 J.J. Briedé, J.W.M. Heemskerk, C. van 't Veer, H.C. Hemker, T. Lindhout. Contribution of platelet-derived factor $\mathrm{Va}$ to thrombin generation on immobilized collagen- and fibrinogenadherent platelets, Thrombosis and Haemostasis 85 (2001) 509-513.

6 J.J. Briedé, G. Tans, G.M. Willems, H.C. Hemker, T. Lindhout. Regulation of platelet factor Vadependent thrombin generation by activated protein $\mathrm{C}$ at the surface of collagen-adherent platelets, Journal of Biological Chemistry 276 (2001) 7164-7168. 


\title{
DANKWOORD
}

\author{
En ik kan het niet \\ Ik kan er niet omheen \\ Ik kan het niet \\ Ik kan het niet alleen
}

"De Dijk"

Dit geldt zeker ook voor al het werk dat verricht is en dat uiteindelijk geleid heeft tot dit proefschrift. Een aantal mensen die hieraan, op een al dan niet wetenschappelijke wijze, hebben bijgedragen, wil ik graag met name noemen.

In de eerste plaats mijn begeleider en co-promotor Theo Lindhout. Theo, jij hebt je de afgelopen jaren dagelijks druk bezig gehouden met het mij aanleren van een flink aantal wetenschappelijke vaardigheden. Een zware opgave, maar ik hoop dat dit proefschrift een bewijs is dat ik in al die jaren heel veel van jou geleerd heb. Want tussen het bedenken van een goede proef en het schrijven van een artikel zijn nog vele (mis)stappen mogelijk. In het maken van al die stappen heb je mij prima begeleid en voor het maken van al te veel misstappen heb je me gelukkig kunnen behoeden.

Verder wil ik mijn promotor professor Hemker bedanken voor de mogelijkheid om als onderzoeker in opleiding te werken onder zijn hoede. Hoewel u niet betrokken was bij mijn dagelijkse begeleiding, heeft $u$ altijd de tijd genomen om mijn vorderingen kritisch te volgen en was $u$ altijd bereid om mijn manuscripten te lezen en te beoordelen.

Johan Heemskerk, jouw praktische en theoretische kennis op het gebied van de bloedplaatjes is één van de weinige dingen die in de wetenschap onmeetbaar groot zijn. Ik wil je bedanken voor de altijd motiverende en ondersteunende rol die je hebt gespeeld binnen mijn onderzoek. George Willems, jou wil ik bedanken voor het delen van jouw kennis op het gebied van de wiskunde en de stromingsmodellen, ondanks dat volgens jou het meeste van deze kennis al in het voortgezet onderwijs aangeleerd zou moeten zijn. Cees van 't Veer wil ik bedanken voor de antilichamen en de bijdrage aan hoofdstuk 3. Guido Tans, bedankt voor het ruimhartig afstaan van APC en het meeschrijven aan hoofdstuk 4. Verder wil ik Jos Broers bedanken voor zijn hulp bij het maken van de opnames met behulp van de confocale microscoop. En Chris Reutelingsperger voor het afstaan van vele ml's ("weet je wel hoeveel dat kost?") fluorescent gelabeld annexine V. 
Wetenschap bedrijven met enkel theoretici is praktisch onmogelijk en daarom wil ik de volgende personen bedanken voor hun bijdrage aan alle proeven, al dan niet beschreven in dit proefschrift. Viviane, analiste van het eerste uur en tevens paranimf. Ik kon geen beter analiste bedenken om mij te helpen in die eerste jaren. Bedankt dat je mij ook in de laatste uren van de strijd wilt bijstaan. Simone, jou wil ik graag bedanken voor je bijdrage aan de laatste hoofdstukken van dit proefschrift. Marion, jou wil ik bedanken als vaste kracht op het lab van Johan en voor het delen van al je praktische kennis op het gebied van bloed(plaatjes). En Jo, ondanks dat je de roterende schijf soms als een echte rot-disk hebt ervaren, bedankt voor je inzet.

Natuurlijk zijn er ook mensen die niet direkt hebben geholpen bij de totstandkoming van dit proefschrift, maar die wel hebben gedeeld in het plezierige tijd die we hebben gehad bij Biochemie. Zoals de steeds meer ruimte in beslag nemende groep "van" Jan; met name Joyce, Stella, Lico, Kristien, José, Tilman, Gerry en Rory. Waarschijnlijk hebben sommige van jullie waarschijnlijk als laatste kennis kunnen nemen van mijn capriolen op de ski. Paul, Henry, Lavienja en Leon, en de laatsten ook veel succes met jullie promotie gewenst. Leo "Down under" Koole, Monique en Yvette (ook bedankt voor het gebruik van jullie EM). Imke en Aafke (of was het nu Aafke en Imke?), met jullie was elk experiment een eitje/uitje. En verder alle andere leden van Biochemie.

Jeffrey, bedankt dat je de rol als paranimf wilt vervullen en nog veel succes met je verdere promotie-onderzoek.

Trees en Mariet, bedankt voor jullie secretariële ondersteuning en de moederlijke adviezen.

ledereen binnen mijn "nieuwe" vakgroep GRAT: Bedankt voor de ondersteuning bij de allerlaatste loodjes.

Tot slot: Mijn ouders en René, bedankt voor jullie steun tijdens mijn promotiewerk. Hoewel ik ervoor heb moeten verhuizen naar het "verre" Maastricht, hoop ik dat de afstand tussen ons nooit te groot is geweest. En dat mijn verblijf bij de vakgroep biochemie echt heel veel moois heeft opgeleverd, dat bewijs jij, Irene.

Jacco 


\section{Curriculum Vitae}

Jacob Jan (Jacco) Briedé werd geboren op 3 november 1968 te Utrecht. Na te zijn verhuisd van deze provinciestad naar de slaapstad Nieuwegein, werd daar in 1987 aan het Oosterlichtcollege het VWO diploma behaald. In het bezit van dit diploma werd in Utrecht begonnen aan de verkorte opleiding tot chemisch analist aan de Hogeschool Utrecht, afdeling Hoger Laboratorium Onderwijs (HLO). Met een stage bij de sectie Methodenontwikkeling van het Keuringsinstituut voor Waterleidingartikelen (KIWA), waar is gewerkt aan de ontwikkeling van een methode om een metaboliet (ethyleenthioureum) van een groep van bestrijdingsmiddelen (ethyleenbisdithiocarbamaten) in water te analyseren, is deze studie in 1991 afgerond met het HLO diploma. Direkt hierna is verder gegaan met de de verkorte studie scheikunde aan de universiteit Utrecht. Het hoofdvak voor deze studie is uitgevoerd bij het Centrum voor Biomembranen en Lipiden Enzymologie (CBLE). waar onder begeleiding van Dr. B. Roelofsen en Dr. W.P. Vermeulen onderzoek is gedaan naar de mogelijke mechanismen die de asymmetrische verdeling van de fosfolipiden in het plasmamembraan van de rode bloedcel in stand houden. Voor deze studie scheikunde werd in 1994 het universitaire diploma behaald. $\mathrm{Na}$ als tussendoortje twee jaar rond te hebben gelopen in de geur- en smaakstoffenproduktie bij Quest international B.V., werd in 1996 besloten de wetenschappelijke carrière voort te zetten als onderzoeker in opleiding bij het Cardiovacular Research Institute Maastricht (CARIM), capaciteitsgroep Biochemie, bij de promotor Prof. Dr. H.C. Hemker en onder begeleiding van de co-promotor Dr. $T$. Lindhout. Hier is onderzoek gedaan naar de regulatie van trombinevorming aan het oppervlak van geadhereerde bloedplaatjes, zoals beschreven is in dit proefschrift. Sinds 1 mei 2001 is Jacco Briedé werkzaam als postdoctoraal onderzoeker bij de capaciteitsgroep Gezondheidsrisico Analyse en Toxicologie. faculteit Gezondheidswetenschappen van de universiteit Maastricht. Hier houdt hij zich bezig met de analyse en determinatie van de biologische consequenties van vrije radikaalvorming in de milieu toxocologie met behulp van elekron spin resonantie-technieken. 


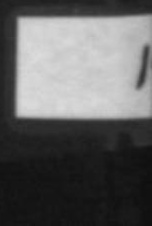

